\title{
DEFINIÇÃO DE ÁREAS PRIORITÁRIAS PARA CONSERVAÇÃO E PRESERVAÇÃO FLORESTAL POR MEIO DA ABORDAGEM MULTICRITERIAL EM AMBIENTE SIG
}

\author{
Roberta de Oliveira AVERna VALENTE
}

\begin{abstract}
Tese apresentada à Escola Superior de Agricultura "Luiz de Queiroz", Universidade de São Paulo, para obtenção do título de Doutor em Recursos Florestais, com opção em Conservação de Ecossistemas Florestais.
\end{abstract}

P I R A C I C A B A

Estado de São Paulo - Brasil

Janeiro - 2005 


\title{
DEFINIÇÃO DE ÁREAS PRIORITÁRIAS PARA CONSERVAÇÃO E PRESERVAÇÃO FLORESTAL POR MEIO DA ABORDAGEM MULTICRITERIAL EM AMBIENTE SIG
}

\author{
Roberta de Oliveira AVERna VAlente \\ Engenheiro Florestal
}

Orientador: Prof. Dr. CARLOS ALBERTO VETTORAZZI

\begin{abstract}
Tese apresentada à Escola Superior de Agricultura "Luiz de Queiroz", Universidade de São Paulo, para obtenção do título de Doutor em Recursos Florestais, com opção em Conservação de Ecossistemas Florestais.
\end{abstract}

P I R A C I C A B A

Estado de São Paulo - Brasil

Janeiro - 2005 
Dados I nt er naci onai s de Cat al ogação na Publ i cação ( CI P) DI VI SÃO DE BI BLI OTECA E DOCUMENTAÇÃO - ESALQI USP

Valente, Roberta de Oliveira Averna

Definição de áreas prioritárias para conservação e preservação florestal por meio da abordagem multicriterial em ambiente SIG / Roberta de Oliveira Averna Valente. - Piracicaba, 2005.

121 p. : il.

Tese (Doutorado) - - Escola Superior de Agricultura Luiz de Queiroz, 2005. Bibliografia.

1. Bacia hidrográfica 2. Biodiversidade 3. Corumbataí, Rio 4. Ecologia de paisagem 5. Geoprocessamento 6. Proteção ambiental 7. Sensoriamento remoto 8. Sistema de Informação Geográfica I. Título 
Aos meus pais Roberto e Aparecida,

meus irmãos Luisa e Luciano e minha avó Margarida

pelo amor incondicional que me dedicam

\section{Ofereço}

Ao meu esposo Alfredo, grande

incentivador, companheiro e amor

Dedico 


\section{AGRADECIMENTOS}

Ao Prof. Dr. Carlos Alberto Vettorazzi por sua dedicada orientação e imensurável contribuição, não somente nesse trabalho mas durante toda minha caminhada acadêmica e profissional. Obrigada por compartilhar muitas de suas idéias, pelas oportunidades, por suas palavras amigas e incentivadoras, ao longo desses anos.

Ao Prof. Dr. Rubens Angulo Filho por suas constantes colaborações ao enriquecimento de meus conhecimentos, por sua confiança, amizade e por ter feito sugestões, no exame de qualificação, que nos auxiliaram na finalização desse trabalho.

Aos Professores Dr. Gilberto José Garcia e Dr. Walter de Paula Lima por terem participado do exame de qualificação e contribuído com valiosas sugestões para o término desse trabalho.

Aos Professores Dr. Efrain Rodrigues, Dr. Hilton Thadeu Z. do Couto, Dr. Jean Paul Metzger, Dra. Vânia R. Pivello e Dr. Walter de Paula Lima por suas sugestões referentes aos fatores.

À Fundação de Amparo à Pesquisa do Estado de São Paulo (FAPESP) por ter financiado minha bolsa de estudos e reserva técnica, possibilitando o desenvolvimento desse trabalho.

Ao programa de pós-graduação em Recursos Florestais da ESALQ/USP pela oportunidade de realização do curso.

Aos estagiários Hilton Luís Ferraz da Silveira, Saulo Silva Delgado e Ana Paula Rosa Mendes, do laboratório de Geoprocessamento - Departamento de Engenharia Rural da ESALQ/USP, por suas colaborações.

À amiga Roberta Carnevalli e aos funcionários do Departamento de Engenharia Rural da ESALQ/USP, em especial à Vanda, Hamilton e Jesuíno pela amizade e apoio. 


\section{SUMÁRIO}

\begin{tabular}{|c|c|}
\hline \multirow{2}{*}{ 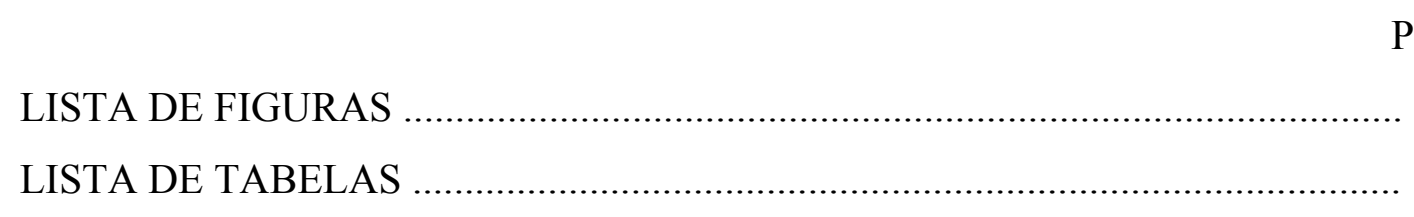 } & \\
\hline & viii \\
\hline RESUMO & xii \\
\hline SUMMARY . & xiv \\
\hline 1 INTRODUÇÃO ....................................... & \\
\hline 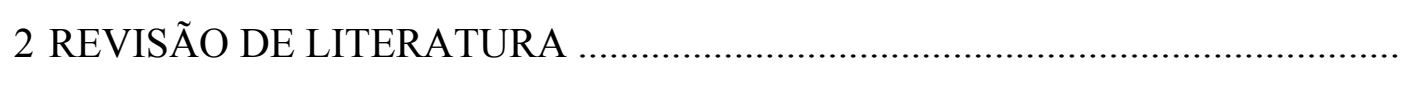 & \\
\hline 2.1 Conservação e preservação florestal visando ao incremento da biodiversidade .. & 3 \\
\hline 2.2 A Definição de áreas prioritárias na conservação e preservação florestal ............ & \\
\hline 2.3 Abordagem multicriterial .................... & \\
\hline 2.3.1 Média Ponderada Ordenada ...... & 12 \\
\hline 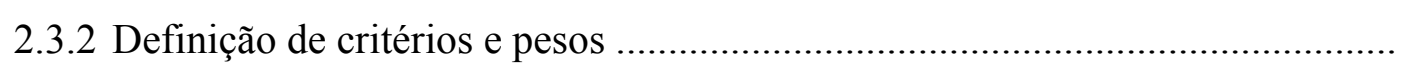 & 15 \\
\hline 2.3.3 Análise de sensibilidade .. & 16 \\
\hline 3 MATERIAL E MÉTODOS . & 18 \\
\hline 3.1 Material ............................. & 18 \\
\hline 3.1.1 Área de estudo ... & 18 \\
\hline 3.1.1.1 Localização .. & 18 \\
\hline 3.1.1.2 Relevo .......... & \\
\hline 3.1.1.3 Geologia & \\
\hline 3.1.1.4 Clima & 11 \\
\hline 3.1.1.5 Solos ............... & 22 \\
\hline 3.1.1.6 Uso e cobertura do solo. & \\
\hline & \\
\hline
\end{tabular}




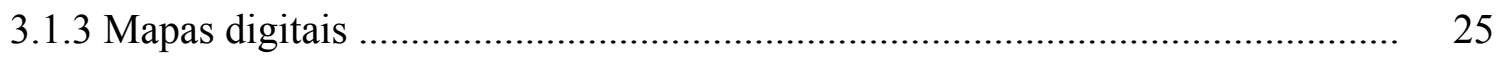

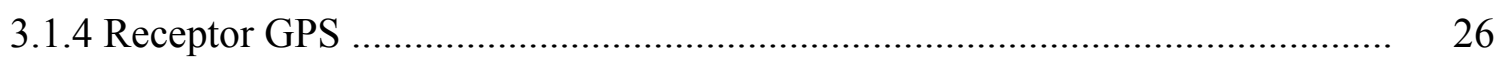

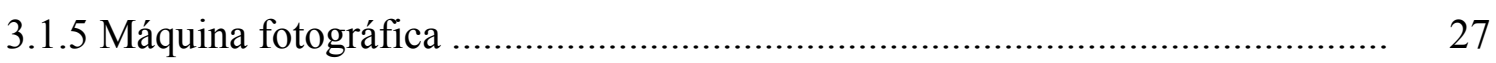

3.1.6 Sistemas computacionais ......................................................................... 27

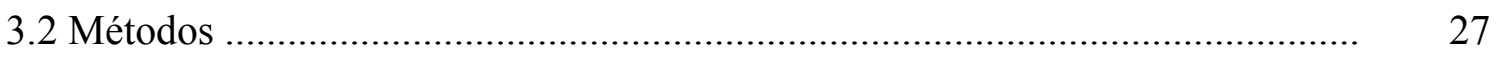

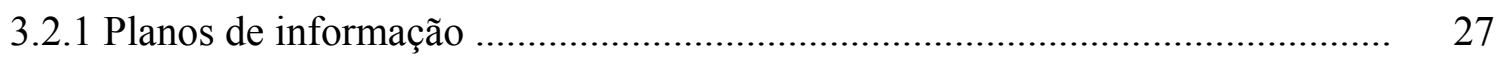

3.2.1.1 Uso e cobertura do solo .............................................................................. 27

3.2.1.2 Fragmentos de floresta .................................................................... 37

3.2.1.3 Área nuclear dos fragmentos de floresta. ................................................. 37

3.2.1.4 Centros urbanos .............................................................................. 38

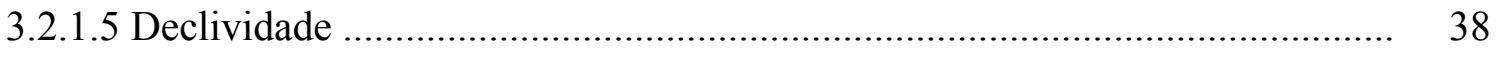

3.2.2 Mapas de fatores ........................................................................... 38

3.2.2.1 Proximidade entre fragmentos de maior área nuclear ................................... 39

3.2.2.2 Proximidade à cobertura florestal ............................................................. 41

3.2.2.3 Proximidade à rede hidrográfica .............................................................. 43

3.2.2.4 Distância aos centros urbanos ....................................................................... 44

3.2.2.5 Distância à malha viária .......................................................................... 46

3.2.2.6 Vulnerabilidade à erosão ......................................................................... 47

3.2.3 Mapa de restrições ................................................................................... 50

3.2.4 Abordagem multicriterial ...................................................................... 51

3.2.4.1 Definição dos pesos de compensação ……………………………………... 51

3.2.4.2 Definição dos pesos de ordenação ............................................................... 53

3.2.4.3 Método da Média Ponderada Ordenada ..................................................... 56

3.2.4.4 Avaliação dos pesos de ordenação ............................................................... 57

3.2.4.5 Análise de sensibilidade ......................................................................... 57

3.2.4.6 Alternativas na definição de áreas prioritárias . ............................................... 61

3.2.4.7 Definição das classes de áreas prioritárias . ................................................... 62

4 RESULTADOS E DISCUSSÃO …………………....................................... 63

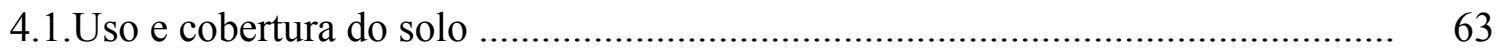

4.2 Áreas prioritárias para a conservação e a preservação florestal ............................. 67 
4.2.1 Método da Média Ponderada Ordenada ..................................................... 67

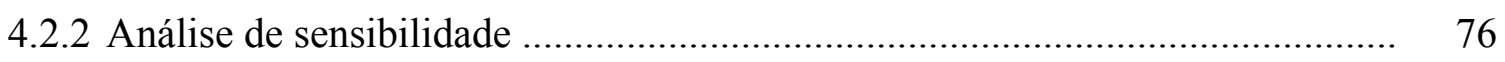

4.2.2.1 Proximidade entre fragmentos de maior área nuclear ................................. 76

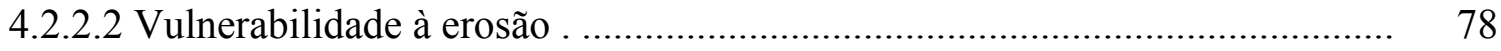

4.2.2.3 Proximidade à cobertura florestal ......................................................... 81

4.2.2.4 Proximidade à rede hidrográfica ............................................................. 83

4.2.2.5 Distância à malha viária . ....................................................................... 86

4.2.2.6 Distância aos centros urbanos ............................................................. 88

4.2.3 Avaliação da alternativa proposta para a definição de áreas prioritárias .......... 90

4.2.4 Mapa de áreas prioritárias para a conservação e a preservação florestal .......... 96

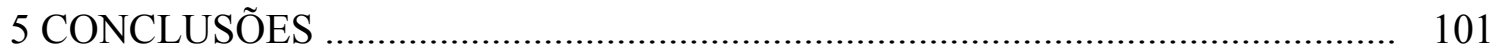

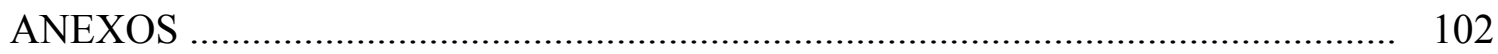

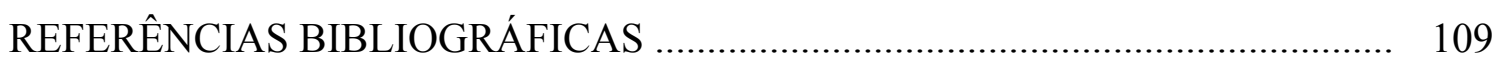




\section{LISTA DE FIGURAS}

Página

1 Localização da Bacia do Rio Corumbataí ......................................................... 18

2 Bacia do Rio Corumbataí: divisão em sub-bacias .............................................. 19

3 Classes de declividade da Bacia do Rio Corumbataí ........................................... 20

4 Grandes grupos de solos da Bacia do Rio Corumbataí ........................................ 22

5 Distribuição de pontos para verificação da exatidão da classificação e trajeto de

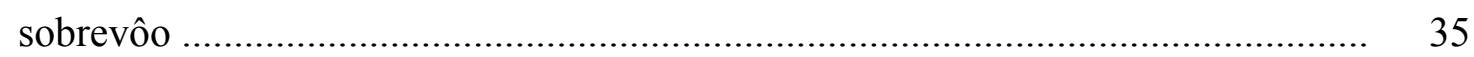

6 Proximidade entre fragmentos de maior área nuclear ........................................ 41

7 Proximidade à cobertura florestal ................................................................. 42

8 Proximidade à rede hidrográfica ................................................................ 44

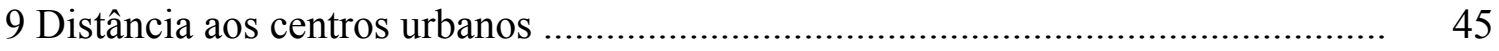

10 Distância à malha viária ...................................................................................... 47

11 Vulnerabilidade à erosão .......................................................................... 50

12 Espaço de estratégia para a tomada de decisão ................................................ 51

13 Escala contínua para a elaboração da matriz de comparação pareada ................. 52

14 Mapas de prioridades: operador OR (A) e operador AND (B) ......................... 56

15 Uso e cobertura do solo da Bacia do Rio Corumbataí (2003) ............................. 63

16 Uso e cobertura do solo: área ocupadas nos anos de 2000 e 2003 ...................... 66

17 Áreas prioritárias com risco alto: combinação de todos os fatores (escala 0 a 255

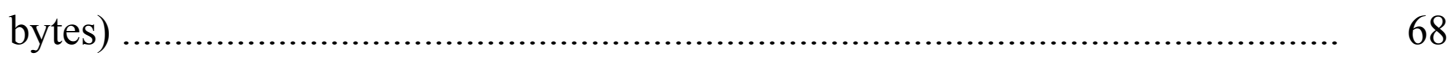

18 Áreas prioritárias com risco alto: combinação de todos os fatores (classes de

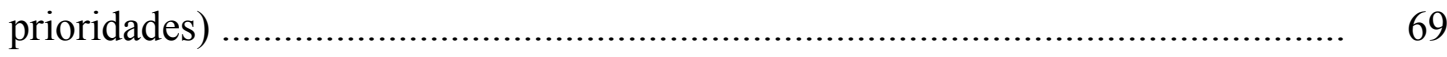


19 Área (\%) ocupada por classes de prioridades: mapas com riscos médio, baixo e

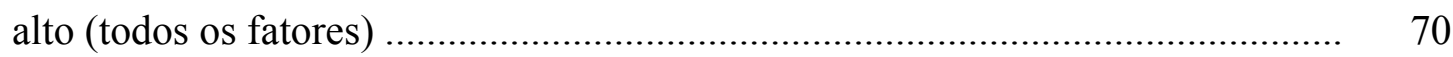

20 Áreas prioritárias com risco médio: combinação de todos os fatores (escala 0 -

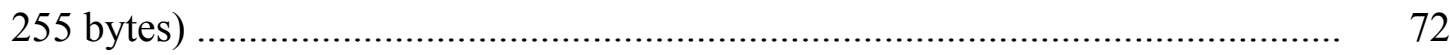

21 Mapas com riscos médio (A) e baixo (B): combinação de todos os fatores (classes de prioridades)

22 Áreas prioritárias com risco baixo: combinação de todos os fatores (escala 0 255 bytes)

23 Áreas prioritárias, sem fator proximidade entre fragmentos de maior área nuclear : risco médio-baixo (escala 0 - 255 bytes (A) e em classes (B))

24 Áreas prioritárias, sem fator vulnerabilidade à erosão : risco médio-baixo (escala $0-255$ bytes (A) e em classes (B))

25 Áreas prioritárias, sem o fator proximidade à cobertura florestal : risco médioalto (escala $0-255$ bytes (A) e em classes (B))

26 Áreas prioritárias, sem o fator proximidade à rede hidrográfica : risco médioalto (escala $0-255$ bytes (A) e em classes (B))

27 Áreas prioritárias, sem o fator distância à malha viária : risco baixo (escala 0 255 bytes (A) e em classes (B))

28 Áreas prioritárias, sem o fator distância aos centros urbanos : risco médio-baixo (escala 0 - 255 bytes (A) e em classes (B))

29 Análise de sensibilidade: área (\%) das classes de prioridades

30 Áreas prioritárias com risco médio: sem o fator proximidade à rede hidrográfica (escala $0-255$ bytes)

31 Áreas prioritárias com risco médio-baixo: sem o fator proximidade à rede hidrográfica (escala $0-255$ bytes)

32 Mapas com riscos médio (A) e médio-baixo (B): sem o fator proximidade à rede hidrográfica (classes de prioridades)

33 Áreas prioritárias para conservação e preservação florestal na Bacia do Rio Corumbataí 


\section{LISTA DE TABELAS}

Página

1 Constituição geológica, características e potencial mineral das formações da Bacia do Rio Corumbataí

2 Grandes grupos de solos da Bacia do Rio Corumbataí ........................................... 23

3 Características do modo de operação do sensor ETM+ ....................................... 25

4 Número de pontos de controle e erro médio quadrático (RMS) ............................. 28

5 Número de subclasses e de pixels (NPs) amostrados, para os diferentes usos e coberturas do solo ............................................................................... $\quad 30$

6 Uso e cobertura do solo na Bacia do Rio Corumbataí ............................................... 31

7 Classes de qualidade do índice Kappa ............................................................. 37

8 Classes de área nuclear dos fragmentos de floresta e intervalos de normalização dos valores de distância .................................................................................. 40

9 Intervalos de normalização: classes de declividade …………………………….... 49

10 Intervalos de normalização: classes de erodibilidade …………………………...... 49

11 Matriz de comparação pareada entre os mapas de fatores ................................... 52

12 Risco assumido para a tomada de decisão ………………………………........ 54

13 Pesos de ordenação para a matriz de comparação pareada .................................. 55

14 Matriz de comparação pareada: sem proximidade entre fragmentos de maior

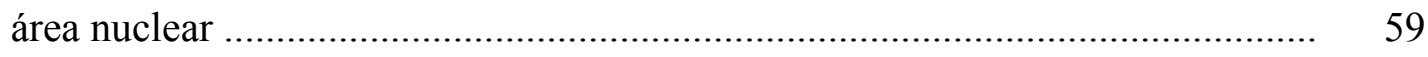

15 Matriz de comparação pareada: sem vulnerabilidade à erosão ............................. 59

16 Matriz de comparação pareada: sem proximidade à cobertura florestal .............. 60

17 Matriz de comparação pareada: sem proximidade à rede hidrográfica ................. 60 
18 Matriz de comparação pareada: sem distância à malha viária ............................ 61

19 Matriz de comparação pareada: sem distância aos centros urbanos .................... 61

20 Pesos de ordenação*: sem proximidade à rede hidrográfica ............................. 62

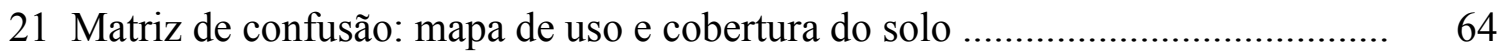

22 Exatidão de classificação para as classes de uso e cobertura do solo .................. 64

23 Uso e cobertura do solo na Bacia do Rio Corumbataí (2003) ............................ 66

24 Matriz de comparação pareada entre os fatores $(\mathrm{A})$......................................... 103

25 Matriz de comparação pareada entre os fatores $(\mathrm{B})$......................................... 103

26 Matriz de comparação pareada entre os fatores $(\mathrm{C})$........................................... 104

27 Matriz de comparação pareada entre os fatores (D) ....................................... 104

28 Matriz de comparação pareada entre os fatores (E) ......................................... 104

29 Matriz de comparação pareada entre os fatores (F) ......................................... 105

30 Matriz de comparação pareada entre os fatores $(\mathrm{G})$....................................... 105

31 Matriz de comparação pareada entre os fatores $(\mathrm{H})$......................................... 105

32 Pesos de compensação* e de ordenação, propostos ......................................... 106

33 Pesos de ordenação*: sem proximidade à cobertura florestal ............................ 107

34 Pesos de ordenação*: sem proximidade à rede hidrográfica ............................. 107

35 Matriz de comparação pareada: sem distância à malha viária ........................... 108

36 Matriz de comparação pareada: sem distância aos centros urbanos ................... 108 


\title{
DEFINIÇÃO DE ÁREAS PRIORITÁRIAS PARA CONSERVAÇÃO E PRESERVAÇÃO FLORESTAL POR MEIO DA ABORDAGEM MULTICRITERIAL EM AMBIENTE SIG
}

\author{
Autora: ROBERTA DE OLIVEIRA AVERNA VALENTE \\ Orientador: Prof. Dr. CARLOS ALBERTO VETTORAZZI
}

\section{RESUMO}

A intensa fragmentação florestal da Bacia do Rio Corumbataí, SP, resultante do processo desordenado de uso e ocupação do solo da região em que ela está inserida, motivou a definição de áreas prioritárias para sua conservação e preservação florestal, tendo em vista o incremento da biodiversidade regional. Empregou-se a abordagem multicriterial, em ambiente SIG, com o Método da Média Ponderada Ordenada, para combinação dos fatores (características da paisagem) importantes ao objetivo do projeto. A princípio os fatores selecionados foram: proximidade entre fragmentos de maior área nuclear; proximidade à cobertura florestal; proximidade à rede hidrográfica; distância à malha viária; distância aos centros urbanos; e vulnerabilidade à erosão. Para a obtenção desse fatores foram necessários os planos de informação: uso e cobertura do solo; fragmentos de floresta; área nuclear dos fragmentos de floresta; rede hidrográfica; centros urbanos; malha viária; declividade; e erodibilidade do solo. Para auxiliar na definição dos fatores, seus pesos de compensação (expressam a ordem de importância dos fatores no processo de decisão) e restrições (categorias restritivas das características) utilizou-se a Técnica Participatória e o Processo Hierárquico Analítico, no próprio SIG. $\mathrm{Na}$ determinação dos melhores pesos de ordenação (controlam a maneira como os 
fatores são agregados e o nível de compensação entre eles) foi considerado o risco assumido no processo de tomada de decisão. Foram, dessa maneira, avaliados mapas de áreas prioritárias com riscos médio, alto e baixo. Os mapas de prioridades foram reclassificados de maneira a apresentar cinco classes de prioridade: muito baixa, baixa, média, alta e muito alta. O mapa final de áreas prioritárias foi reclassificado em sete classes, que possibilitaram o melhor entendimento das alterações propostas para a estrutura da bacia. Na avaliação da importância e da influência dos fatores, para o processo de tomada de decisão, utilizou-se a análise de sensibilidade. Ela foi realizada somente para o mapa de prioridades referente ao grupo de pesos de ordenação mais adequado. Essa análise indicou que a melhor alternativa, para a priorização de áreas, foi o mapa sem o fator proximidade à rede hidrográfica, que apresentou risco médio-alto $(\mathrm{R}=0,46)$ e compensação de $73 \%$ entre seus fatores. Os pesos de ordenação desse mapa de prioridades promoveram a definição de áreas prioritárias de acordo com o préestabelecido para esse processo de tomada de decisão. A grande maioria das áreas com maior prioridade coincidiram com regiões da bacia que concentram sua área de floresta nativa e, ainda, seus melhores fragmentos (maiores, mais próximos uns dos outros, com melhores formas e maiores áreas nucleares). Conclui-se que a abordagem multicriterial, com o método da Média Ponderada Ordenada, é eficiente para a definição de áreas prioritárias para a conservação e preservação florestal e o processo de tomada de decisão apresenta robustez, com pesos de compensação, ordenação e solução coerentes. 


\title{
DEFINITION OF PRIORITY AREAS FOR FOREST CONSERVATION AND PRESERVATION USING MULTICRITERIAL EVALUATION WITH GIS
}

\author{
Author: ROBERTA DE OLIVEIRA AVERNA VALENTE \\ Adviser: Prof. Dr. CARLOS ALBERTO VETTORAZZI
}

\section{SUMMARY}

The forest fragmentation of the Corumbataí River Basin, SP (Brazil) is a consequence an unplanned process of soil occupation and use. The purpose of this study was to define priority areas for forest conservation and preservation in that river basin, aiming at improve the regional biodiversity. Multicriteria evaluation with Ordered Weighted Average was used to aggregate factors (characteristics of landscapes). Factors considered important were: proximity to forest patches; proximity to forest with larger core area; proximity to water; distance to roads; distance to urban areas; and vulnerability to erosion. In order to produce these factors it was necessary the layers: land use/land cover; forest patches; core area of forest patches; streams; urban areas; roads; slope; and erodibility. In the definition of the factors, the factors importance weights (define the importance of each factor in the process) and constraints, the Participatory Technique and the Hierarchical Analytic Process were used. In the determination of the factors order weights (controls the manner in which the weighted factors are aggregate) its was considered the risk-taking. Maps were produced with low, medium, and high risk. These maps were reclassified in order to show only five levels of priority (very low, low, medium, high, very high), and the final map in seven levels of priority. The sensitivity analysis was employed to identify the importance and the influence of factors (only to the selected priority map with adequate risk-taking). 
According to this analysis the best alternative was the priority map without proximity to water, that showed high risk $(\mathrm{R}=0.40)$ and $78 \%$ of trade-off among the factors. The order weights of this final map promoted the definition of priority areas, according to the objective of this project. Finally, it is concluded that the multicriteria evaluation with Ordered Weighted Average is efficient to determine priority areas to forest conservation and preservation; and the process presents robustness. 


\section{INTRODUÇÃO}

A Bacia do Rio Corumbataí representa muito bem a situação de grande parte do território brasileiro originalmente coberto pela Mata Atlântica - classificada por Myers et al. (2000) como um dos cinco hotspots, dentre os 25 identificados mundialmente (Mittermeier et al., 1998) e que é marcado por uma intensa fragmentação florestal.

No caso específico dessa bacia, a fragmentação florestal é um dos resultados do processo desordenado de uso e ocupação do solo que se observa nessa região, considerada de grande importância econômica em termos de Estado de São Paulo e de Brasil.

$\mathrm{Na}$ tentativa de garantir a manutenção da estrutura e dos processos de paisagens, em situações semelhantes à dessa região, tem sido dada muita atenção às ações conservacionistas e preservacionistas em nível de paisagem.

No que se refere à espacialização dessas ações, a priorização de áreas representa um dos métodos mais efetivos e econômicos no manejo de bacias hidrográficas. Seu sucesso tem como principal componente a capacidade de interação e análise dos diferentes planos de informação (características e/ou processos) que compõem as paisagens, em Sistemas de Informações Geográficas (SIGs) que, por sua vez, também

possibilitam a produção dos mapas de prioridades em curto espaço de tempo e com confiabilidade.

A abordagem multicriterial é uma das técnicas empregadas para a tomada de decisão que foi incorporada aos SIGs. Nesta abordagem, a base para a tomada de decisão, que pode ser medida e avaliada, é chamada de critério, que pode ser dividido em fatores e restrições. Os fatores equivalem às diferentes características e/ou processos de uma paisagem, importantes à geração do mapa de prioridades. Eles podem ser 
representados de forma contínua, o que é uma vantagem em relação à representação das características de uma paisagem em intervalos discretos, o que normalmente leva à perda de informação e à propagação de erros.

A representatividade dos atributos de uma paisagem por fatores é assegurada, ainda, por pesos que eles recebem. Esse pesos descrevem a importância de cada um dos fatores no processo de tomada de decisão, assim como o nível de compensação necessário entre os fatores e o risco a ser assumido no mapa de prioridades.

As restrições são características da paisagem que limitam espacialmente aquelas importantes à geração do mapa de prioridades.

Com o desenvolvimento do processo de tomada de decisão, várias técnicas foram criadas para auxiliar na definição dos fatores, seus pesos e restrições. Dentre elas encontram-se a Técnica Participatória e o Processo Hierárquico Analítico, que já se encontra incorporado à maioria dos SIGs.

Neste contexto, o presente trabalho teve por objetivo definir áreas prioritárias para a conservação e a preservação florestal na Bacia do Rio Corumbataí, SP, visando ao incremento da biodiversidade regional, utilizando a abordagem multicriterial (método da Média Ponderada Ordenada). Os objetivos específicos foram:

(1) definir os fatores e seus respectivos pesos, importantes à conservação e preservação florestal; e

(2) avaliar a importância e a influência dos fatores e pesos escolhidos, para o processo de tomada de decisão. 


\section{REVISÃO DE LITERATURA}

\subsection{A conservação e a preservação florestal visando ao incremento da biodiversidade}

A conservação florestal pode ser definida como o conjunto de ações que são realizadas em um ecossistema, tendo em vista sua restauração, sua proteção e, sobretudo, a sustentabilidade da qualidade e quantidade de seus componentes e processos (Dunster \& Dunster, 1996). Esses mesmos autores definem a preservação, por sua vez, como um uso que dever ser dado a determinado ecossistema, no qual a interferência humana deve ser mínima, ou mesmo inexistente.

Para Baker \& Cai (1992) e Noss (1990), um aspecto importante para a conservação e preservação dos recursos florestais, em nível de ecossistema, é o conhecimento da estrutura (composição e configuração) e processos de sua paisagem, o que torna possível identificar os fatores importantes à manutenção da biodiversidade regional.

Segundo McNeely et al. (1990), a biodiversidade abrange todas as espécies de plantas, animais e microorganismos, assim como os ecossistemas e os processos ecológicos nos quais eles tomam parte.

A fragmentação florestal de origem antrópica tem sido uma das principais causas de alteração, tanto na estrutura como nos processos de diferentes paisagens (Lord \& Norton, 1990; Putz et al., 2001).

Geneletti (2004) cita que a fragmentação de ecossistemas, de maneira geral, caracteriza-se por três principais efeitos: aumento no isolamento dos fragmentos, diminuição em seus tamanhos e aumento da suscetibilidade à distúrbios externos, 
tais como invasão por espécies exóticas ou alterações em suas condições físicas. Esses efeitos promovem, por sua vez, a redução da biodiversidade, da estabilidade dos ecossistemas e sua capacidade de recuperação frente a distúrbios (Saunders et al., 1991; Baskent, 1999).

Metzger (1999) complementa que, com esse processo antrópico de fragmentação do habitat, a estrutura da paisagem é modificada, resultando em mudanças na composição e diversidade das comunidades.

Segundo Geneletti (2004), as ações de conservação e preservação florestais devem, portanto, caminhar no sentido contrário ao da fragmentação. Dessa maneira poderá garantir-se a manutenção e/ou restauração da biodiversidade da paisagem afetada.

Noss et al. (1997) citam que fragmentos maiores e conectados são tipicamente melhores, para a conservação da biodiversidade, do que os pequenos e isolados. $\mathrm{O}$ primeiro grupo possui espécies e populações em número maior que o segundo e, assim, apresenta-se menos suscetível à extinção (espécies, populações e o próprio fragmento).

O tamanho considerado como mínimo necessário para a estabilidade um fragmento de Floresta Semidecídua, tendo em vista a sua florística, é de 25 ha (Metzger, 1997).

Yahner (1998) explica que, como os fragmentos estão inseridos em uma paisagem com estrutura ecológica predominante diferente da sua, existe a formação de uma borda nesses fragmentos, visto a recepção direta de impactos das mais diversas naturezas. Como resultado da borda têm-se as alterações no seu microclima e, por conseqüência, o distúrbio desses fragmentos. Como outro fator que irá interferir nesse efeito de borda Forman (1997) cita, ainda, a forma dos fragmentos.

Um melhor indicativo da qualidade dos fragmentos é, dessa maneira, sua área nuclear, que é a área do fragmento sem considerar a faixa da borda (Temple, 1986).

Por esses motivos, Lathrop et al. (1998) e Geneletti (2004) citam que as ações de conservação e preservação florestal devem favorecer a conecção dos fragmentos de maior área nuclear, como uma maneira de reestruturação da paisagem e incremento de sua biodiversidade. Nesse sentido, Farina (1998) afirma que, com a conectividade 
restabelecida entre esses fragmentos, sub-populações passar a estar interconectadas em uma nova unidade.

Metzger (2003) esclarece que uma paisagem fragmentada, ideal para conservação biológica, tem que ter, além dos grandes fragmentos, uma rede de fragmentos menores interligados por corredores largos e imersos numa matriz permeável, de forma a aumentar a conectividade funcional. Metzger (1997) cita que fragmentos com área superior a 0,72 ha têm condições de assumir a função de "steppingstones" na conexão florestal. Vários trabalhos atestam a importância destas áreas nos fluxos biológicos (Metzger, 2000).

Para Farina (1998)e Roy \& Tomar (2000), esses fragmentos de menor tamanho, quando próximos daqueles considerados "focos de biodiversidade" da paisagem, por serem os fragmentos com maior área nuclear, alcançarão mais rapidamente a estabilidade de sua estrutura interna. Esse fato ocorre, ainda segundo os autores, porque será estabelecido e/ou reestabelecido o fluxo gênico da paisagem. Serrano et al.(2002) ressaltam que devem ser consideradas influências antrópicas nesse processo, tais como incêndios, fontes de distúrbios, vizinhança etc.

Alguns corredores antrópicos, em particular as estradas, podem também, de acordo com Metzger (2003), funcionar como barreiras aos fluxos biológicos. Nesse caso, o autor citar que o restabelecimento dos fluxos significa criar mecanismos que permitam a passagem sob ou sobre esse obstáculo.

Byron et al. (2000) e Geneletti (2003) citam que as estradas, por apresentarem estrutura linear, são fontes de distúrbio mais intensas para as áreas de floresta natural que outros focos de desenvolvimento, como por exemplo os parques industriais e as áreas urbanas. As estradas causam nos fragmentos de floresta, principalmente, o aumento do grau de isolamento, a diminuição de tamanho e o aumento de seu efeito de borda (Geneletti, 2004).

As ações de conservação e preservação florestal devem atender não só essa necessidade de conexão e restabelecimento de fluxo gênico. $O$ incremento da biodiversidade está relacionado à estabilidade da estrutura de toda a paisagem. Dessa 
maneira, essas ações devem ser pensadas de maneira que as áreas mais sensíveis, e também importantes à reestruturação dessa paisagem, sejam beneficiadas.

Nesse sentido, Forman (1997) considera como outros fatores importantes às ações de conservação e preservação florestal o aspecto (face de exposição do terreno), a declividade, os tipos de solo e, principalmente, a sua suscetibilidade à erosão.

Metzger (2003), concluindo sobre alguns aspectos importantes a serem considerados na restauração da conectividade de paisagens fragmentadas, menciona que o ideal não é fazer restauração, e sim de fragmentar-se a paisagem de forma inteligente. $\mathrm{O}$ autor cita algumas características que devem ser atendidas e dentre elas estão: a manutenção de fragmentos grandes e corredores ripários largos, incluindo áreas que estejam fora dos efeitos das enchentes; manutenção de vegetação florestal em áreas de risco de erosão ou de proteção de mananciais; e manutenção de uma matriz porosa.

\subsection{A definição de áreas prioritárias na conservação e preservação florestal}

A integração desse processo de tomada de decisão (o que e onde conservar e/ou preservar) com os SIGs tem facilitado, de acordo com Kangas et al. (2000) e Vlahos \& Herbst (2000), o planejamento, a otimização e o sucesso das ações de conservação e preservação florestal. Esta integração permite que as ações sejam direcionadas, pela determinação das áreas de maior risco, suscetíveis ou prioritárias às ações.

A análise de áreas prioritárias, segundo Collins et al. (2001), tem em vista, principalmente, a identificação do padrão espacial mais apropriado para os futuros usos do solo de uma determinada região, de acordo com fatores específicos e preditores de uma atividade ou de um objetivo.

Segundo Store \& Kangas (2001), a definição de áreas prioritárias com base nos SIGs tem sido amplamente aplicada em uma variedade de situações, como a definição de áreas ou regiões prioritárias para espécies animais ou vegetais; para a favorabilidade geológica; para atividades agrícolas; para risco de impactos ambientais; para a biodiversidade, entre outras. 
$\mathrm{Na}$ área de conservação e preservação florestal pode-se citar Campanella (1993) que, com base na proximidade entre fragmentos de floresta fechada em Honduras, determinou as áreas críticas para a recuperação florestal. Bojorqueztapia et al. (1995), no México, e Funk et al. (1999), na Guiana, determinaram áreas com alta prioridade para a conservação florestal, tendo como indicativo a riqueza de espécies típicas das formações florestais de suas áreas de estudo. Iverson et al. (2001), nos Estados Unidos, com base no uso e cobertura do solo, priorizaram os rios que deveriam ter suas margens restauradas com vegetação ripária.

Como autores que integraram mais de um fator para a determinação de áreas prioritárias podem-se citar Russel et al. (1997), que utilizaram mapas topográficos e de uso e cobertura do solo para ordenar as áreas a serem priorizadas na conservação e/ou recuperação florestal no sul da Califórnia; O’Neill et al. (1997), que integraram as características geomorfológicas, hidrológicas e da vegetação para determinar as áreas críticas na recuperação da vegetação ripária em uma bacia hidrográfica do Arkansas (EUA); Khan et al. (2001), na Índia, que priorizaram as sub-bacias a serem manejadas de acordo com as informações do mapa de erodibilidade do solo, do mapa com os valores do índice de produção de sedimentos e do mapa de vegetação; e Geneletti (2004), que utilizou os indicadores área nuclear, distância a focos de distúrbios (áreas urbanas, infraestruturas etc.) e distância média entre fragmentos (borda a borda) para a priorização de ações de recuperação em áreas florestais fragmentas por infraestruturas lineares, na província de Trento, Itália.

Com a evolução dos SIGs também observa-se uma evolução das metodologias empregadas na definição de áreas prioritárias. Para Malczewski (2004), o cruzamento entre diferentes planos de informação nos SIGs tem sido o procedimento básico para o desenvolvimento da maioria dos trabalhos. Ainda segundo esse autor, com base nesse procedimento houve a implementação de várias técnicas nos SIGs, como a abordagem multicriterial, o método de inteligência artificial, os métodos de visualização e os WebSIGs. 


\subsection{Abordagem multicriterial}

A abordagem multicriterial é uma das técnicas empregadas para a tomada de decisão e a sua integração com os SIGs foi considerada um avanço em relação ao procedimento convencional de cruzamento de planos de informação para a priorização de áreas (Eastman, 1997; Malczewski, 1999; Thill, 1999). Com essa integração abordagem multicriterial pode ser considerada como um processo que combina e transforma dados espaciais (planos de informação de entrada) em mapas finais para a tomada de decisão, sendo as regras de decisão é que definem as relações entre os dados de entrada e os mapas finais (Malczewski, 1999).

Segundo Malczewski (2004), essa abordagem envolve a utilização de dados georreferenciados, os conceitos dos tomadores de decisão e a manipulação desses dados e conceitos com base em regras de decisão específicas. Para esse autor duas considerações são, dessa forma, de extrema importância para a utilização dessa abordagem: (i) a capacidade do SIG de adquirir, armazenar, recuperar, manipular e analisar os dados georreferenciados e (ii) a capacidade de combinar esses dados e os conceitos dos tomadores de decisão em alternativas de decisões.

Os conceitos dos tomadores de decisão são expressos pelos critérios que, de acordo com Eastman (2001), são a base do processo de tomada de decisão e que podem ser medidos e avaliados. Para esse autor, o critério é a evidência sobre a qual um indivíduo pode ser designado a um conjunto de decisão. Os critérios podem ser de dois tipos: fatores e restrições e podem referir-se tanto a atributos do indivíduo como ao conjunto todo de decisão (Eastman, 2001).

Os fatores irão realçar ou diminuir a suscetibilidade de uma alternativa específica para uma atividade ou objetivo (Eastman, 2001). Para Randhir et al. (2001) os fatores utilizados no processo de tomada de decisão são aqueles que representam as características críticas de um habitat.

As restrições podem ser entendidas como categorias restritivas das alternativas (fatores), excluindo áreas e limitando espacialmente a distribuição das possibilidades de escolha (Eastman et al., 1993). 
Para a integração dos diferentes fatores, com base na abordagem multicriterial, vários métodos vêm sendo utilizados, como o Booleano; o do Ponto Ideal; o da Combinação Linear Ponderada; o da Análise de Concordância; e mais recentemente o da Média Ponderada Ordenada (Malczewski, 2000). Dentre esses métodos a Combinação Linear Ponderada e o Booleano são os mais robustos e os empregados com mais freqüência (Malczewski, 2004).

No Método Booleano os critérios são reduzidos a declarações lógicas de adequação e então combinados por meio de um ou mais operadores lógicos, tais como intersecção (AND) e união (OR) (Eastman, 2001).

$\mathrm{Na}$ definição de áreas prioritárias, de acordo com Carver (1991), a lógica booleana não tem apresentado resultados satisfatórios, pela dificuldade de representar os diferentes atributos das paisagens em classes com intervalos discretos o que, por sua vez, acarreta na perda de informação e, provavelmente, na geração de erros no processo de tomada de decisão.

A Combinação Linear Ponderada (Carver, 1991; Jankowshi, 1995; Malczewski, 1996; e Jiang \& Eastman, 2000) e a Média Ponderada Ordenada (Malczewski, 1999; Eastman, 2001; Malczewski, 2004) têm sido empregadas em substituição à lógica boolena na determinação de áreas de suscetíveis, de risco e prioritárias.

Na Combinação Linear Ponderada (Voogd, 1983) os critérios (fatores) são padronizados para uma escala numérica comum, recebem pesos e são combinados por meio de uma média ponderada. O resultado é um mapa de prioridades, que pode ser limitado espacialmente por uma ou mais restrições boolenas (Eastman, 2001).

A principal razão da popularidade deste método está na facilidade de sua implementação no ambiente dos SIGs, usando álgebra de mapas e modelagem cartográfica (Berry, 1993). Malczewski (2000) ressalta a facilidade de entendimento e aplicação do método por parte dos tomadores de decisão.

$\mathrm{O}$ método apresenta como principais vantagens em relação à lógica booleana: (i) a representação contínua da paisagem e (ii) a possibilidade dos fatores receberem pesos, de acordo com a importância que possuem para o objetivo do trabalho (Kangas et al. 1998; Chen et al., 2001; Store \& Kangas, 2001). 
A representação contínua da paisagem é possível com a padronização dos fatores para uma escala numérica comum, baseada na lógica fuzzy (Eastman, 2001). Por essa lógica, um conjunto de valores expressos numa dada escala é convertido em outro comparável, expresso em uma escala normalizada (Malczewski, 1996). Por esse motivo é comum denominar essa etapa de padronização dos fatores, no ambiente da abordagem multicriterial, de normalização (Malczewski, 1999; Eastman, 2001)

Segundo Zadeh (1965), citado por Malczewski (1999), a teoria dos conjuntos fuzzy é, em resumo, o passo seguinte de aproximação entre a precisão da matemática clássica e a imprecisão do mundo real. $\mathrm{O}$ conjunto fuzzy é uma generalização do conjunto ordinário. É definido a partir de um domínio contínuo, com graus de pertinência variando de 0 a 1 ou 0 a 255 (bytes), após a normalização. Na teoria geral, a pertinência ou afirmativa de um dado fenômeno é relativa. Com o advento dessa teoria obteve-se uma estrutura conceitual apropriada de tomada de decisão, pois a lógica fuzzy auxilia a diminuir a subjetividade na escolha e aumentar o raciocínio no processo de decisão (Calijuri et al., 2002).

Eastman (2001) cita que várias funções de pertinência (por ex.: linear, sigmoidal e j-invertido) ao conjunto fuzzy podem ser utilizadas na etapa de normalização, sendo a escolha da função relacionada à melhor representação espacial do fator a ser normalizado. Dessa maneira garante-se que o mapa de fator seja positivamente relacionado com o atributo da paisagem por ele representado (Eastman \& Jiang, 1996).

Para a comparação dos métodos da Combinação Linear Ponderada e Booleano, Jiang \& Eastman (2000) utilizaram a definição de áreas para a locação do parque industrial de Nakuru, no leste da África. Os resultados obtidos com a aplicação dos dois métodos, nesse caso, foram bem distintos, sendo o produto do método Booleano muito influenciado pelas classes de uso e cobertura do solo, não se mostrando satisfatório.

Liotte (2002) também fez a comparação desses dois métodos em seu estudo sobre planejamento físico-territorial do Município de Pariquera-Açu, SP, obtendo, da mesma forma que Jiang \& Eastman (2000), áreas bens distintas como resultado da aplicação de cada um dos métodos. O autor concluiu que para um melhor planejamento é indicado o uso da Combinação Linear Ponderada. 
Para a definição de áreas sensíveis, prioritárias ou de risco, o método da Combinação Linear Ponderada vem sendo empregado em diversos campos da pesquisa. Malczewski (1996) o utilizou para determinação de locais para empreendimentos nocivos. Cafiso et al. (2002) para definir áreas próprias para locação de estradas, na Catania, Itália. Zhu \& Dale (2001) desenvolveram um software, com base nesse método, e o empregaram para a determinação de áreas prioritárias para o manejo sustentável, tendo em vista a qualidade da água, de uma bacia hidrográfica na região centro-oeste da Austrália.

$\mathrm{Na}$ priorização de áreas para o manejo sustentável de florestas, Varma et al. (2000) utilizaram esse método na Austrália, sendo seus fatores baseados em características físicas, espaciais, ecológicas e econômicas. Kangas et al. (2000) o empregaram para o manejo florestal na Finlândia, porém com a abordagem multicritérios/múltiplos objetivos. Os autores utilizaram múltiplos objetivos porque tinham em vista a produção de madeira e o manejo florestal com base nos princípios da Ecologia da Paisagem.

Na maioria dos trabalhos desenvolvidos, sobre a priorização de áreas relacionada aos recursos naturais, observa-se que a estrutura do processo de tomada de decisão tem por base múltiplos critérios (Kangas et al., 2000). Eastman (2001) ressalta que podem existir variações nessa estrutura, sendo possível todas as combinações entre único e múltiplos critérios e único e múltiplos objetivos.

No campo da conservação e preservação florestal pode-se citar Lathrop et al. (1998), que integraram os fatores declividade, proximidade aos corpos d'água, distância às estradas, proximidade às áreas sensíveis para a vida silvestre, com a Combinação Linear Ponderada, para determinar áreas prioritárias para a conservação da Floresta de Sterling, região metropolitana de Nova York.

A Combinação Linear Ponderada também foi empregada no projeto “Conservação dos Recursos Hídricos por meio da Recuperação e da Conservação da Cobertura Florestal da Bacia do Rio Corumbataí’(IPEF, 2001), para a definição de áreas prioritárias para a recuperação florestal. Nesse estudo os critérios e pesos foram avaliados considerando-se apenas a Taxa de Consistência (TC). 
Vettorazzi et al. (2000) e Chen et al. (2001) utilizaram o mesmo método para a determinação de áreas de risco de incêndios florestais. O primeiro trabalho foi realizado na Bacia do Rio Corumbataí, SP, e teve por base os fatores uso e cobertura do solo, proximidade aos corpos d'água, proximidade às estradas, declividade e aspecto. $\mathrm{O}$ segundo foi desenvolvido em Sidney, Austrália, com os fatores proximidade às áreas urbanas, proximidade aos corpos d' água, declividade e aspecto.

Geneletti (2004) identificou, na Província de Trento, Itália, áreas prioritárias para a conservação de ecossistemas importantes à sua região, com base na abordagem multicriterial - método da Combinação Linear Ponderada. O autor utilizou os fatores raridade, isolamento, distúrbio e área nuclear.

Graravelli et al. (2004) priorizaram áreas para a restauração florestal, também com a Combinação Linear Ponderada, no Parque Nacional de Snowdonia, Inglaterra, com base em critérios importantes às espécies florestais da região.

Para Jiang \& Eastman (2000) a Combinação Linear Ponderada, apesar de sua ampla utilização, apresenta limitações para algumas aplicações no processo de tomada de decisão. Os autores discutem essas limitações e sugerem a utilização do método da Média Ponderada Ordenada.

\subsubsection{Média Ponderada Ordenada}

A Média Ponderada Ordenada (Yager, 1988) diferencia-se da Combinação Linear Ponderada, principalmente pela presença de um segundo grupo de pesos, denominados de ordenação (Eastman, 1997). Os pesos de fatores (Combinação Linear Ponderada) passam, nesse método, a ser nomeados de pesos de compensação (Malczewski, 1999).

Os pesos de ordenação não se aplicam a qualquer fator. Eles são aplicados pixela-pixel a escores de fatores, determinado pelo ranqueamento desses fatores em cada local (pixel). O peso de ordenação 1 (um) é assinalado ao fator de menor ranqueamento para aquele pixel (isto é, fator com menor escore), peso de ordenação 2 (dois) para o próximo fator melhor ranqueado, e assim por diante (Eastman, 2001). 
Segundo Jiang \& Eastman (2000) os pesos de ordenação controlam a maneira pela qual os pesos de compensação serão agregados e determinam o nível de compensação necessário entre os fatores. Os autores citam que um fator ao qual foi atribuído um alto peso de compensação pode receber, por exemplo, um baixo peso de ordenação.

Malczewski (2004) cita que, enquanto o método Booleano caracteriza-se por ser um método de extremos e, dessa forma, por apresentar soluções totalmente aversas a risco (operador de intersecção AND - um local deve atender a todos os critérios para ser incluído no conjunto de decisão) ou totalmente arriscadas (operador de união OR - um local será incluído no conjunto de decisão se pelo menos um critério for atendido), o método da Média Ponderada Ordenada tem a flexibilidade de assumir soluções em qualquer ponto entre esses extremos. Malczewski (2003) complementa que são os pesos de ordenação que determinarão essa posição, das soluções/hipóteses, entre os extremos e, portanto, o risco assumido no processo de tomada de decisão.

O método da Combinação Linear Ponderada é, segundo Malczewski (2000), formalizado por médias e, dessa maneira, suas soluções não serão nem arriscadas e nem aversas a risco porque sempre estarão no meio dos extremos (AND e OR). Malczewski (1996) cita que esse método pode ser considerado uma simples variação do método da Média Ponderada Ordenada.

O método da Média Ponderada Ordenada pode ser, assim, considerado como uma extensão e uma generalização dos procedimentos convencionais nos SIGs, especialmente daqueles relacionados à abordagem multicriterial (Jiang \& Eastman, 2000). Os mesmos autores comparam soluções obtidas com os métodos Booleano, da Combinação Linear Ponderada e da Média Ponderada Ordenada, para a locação de um parque industrial, no leste da África. Essas soluções (mapas) mostraram-se bem distintas, principalmente as obtidas com variações dos pesos de ordenação, no método da Média Ponderada Ordenada. Nessas últimas observou-se um aumento no número de classes à medida em que a solução "caminhava" entre os extremos (AND para OR), o que indica a melhor definição das áreas adequadas à locação do parque industrial. 
Araújo (1999), comparando os três métodos em seu estudo de avaliação da favorabilidade de mineralizações de metais básicos, obteve conclusões semelhantes. $\mathrm{O}$ método da Média Ponderada Ordenada possibilitou a obtenção de um maior número de classes, enquanto que com a Combinação Linear Ponderada essas classes passaram a constituir uma única região.

Malczewski (1999) utilizou o método da Média Ponderada Ordenada para determinação de áreas adequadas à urbanização no México. Segundo o autor, as alternativas propostas apresentaram alta correlação com a realidade da região.

Calijuri et al. (2002), na identificação de áreas para a implantação de aterros sanitários em Cachoeiro do Itapemirim, ES, com o método da Média Ponderada Ordenada, também obtiveram soluções compatíveis com as características da paisagem, tendo a melhor solução risco médio-alto e compensação parcial entre os fatores utilizados.

Malczewski (2003) empregou esse mesmo método para a priorização de áreas à serem reabilitadas/restauradas na bacia hidrográfica de Cedar Creek, Canadá, com os objetivos de incrementar a sua cobertura florestal natural; incrementar a qualidade e a biodiversidade de suas áreas naturais; proteger sua água superficial; e melhorar a "saúde" de seus corpos d'água. Foram utilizados os fatores: proteção de áreas de recarga; distância às nascentes; proteção as áreas suscetíveis à erosão; proteção de áreas úmidas; proteção da área nuclear de floresta; proximidade aos corpos d'água de superfície; proximidade às áreas naturais; proteção ao uso do solo; proteção às propriedades particulares; e visibilidade. Para determinar a melhor alternativa/solução foi considerada a viabilidade econômica de implantação de projetos. Dessa forma, foi escolhida uma solução com risco e compensação, entre fatores, moderados. Os tomadores de decisão consideraram adequada a solução proposta porque foi recomendado que a restauração fosse iniciada onde já existissem áreas naturais. As áreas de prioridade muito alta foram as próximas às áreas úmidas de Cedar Creek e ao redor dos bosques. As áreas próximas aos cursos d'água foram identificadas como de alta ou média prioridade. 


\subsubsection{Definição de critérios e pesos}

Eastman et al. (1993), Malczewski (1999), Kangas et al. (2000), Roy \& Tomar (2000), Chen et al. (2001) e Store \& Kangas (2001) propõem o emprego da Técnica Participatória, que consiste na reunião entre especialistas nas diferentes áreas de interesse ao projeto, para auxiliar na definição dos critérios e dos pesos (fatores).

Para Malczewski (2004) essa integração entre especialistas e os SIGs colabora para o sucesso da priorização de áreas e caracteriza o processo de tomada de decisão como um processo socioeconômico, além de ambiental.

Vários métodos foram desenvolvidos para auxiliar na definição dos pesos de compensação dos fatores, dentre eles o da ordenação, da escala de pontos, da distribuição de pontos e da comparação pareada (Malczewski, 1999; Thill, 1999; Ramos \& Mendes, 2001). O mais promissor e utilizado é o método da Comparação Pareada, desenvolvido por Saaty (1977) no contexto do Processo Hierárquico Analítico e adaptado, pela primeira vez, para o uso em um SIG, por Rao et al. (1991) (Alho \& Kangas, 1997). Para Mendoza \& Prabhu (2000), a grande aceitação do método por parte dos tomadores de decisão, está na consistência entre os pesos atribuídos aos fatores e a importância, nas paisagens, de características por eles representadas.

Neste método, para a elaboração de uma matriz de comparação, os valores atribuídos aos fatores são derivados de uma escala contínua de nove pontos, sendo que os fatores são comparados entre sí, dois a dois, e classificados segundo a importância relativa entre eles (Eastman, 2001).

Segundo Saaty (1980), a matriz de comparação é simétrica, sendo necessário preencher somente sua parte triangular inferior. A consistência dessa matriz é avaliada

por sua Taxa de Consistência (TC), que indica a probabilidade de que os valores de comparação entre os fatores tenham sido gerados aleatoriamente. $\mathrm{O}$ autor cita que os valores de TC devem estar sempre abaixo de 0,10 e, no caso de estarem acima deste valor, o autor sugere que se reorganize a matriz, alterando os valores de comparação entre os fatores. 


\subsubsection{Análise de sensibilidade}

No processo de tomada de decisão com a abordagem multicriterial, os resultados são, inevitavelmente, associados a uma variedade de incertezas, as quais são causadas pelos componentes: fatores; pesos; e prioridades (Voodg, 1983). Essas incertezas podem ser identificadas e avaliadas por uma análise de sensibilidade que, segundo Butler et al. (1997), determina a robustez das soluções obtidas no processo de tomada de decisão.

Malczewski (1999) define essa análise como o procedimento para determinar como o curso das soluções ou alternativas, que se obteve com a priorização de áreas, pode ser modificado com alterações no início do processo de tomada de decisão. Ainda segundo esse autor, se as alterações não afetarem significativamente as saídas (soluções/alternativas), o ordenamento pode ser considerado robusto. Se os resultados encontrados forem insatisfatórios, pode-se utilizar as informações de saída na etapa de formulação do problema.

Para Store \& Kangas (2001), o propósito geral da análise de sensibilidade é avaliar a influência e a importância dos diferentes critérios e pesos no padrão de distribuição espacial da prioridade avaliada. Os autores citam que, com o auxílio de programas computacionais específicos, podem-se realizar as alterações dos pesos dos fatores e/ou a omissão de alguns fatores e avaliar-se a influência dessas alterações na determinação de áreas prioritárias.

A análise de sensibilidade pode ser pensada, de acordo com Malczewski (2004), como um processo exploratório pelo qual os tomadores de decisão adquirem um conhecimento profundo da estrutura do problema. Ela auxilia no entendimento de como os elementos interagem para culminarem em uma alternativa e quais elementos são importantes, ou não, para o problema em questão.

A incorporação do processo de tomada de decisão nos SIGs vem acontecendo gradativamente (Zhou \& Civco, 1996). Alguns procedimentos, como a análise de sensibilidade (Lodwick et al., 1990) e a análise de propagação de erro (Hevelink et al., 1989), têm apresentado problemas e incompatibilidade com os SIGs. Malczewski (2004) 
cita que a principal dificuldade continua sendo trabalhar com a interpretação e a ambigüidade dos dados de entrada (conceitos dos especialistas; critérios nem sempre mensuráveis) e a característica de continuidade espacial dos fatores (lógica fuzzy).

Como soluções para a análise de sensibilidade, Carver (1991) e Malczewski (1996 e 2000) propõem ou a posterior integração com outros técnicas (por ex. inteligência artificial) ou sucessivas alterações nas entradas (critérios e/ou pesos) e saídas (alternativas e/ou soluções), no processo de tomada de decisão no próprio ambiente SIG. 


\section{MATERIAL E MÉTODOS}

\subsection{Material}

\subsection{1 Área de estudo}

\subsubsection{Localização}

A Bacia do Rio Corumbataí (Figura 1), localizada na porção centro-leste do Estado de São Paulo, entre os paralelos $22^{\circ} 04^{\prime} 46^{\prime \prime}$ S e $22^{\circ} 41^{\prime} 28^{\prime \prime} \mathrm{S}$ e os meridianos $47^{\circ}$ $26^{\prime} 23^{\prime}$ 'W e $47^{\circ} 56$ ' $15^{\prime}$ 'W, tem aproximadamente 170.000 ha, sendo que a maior parte de suas terras encontra-se na Depressão Periférica Paulista. Seu perímetro é de aproximadamente $301,52 \mathrm{~km}$, tendo $63,72 \mathrm{~km}$ de extensão no direção norte-sul e 26,80 km (maior largura) na direção leste-oeste. É uma sub-bacia do Rio Piracicaba, estando situada à sua margem direita.

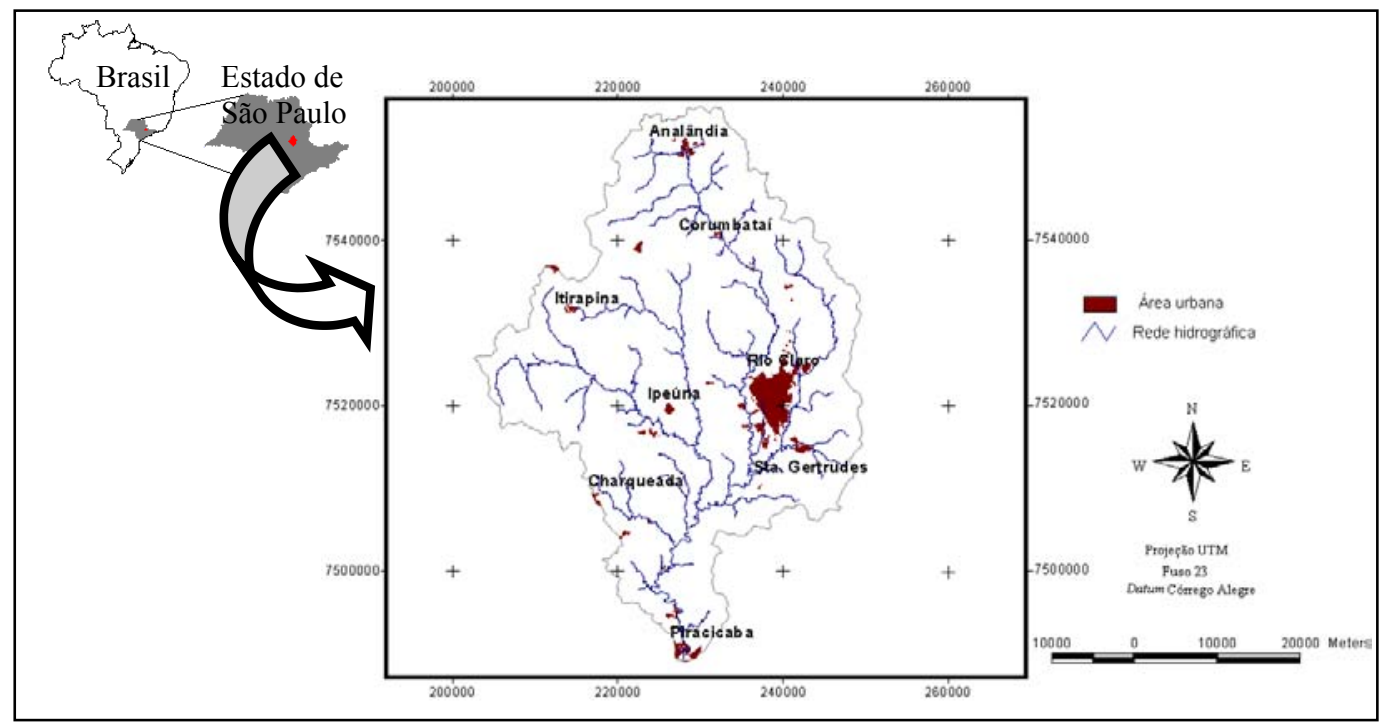

Figura 1 - Localização da Bacia do Rio Corumbataí 
Os municípios que a compõem são: Corumbataí; Ipeúna; Rio Claro; e Santa Gertrudes; e parte dos municípios de Analândia; Charqueada; Itirapina; e Piracicaba.

Tradicionalmente a bacia é dividida nas seguintes sub-bacias: Alto Corumbataí (31801,68 ha); Passa-Cinco (52757,60 ha); Médio Corumbataí (29316,60 ha); Ribeirão Claro (28174,90 ha) e Baixo Corumbataí (28724,84 ha), conforme a Figura 2.

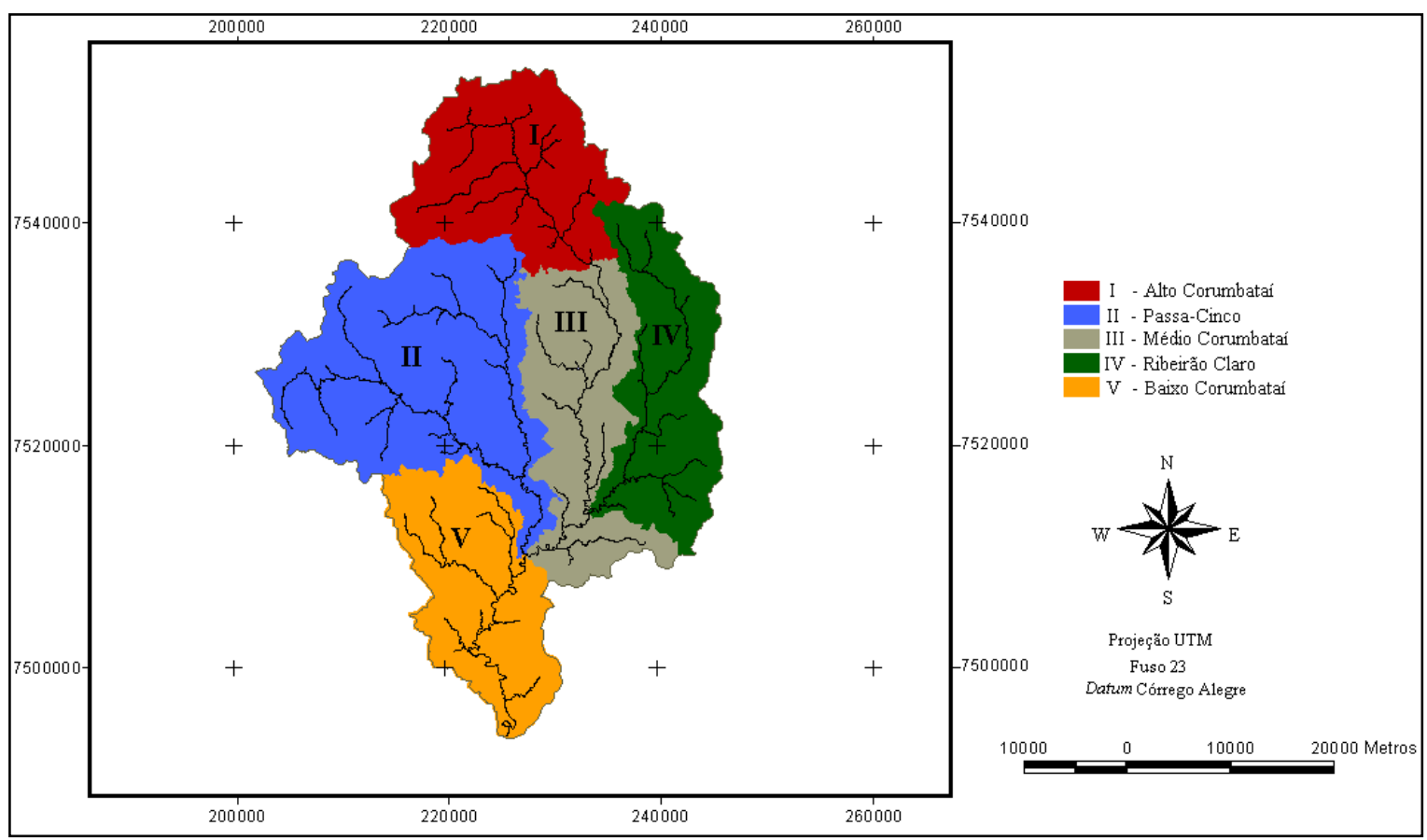

Figura 2 - Bacia do Rio Corumbataí: divisão em sub-bacias

\subsubsection{Relevo}

O relevo da bacia é representado, segundo Koffler (1993), principalmente por duas modalidades:

(1) Morrotes alongados e espigões: predominam interflúvios sem orientação preferencial, topos angulosos e achatados e vertentes ravinadas com perfis retilíneos, possuindo a drenagem de média a alta densidade, padrão dendrítico, vales fechados; e

(2) Colinas médias e amplas: predominando interflúvios com áreas de $1 \mathrm{~km}^{2}$ a mais de $4 \mathrm{~km}^{2}$, topos aplainados, vertentes com perfis convexos a retilíneos que se 
conectam à drenagem de média a baixa densidade e apresentam padrão subangular, vales abertos e fechados, planícies interiores restritas a presença de lagoas perenes ou intermitentes.

As declividades (Figura 3) na bacia variam de planas à muito íngremes, sendo que as maiores declividades são encontradas nas sub-bacias do rio Passa-Cinco e do Alto Corumbataí.

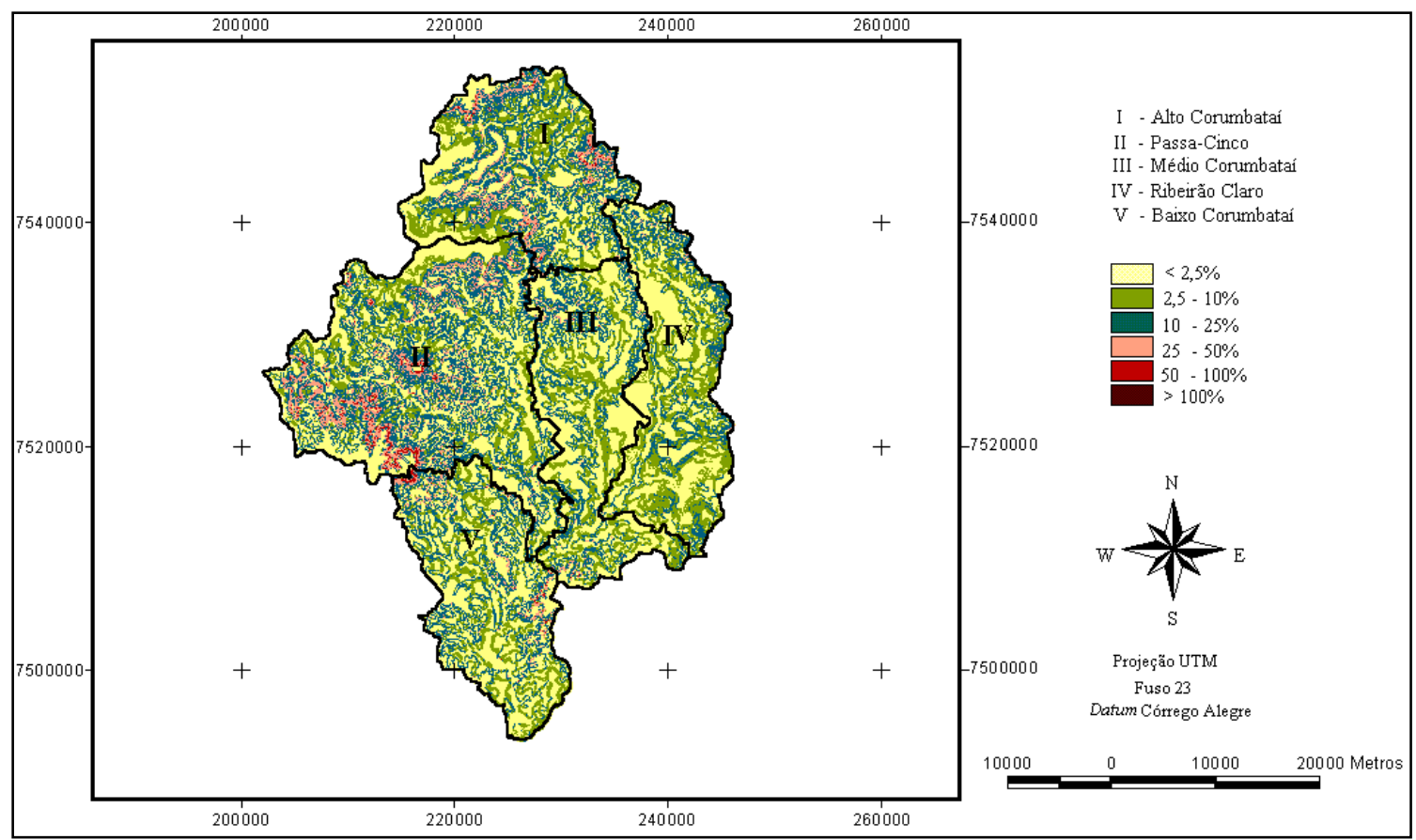

Figura 3 - Classes de declividade da Bacia do Rio Corumbataí

Viadanna (1985) classificou como monótona a paisagem dessa bacia, havendo a predominância de extensas áreas suavemente onduladas, interrompidas por escarpas arenítico-basálticas e cortadas pela rede hidrográfica com padronagem dendrítica.

\subsubsection{Geologia}

A Bacia do Rio Corumbataí é composta pelas formações Rio Claro, Pirambóia, Corumbataí e Irati (Koffler, 1994). As características e o potencial mineral de cada formação podem ser observados na Tabela 1. 
Tabela 1. Constituição geológica, características e potencial mineral das formações da Bacia do Rio Corumbataí

\begin{tabular}{lll}
\hline Formação & Características & Potencial Mineral \\
\hline Rio Claro & arenitos, arenitos conglomeráticos e arenitos & areia (principal); argila \\
& argilosos, restrito à região de Ipeúna & \\
Pirambóia & arenitos finos a médios sílticos argilosos de & argila \\
& cor avermelhada, intercalados por níveis de & \\
& argilito, folhelhos e arenitos argilosos de & \\
& cores variadas, típicos de ambiente fluvial e & \\
& de planície de inundação \\
Corumbataí & argilitos, folhelhos sílticos cinza, arroxeados & argila \\
& ou avermelhados associados a depósitos de & \\
& planície de maré \\
& siltitos, argilitos, folhelhos sílticos cinza, calcário e dolomito \\
& folhelhos pirobetuminosos intercalados com & \\
& calcários creme, de ambiente marinho raso & \\
\hline
\end{tabular}

Fonte: Koffler (1994).

Koffler (1993) cita que, sob o ponto de vista geológico, essa bacia localiza-se na Bacia Sedimentar do Paraná, sendo ali encontradas litologias relativas ao Cenozóico, ao Mesozóico e ao Paleozóico.

\subsubsection{Clima}

O clima da região, na classificação de Köppen, é do tipo Cwa, ou seja subtropical, seco no inverno e chuvoso no verão, com temperatura média do mês mais quente superior a $22^{\circ} \mathrm{C}$. As temperaturas mais altas ocorrem no período de dezembro a março e as mais baixas no bimestre junho e julho, com $17^{\circ} \mathrm{C}$ de temperatura (Salati, 1996). 
O regime de chuvas é tropical, com duas estações definidas: um período seco, de março a setembro, com menos de $20 \%$ da precipitação anual, e um período chuvoso, de outubro a fevereiro, com mais de $80 \%$ da precipitação anual, sendo o total precipitado no ano em torno de 1390mm (Troppmair \& Machado, 1974).

A insolação é de 2420 horas anuais, o que significa que $56 \%$ do período de claridade apresenta-se ensolarado. Os ventos são moderados, predominando a direção ESE (Koffler, 1993).

\subsubsection{Solos}

A Bacia do Rio Corumbataí, com base na primeira ordem do Novo Sistema de Classificação de Solos Brasileiros (Prado, 2003), tem aproximadamente 46\% de sua área ocupada com Argissolos; 30\% com Latossolos; 22\% com Neossolos; 0,56\% com Gleissolos; 0,41\% com Nitossolos; e apenas 0,28\% com Chernosssolos. A distribuição desses grandes grupos de solos pode ser observada na Figura 4 e ainda na Tabela 2.

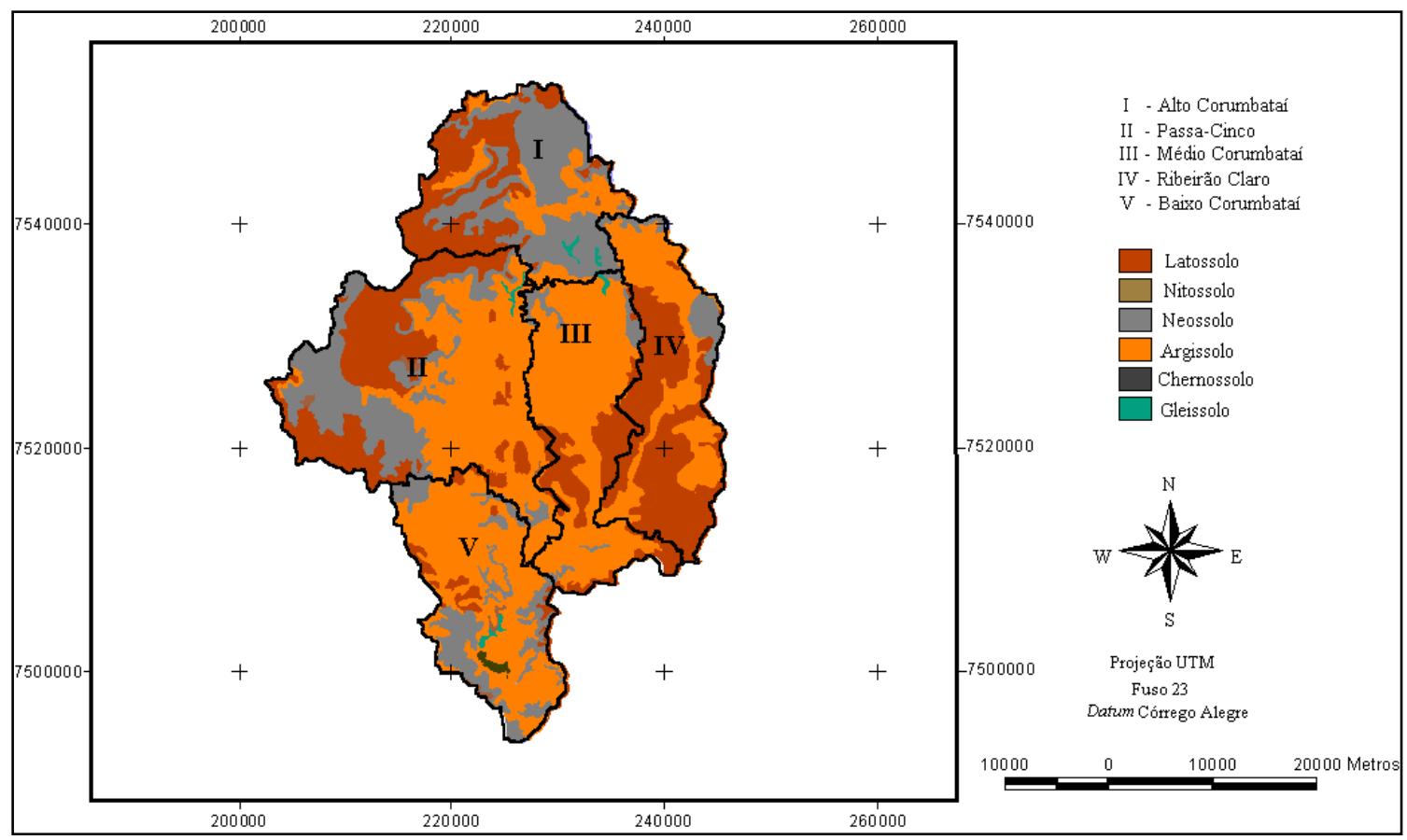

Figura 4 - Grandes grupos de solos da Bacia do Rio Corumbataí 
O mapa com os grandes grupos de solos (Figura 4) foi obtido com a reclassificação do mapa de solos já existente para a bacia, também em grandes grupos, produzido a partir do levantamento pedológico semidetalhado do Estado de São Paulo (Oliveira \& Prado,1989), na escala 1:100.000.

Tabela 2. Grandes grupos de solos da Bacia do Rio Corumbataí

\begin{tabular}{lccccc}
\hline Tipo de solo & $\begin{array}{c}\text { Alto } \\
\text { Corumbataí }\end{array}$ & Passa-Cinco & $\begin{array}{c}\text { Médio } \\
\text { Corumbataí } \\
\text { Área (\%) }\end{array}$ & $\begin{array}{c}\text { Ribeirão } \\
\text { Claro }\end{array}$ & $\begin{array}{c}\text { Baixo } \\
\text { Corumbataí }\end{array}$ \\
\hline Latossolos & 33,20 & 30,23 & 24,54 & 54,22 & 8,20 \\
Argissolos & 18,76 & 43,98 & 69,96 & 37,96 & 64,87 \\
Nitossolos & 0,14 & 0,67 & 0,00 & 0,00 & 1,03 \\
Neossolos & 47,10 & 24,71 & 5,02 & 7,81 & 22,91 \\
Gleissolos & 0,79 & 0,31 & 0,36 & 0,00 & 0,60 \\
Chernossolos & 0,00 & 0,00 & 0,00 & 0,00 & 1,09 \\
\hline
\end{tabular}

\subsubsection{Uso e cobertura do solo}

Segundo Koffler (1993), a Bacia do Rio Corumbataí era originalmente coberta por florestas, cerrados e campos cerrados.

A cafeicultura, as ferrovias com máquina a vapor e as numerosas olarias e serrarias do século XIX teriam sido responsáveis pelo desaparecimento dessa vegetação original, da qual existem hoje apenas vestígios (Garcia, 2000).

Valente \& Vettorazzi (2003), com base no mapa de uso e cobertura do solo produzido para o ano de 2000, citam que, na área da bacia, existem apenas $11 \%$ de floresta nativa e 1,25\% de cerrado "lato sensu" e que essa vegetação remanescente encontra-se altamente fragmentada. As sub-bacias do rio Passa-Cinco e Alto Corumbataí concentram as maiores áreas de floresta nativa e os melhores fragmentos (maiores, mais próximos uns dos outros e com melhor forma) da bacia (Valente \& Vettorazzi, 2002). 
Esses autores ressaltam que o cerrado ocorre predominantemente nessa duas sub-bacias, com alguns poucos fragmentos na sub-bacia do Ribeirão Claro.

Os remanescentes florestais pertencem às formações: Floresta Estacional Semidecidual, Floresta Ripária, Floresta Paludosa e Floresta Estacional Decidual (Rodrigues, 1999).

As culturas agrícolas, ainda segundo Valente \& Vettorazzi (2003), predominam nessa paisagem, sendo que a pastagem representa, aproximadamente $44 \%$ do uso do solo. A cana-de-açúcar, segunda cultura agrícola de maior representatividade, corresponde a aproximadamente $26 \%$ da área total da bacia. Ocorrem ainda outros usos do solo, como a fruticultura e os plantios comercias de eucalipto, que representam, respectivamente, $3 \%$ e 7\%, aproximadamente, dessa paisagem.

Koffler (1993) e Vettorazzi et al. (2000) e em seus mapeamentos de uso e cobertura do solo dessa bacia, para os anos de 1991 e 1998, respectivamente, também observaram a predominância da pastagem e da cana-de-açúcar. Os autores constataram que a floresta nativa ocupava 6,1\% no ano de 1991 e 9,6\% da área total da bacia no ano de 1998. Essa tendência de aumento da área ocupada por floresta nativa também foi constatada no inventário do Instituto Florestal (2003), que relatou um aumento de 2,86\%, o correspondente a $808 \mathrm{~km}^{2}$, em área ocupada por Mata Atlântica, no Estado de São Paulo (Zorzetto et al., 2003).

\subsubsection{Imagens orbitais}

Para o mapeamento do uso e cobertura do solo foram empregadas imagens orbitais obtidas pelo sensor ETM+, a bordo do satélite LANDSAT-7. Foram necessárias duas cenas para o recobrimento de toda a área da bacia. Essas cenas são referentes à passagem do dia 17 de agosto de 2002.

As bandas espectrais utilizadas foram: ETM3, ETM4 e ETM5, referentes às faixas do vermelho, infravermelho próximo e infravermelho médio do espectro eletromagnético, respectivamente. Com essas bandas foi possível a elaboração de uma composição colorida (4R/5G/3B), que também foi utilizada no processo de obtenção do 
mapa de uso e cobertura do solo (classificação digital supervisionada). Na Tabela 3 podem ser observadas as características do modo de operação do sensor ETM+, a bordo do satélite LANDSAT-7.

Tabela 3. Características do modo de operação do sensor ETM+

\begin{tabular}{ll}
\hline \multicolumn{1}{c}{ Características } & \multicolumn{1}{c}{ ETM+ } \\
\hline Resolução espectral $(\mu \mathrm{m})$ & Banda 1: $0,45-0,52$ \\
& Banda 2: $0,53-0,61$ \\
& Banda 3: $0,63-0,69$ \\
& Banda 4: $0,76-0,90$ \\
& Banda 5: $1,55-1,75$ \\
& Banda 6: $10,40-12,75$ \\
& Banda 7: 2,08-2,35 \\
& Banda 8: $0,52-0,90$ \\
& 30 m (bandas 1 a 5 e 7) \\
Resolução espacial & 60 m (banda 6) \\
& 15 m (banda 8$)$ \\
Resolução radiométrica & 256 níveis de cinza \\
Dimensões de cada cena & 185 km x 185 km \\
Resolução temporal & 16 dias
\end{tabular}

Fonte: Engesat (2004)

\subsubsection{Mapas digitais}

Foram utilizados os seguintes mapas digitais, do banco de dados cartográficos do “Projeto Corumbataí"(IPEF, 2001), com resolução espacial de $20 \mathrm{~m}$ e tendo por base o Datum Córrego Alegre e a projeção Universal Transversa de Mercator - fuso 23:

(1) rede hidrográfica: digitalizada (via mesa digitalizadora) com base nas cartas do Instituto Brasileiro de Geografia e Estatística (IBGE), na escala 1:50.000, no ano de 
1969 e complementada com digitalização em tela, tendo por base um mosaico de imagens digitais orbitais da área de estudo, do ano de 1999;

(2) malha viária: digitalizada (em tela), com base em um mosaico de imagens digitais orbitais, da área de estudo, do ano de 1999;

(3) mapa de solos: produzido a partir do levantamento pedológico semidetalhado do Estado de São Paulo (Oliveira \& Prado,1989), na escala 1:100.000;

(4) erodibilidade do solo: o mapa de solos da bacia foi reclassificado para valores de erodibilidade. Para alguns solos esses valores foram obtidos em Levy (1995) e para outros determinados segundo metodologia proposta por Wischmeier et al. (1971);

(5) modelo digital do terreno (MDT): recortado do MDT produzido para a Bacia do Rio Piracicaba (Projeto PiraCena, 2000), com base em cartas planialtimétricas (IBGE, escala 1:50.000, ano de 1969);

(6) limites da bacia: determinados com base no comportamento gráfico das curvas de nível de cartas planialtimétricas (IBGE, escala 1:50.000, ano de 1969) e digitalizados via mesa digitalizadora; e

(7) limites das sub-bacias: gerados com o modelo SWAT (Soil and Water Assessment Tool), no ambiente ArcView, com base no modelo digital do terreno da bacia, sua rede hidrográfica e do ponto de junção de cada sub-bacia no rio Corumbataí.

Além desses mapas foi utilizado, desse banco de dados, uma imagem SPOT (setembro de 1999), como base para o georreferenciamento do mosaico (imagens LANDSAT) empregado na produção do novo mapa de uso e cobertura do solo. A imagem SPOT foi, por sua vez, georreferenciada tendo como referência cartas planialtimétricas (IBGE, escala 1:50.000, ano de 1969) e apresentando um erro médio quadrático (RMS) de 5,8 m.

\subsubsection{Receptor GPS}

Para as verificações de campo referentes ao processamento digital das imagens de satélite, foi empregado um receptor GPS (Global Positioning System) de navegação, com 12 canais, antena interna e exatidão nominal ao redor de $16 \mathrm{~m}$. 


\subsubsection{Máquina fotográfica}

Uma câmera digital, com resolução espacial de 2,2 Megapixels e zoom de duas vezes, foi empregada para fotografar pontos de interesse durante as verificações de campo.

\subsubsection{Sistemas computacionais}

Os softwares empregados foram:

a) ENVI 3.5: processamento digital de imagens orbitais;

b) IDRISI Kilimanjaro: operações de análise espacial e processo de tomada de decisão;

c) FRAGSTAT 3.3: determinação da área nuclear dos fragmentos de floresta nativa.

\subsection{Métodos}

\subsubsection{Planos de informação}

\subsubsection{Uso e cobertura do solo}

O mapa de uso e cobertura do solo foi produzido pelo processamento digital das imagens orbitais, seguindo as seguintes etapas:

\section{(1) Pré-processamento das imagens}

Nessa etapa realizaram-se as correções atmosférica e geométrica das imagens. A correção atmosférica teve por base o Princípio da Reflectância Zero. Dessa maneira, conforme descrito por Quintanilha (1990), foram avaliados os histogramas das cenas; identificados os pixels que deveriam apresentar valores de reflectância nula; e esses pixels foram reclassificados para apresentarem valores digitais iguais a zero, conseqüentemente corrigindo os demais. 
$\mathrm{Na}$ correção geométrica foi utilizado o modelo de transformação polinomial de primeiro grau e o método de interpolação pelo vizinho mais próximo. Para essa correção houve a identificação e o registro das coordenadas de pontos, denominados de controle, e que eram comuns entre as imagens digitais LANDSAT-7 e uma imagem do satélite SPOT-4 que, por sua vez, representou as coordenadas reais.

Procurou-se distribuir os pontos de controle de forma homogênea nas duas imagens. A posição da maioria desses pontos coincidiu com intersecções da malha viária e confluência de rios. O registro das coordenadas desses pontos foi feito com a digitalização em tela, nas imagens LANDSAT-7 e SPOT-4, no próprio software de processamento digital de imagens.

$\mathrm{Na}$ Tabela 4 podem ser observados o número de pontos de controle empregado e o erro médio quadrático (RMS), utilizados na correção geométrica das duas cenas.

Tabela 4. Número de pontos de controle e erro médio quadrático (RMS)

\begin{tabular}{ccc}
\hline Cena & Total de pontos utilizados & RMS (m) \\
\hline $220 / 75^{*}$ & 26 & 14,79 \\
$220 / 76^{* *}$ & 17 & 14,94 \\
\hline
\end{tabular}

\footnotetext{
* recobre aproximadamente $70 \%$ da área da bacia.

** recobre aproximadamente $30 \%$ da área da bacia.
}

O erro médio quadrático (RMS) é uma forma simples de ter-se o controle de qualidade da correção geométrica e, segundo Jones et al. (1993), expressa o grau de variação entre as coordenadas de imagem e as coordenadas reais.

\section{(2) Elaboração do mosaico}

Para juntar as duas cenas em uma única imagem foi necessário, primeiramente, o ajuste dos histogramas dessas cenas. Utilizando a área de sobreposição das duas cenas, esse ajuste foi feito igualando-se a curva do histograma de uma das cenas, usando a curva da outra como referência. 


\section{(3) Definição das classes de uso e cobertura}

As classes de uso e cobertura do solo foram definidas a partir do conhecimento de campo já adquirido e com base no mapa de uso e cobertura do solo produzido por Valente \& Vettorazzi (2003). As classes estabelecidas foram:

(a) cana-de-açúcar: áreas onde o solo estava coberto com a cultura da cana-de-açúcar em seus vários estádios;

(b) pastagem: áreas utilizadas pela pecuária intensiva e extensiva e também áreas cobertas por gramíneas, contudo sem uso definido, estando sujeitas à regeneração de sua vegetação original ou posterior uso com outro tipo de cultura;

(c) floresta plantada: áreas ocupadas com plantios de Eucalyptus ou Pinus. Procurou-se considerar somente aqueles plantados para fins comerciais;

(d) floresta nativa: abrange as áreas ocupadas pelas diferentes formações florestais nativas existentes na bacia; as áreas onde foram realizados plantios de florestas nativas; e pequenas áreas ocupadas com Eucalyptus antigos, sem características próprias de um plantio comercial, sempre associados à vegetação arbórea natural em diferentes estágios de regeneração;

(e) cerrado: áreas cobertas com vegetação de cerrado "lato sensu";

(f) fruticultura: áreas ocupadas com plantios comerciais de citros;

(g) cultura anual: áreas ocupadas com culturas de milho, sorgo, mandioca etc.;

(h) mineração: áreas exploradas pela extração de calcário ou argila;

(i) área urbana: áreas ocupadas com as sedes dos municípios da bacia, os bairros rurais, os condomínios mais afastados dos principais centros urbanos e outros tipos de ocupação do solo onde existe a predominância de construções, com área igual ou maior que a resolução espacial das imagens empregadas;

(j) solo exposto: diz respeito à condição do solo no momento da passagem do satélite. Contudo, para uma melhor caracterização, essa classe foi posteriormente reclassificada de acordo com a cultura correspondente (cana-de-açúcar, pastagem etc.). 


\section{(4) Tomada das amostras de treinamento}

As amostras de treinamento foram tomadas por digitalização de polígonos em tela, sobre as áreas que representavam as classes de uso e cobertura previamente determinadas, para assim adquirir as estatísticas a serem empregadas pelo algoritmo de classificação. Fato a ressaltar é que, a presença na bacia de culturas em diferentes estádios de desenvolvimento, em alguns casos de variedades distintas e variações nos tipos de solo, tiveram como conseqüência variações no comportamento espectral na maioria das classes de uso e cobertura do solo, levando à necessidade de subdividí-las (Tabela 5).

Tabela 5. Número de subclasses e de pixels (NPs) amostrados, para os diferentes usos e coberturas do solo

\begin{tabular}{lcc}
\hline Uso e cobertura do solo & Número de subclasses & NPs \\
\hline Cana-de-açúcar & 25 & 700 \\
Pastagem & 52 & 600 \\
Floresta plantada & 10 & 500 \\
Cerrado & 7 & 120 \\
Floresta nativa & 30 & 250 \\
Fruticultura & 11 & 170 \\
Cultura anual & 6 & 110 \\
Solo exposto & 38 & 130 \\
\hline Total & 179 & 2529 \\
\hline
\end{tabular}

O número de pixels (NP) amostrados por classe foi determinado pela form. (1):

$N P=\frac{\mathrm{Tp} \times(1,5 \mathrm{a} 3,0 \%)}{\% \mathrm{C}}$

onde:

Tp : total de pixels da imagem; e 
$\% \mathrm{C}$ : percentual que a classe de uso e cobertura do solo ocupa na bacia (Tabela 6), de acordo com o mapeamento de Valente \& Vettorazzi (2003).

Procurou-se, dessa forma, evitar a superamostragem de algumas classes e a subamostragem de outras. Assim, obteve-se o número de pixels por classe de uso e cobertura (form. 2):

$$
N P=\frac{4486824 \times 0,015}{\% \mathrm{C}}
$$

Tabela 6. Uso e cobertura do solo na Bacia do Rio Corumbataí

\begin{tabular}{lc}
\hline Uso e cobertura do solo & $(\% \mathrm{C})$ \\
\hline Cana-de-açúcar & 25,57 \\
Pastagem & 43,68 \\
Floresta Plantada & 7,33 \\
Floresta Nativa & 11,11 \\
Cerrado & 1,25 \\
Fruticultura & 2,82 \\
Cultura Anual & 1,02 \\
Mineração & 0,09 \\
Área Urbana & 2,77 \\
Outros & 4,37 \\
\hline Total & 100,00 \\
\hline
\end{tabular}

Fonte: Valente \& Vettorazzi (2003).

Com o número de subclasses e o número de pixels (NP) a serem amostrados para os diferentes usos e coberturas do solo, calculou-se o número de pixels amostrados por subclasse (NPs), também apresentado na Tabela 5.

Os critérios para incluir as feições nas amostras de treinamento e, assim, atingir o número de pixels desejado, foram: (1) a identificação visual por similaridade de níveis 
de cinza com a subclasse que se desejava amostrar; e (2) a avaliação do histograma da feição amostrada.

\section{(5) Aplicação do algoritmo de classificação supervisionada}

$\mathrm{Na}$ classificação propriamente dita foi empregado o algoritmo de máxima verossimilhança (MAXVER ), cuja conceituação matemática foi estabelecida por Swain \& Davis (1978) e Schalkoff (Jensen, 1996), e um limiar de 0,04.

O limiar é um parâmetro cujos valores variam de 0 a 1 e que é empregado para o controle do nível de probabilidade no qual cada pixel é considerado, para ser classificado. Desse modo, aqueles pixels com menor probabilidade que o limiar estabelecido não são classificados.

\section{(6) Tratamentos pós-classificação}

Procurando atenuar o efeito da presença de pixels isolados, comuns em produtos de classificações com o algoritmo de máxima verossimilhança (MAXVER), foi aplicado um filtro de mediana de $3 \times 3$ pixels.

O filtro de mediana é classificado como um filtro passa-baixa, onde o pixel central da máscara é substituído pela mediana dos seus vizinhos. É um filtro de implementação complexa, devido à necessidade de um ordenamento dos valores, mas é um dos filtros de suavização que melhor preservam as bordas em uma imagem (Crósta, 1993).

Com a aplicação desse filtro observou-se que os fragmentos de floresta passavam a ter sua forma, sua conectividade e, em muitos casos, sua área, alteradas o que levou à necessidade de aplicar o filtro somente nas demais classes de uso e cobertura do solo. Em seguida, foram eliminados os pixels isolados da categoria floresta nativa, que deveriam ter sido eliminados na filtragem, para então ter-se, novamente, o mapa de uso e cobertura incluindo os fragmentos de floresta. 
Feições como as áreas urbanas e os hortos florestais, que não foram classificadas corretamente por meio do processo digital, em função da heterogeneidade de seus componentes, foram nessa etapa digitalizadas em tela, tendo por base a composição colorida.

As áreas ocupadas por solo exposto foram reclassificadas de acordo com a cultura que as ocupam a maior parte do ano. A determinação dessa cultura foi feita com base em informações do mosaico (cenas LANDSAT-7), do mapa de uso e cobertura produzido por Valente \& Vettorazzi, 2003) e dos trabalhos de campo.

Notou-se, nesse produto da classificação, que não houve a distinção entre floresta nativa e cerrado, isto porque as assinaturas espectrais (amostras) dessas duas categorias, não se apresentaram estatisticamente diferentes.

Para a identificação dos fragmentos de cerrado foram extraídos do mapa de solos da bacia aqueles que, segundo a literatura (Coutinho, 2003; Marques, 2003; Pivello \& Coutinho, 1996) estão comumente associados a esse tipo de vegetação. São eles os Latossolos, os Cambissolos, os Litólicos e as Areias Quartzosas. Para essas regiões produziu-se, a partir do mosaico, uma imagem com o Índice de Vegetação da Diferença Normalizada (NDVI) (form. 3):

$$
N D V I=\frac{I V P-V e r}{I V P+V e r}
$$

onde:

$I V P=$ energia refletida (representada pelo nível de cinza) na região do infravermelho próximo no espectro eletromagnético; e

Ver = energia refletida (nível de cinza) na região do vermelho no espectro eletromagnético.

O NDVI é um dos índices de vegetação mais empregados em sensoriamento remoto para a avaliação do vigor da cobertura vegetal, da biomassa e da produtividade (Jensen, 1983; Tucker et al.; 1985, Shimabukuro et al., 1999; Ferreira et al., 2004). Nesse caso, foi importante porque auxiliou na distinção entre as áreas cobertas por floresta nativa e aquelas cobertas por cerrado. O primeiro tipo de vegetação 
apresentando, na maioria das situações, maior quantidade de biomassa, dentre as duas formações, passou a caracterizar-se por pixels com níveis de cinza associados a maiores valores $(0-255$ bytes $)$. O cerrado, de maneira contrária, por caracterizar-se pela presença de menor quantidade de biomassa em seus fragmentos do que a floresta nativa, caracterizou-se por pixels com níveis de cinza associados a menores valores.

Como informações complementares para essa procedimento foram consideradas, ainda:

(a) As características das áreas de abrangência do cerrado no Estado de São Paulo e, em especial, na região dos municípios de São Carlos, Itirapina, Analândia, Corumbataí e Rio Claro (contemplam a área de abrangência dessa vegetação nos limites da bacia), isto de acordo com o levantamento da Secretaria do Meio Ambiente, SP (Kronka et al., 1998);

(b) O mapa de uso e cobertura do solo, produzido por Valente \& Vettorazzi (2003), que contém uma distribuição dos fragmentos de cerrado na bacia;

(c) O mapa com principais pontos de ocorrência dessa vegetação na bacia (IPEF, 2001).

\section{(7) Verificação da exatidão do mapa final de uso e cobertura do solo}

A verificação da exatidão do mapa final de uso e cobertura do solo foi feita por amostragem, tendo como referência as informações de campo e o mosaico (cenas LANDSAT-7). Foi empregada uma amostragem estratificada ao acaso, sendo o número de amostras determinado, de acordo com Eastman. (1995) (form.4 e 5):

$$
\begin{aligned}
& N=\frac{Z^{2} \times p \times q}{e^{2}} ; \mathrm{e} \\
& A=\frac{N}{a}
\end{aligned}
$$

onde:

$Z$ : valor padrão para um nível de confiança especifico (no caso 85\%);

$\mathrm{N}$ : número de amostras;

p : percentual de exatidão esperado; 
$\mathrm{q}: 100-\mathrm{p}$

A : número de amostras para a área de estudo; e $a$ : área de estudo (proporção).

Foram considerados os valores de $85 \%$ para o percentual de exatidão esperado e 5\% para o erro admissível (Anderson, 1979), sendo obtidos 564 pontos (N) para a imagem completa e, para a área que compreende os limites da bacia, 142 pontos (A). A geração e a distribuição desses pontos, de forma estratificada ao acaso (stratified random), foi realizada no próprio SIG e pode ser observada na Figura 5.

O número de pontos que, para a verificação da exatidão, tiveram como referência o mosaico, foi de 20 . No campo foram visitados 122 pontos, dos quais foram registradas as coordenadas geográficas, por meio de um receptor GPS de navegação e alguns deles fotografados. As verificações foram realizadas por terra e por meio de um sobrevôo. O percurso desse sobrevôo também pode ser observado na Figura 5.

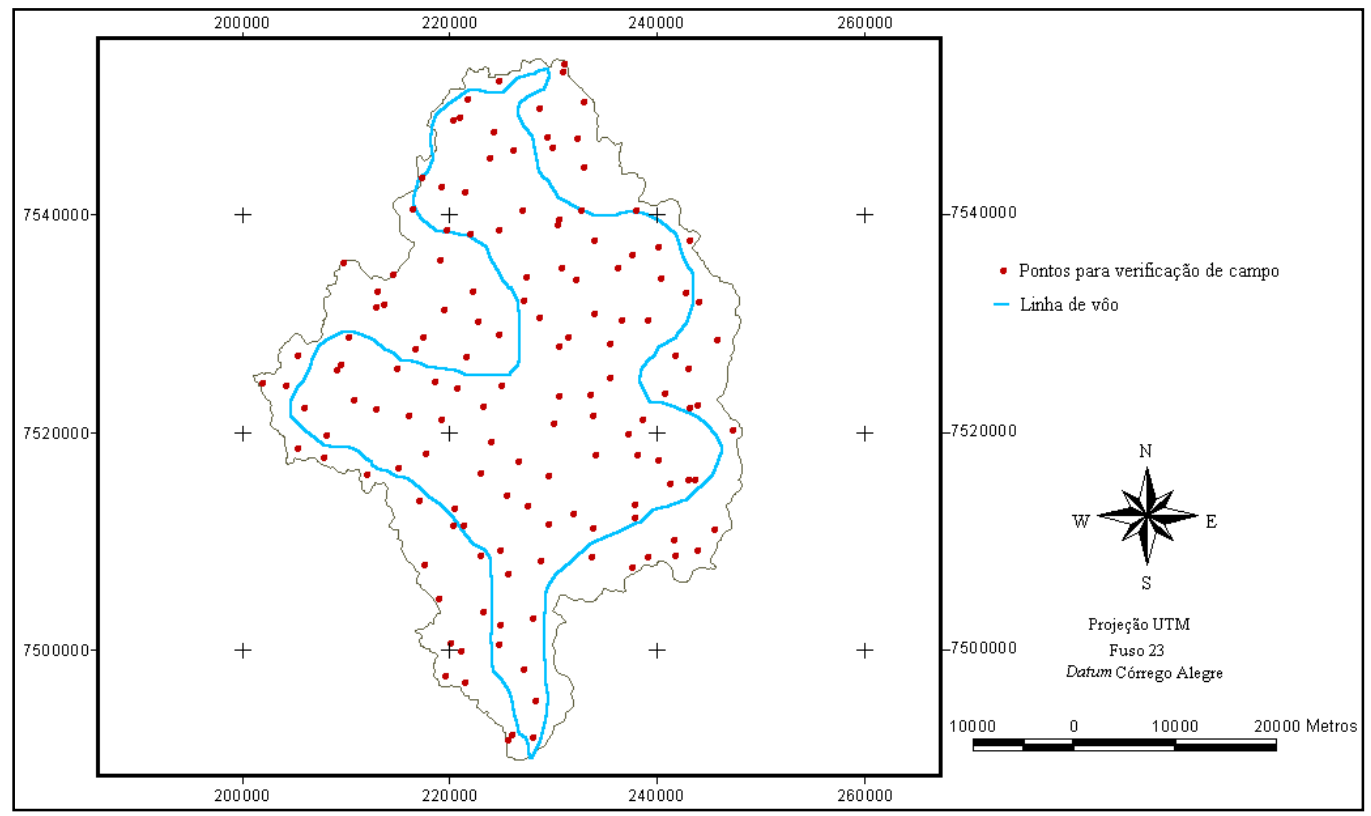

Figura 5 - Distribuição de pontos para verificação da exatidão de classificação e trajeto de sobrevôo

Após as verificações de campo foi gerada uma imagem, onde os 152 pontos constituíam os usos e coberturas de referência (verdade terrestre) e uma imagem onde 
esses pontos representavam o uso e cobertura do solo do mapa temático (produto da classificação). A partir dessas imagens foi possível, ainda no SIG, elaborar uma matriz de confusão, determinar a exatidão de classificação e calcular o índice Kappa (K) para o mapa de uso e cobertura do solo.

O índice Kappa consiste em uma análise multivariada discreta, tendo por base uma matriz de erros, também chamada de matriz de confusão ou de contingência (Ponzoni \& Almeida, 1996). De acordo com Congalton et al. (1983), esse índice é calculado pela form. (6):

$$
\mathrm{K}=\frac{\grave{\mathrm{e}}_{1}-\grave{\mathrm{e}}_{2}}{1-\grave{\mathrm{e}}_{2}}
$$

onde:

$$
\begin{aligned}
& \grave{e}_{1}=\frac{\sum_{i-1}^{r} x_{i j}}{N} ; \\
& \grave{e}_{2}=\frac{\sum_{i=1}^{r}\left(x_{i+} \times x_{+j}\right)}{N^{2}} ;
\end{aligned}
$$

$x_{i j}$ : número de observações na linha $\mathrm{i}$ e coluna $\mathrm{j}$ que se refere à diagonal principal;

$x_{i+} \mathrm{e} x_{+j}$ : os totais marginais da linha i e da coluna $\mathrm{j}$, respectivamente; e

$\mathrm{N}$ : número total de observações da matriz de erros.

A interpretação desse índice foi baseada em Landis \& Koch (1977) que, objetivando a análise de imagens orbitais, definiram intervalos do índice Kappa (K) e relacionaram com a qualidade obtida (Tabela 7).

O mapa final de uso e cobertura do solo foi transformado para a resolução espacial de $20 \mathrm{~m}$, tornando-o compatível com os planos de informação provenientes do banco de dados do "Projeto Corumbatá'" (IPEF 2001) que, por sua vez, tiveram por base o pixel de $20 \mathrm{~m}$ do satélite SPOT. 
Tabela 7. Classes de qualidade do índice Kappa

\begin{aligned} & \hline Kappa Qualidade \\ & \hline$<0,0$ Péssima \\ & $0,0-0,2$ Ruim \\ & $0,2-0,4$ Razoável \\ & $0,4-0,6$ Boa \\ & $0,6-0,8$ Muito boa \\ & $0,8-1,0$ Excelente \\ & \hline\end{aligned}

Fonte: Landis \& Koch (1977).

\subsubsection{Fragmentos de floresta}

Para a geração desse plano de informação foram extraídos do mapa de uso e cobertura do solo os fragmentos de floresta nativa e de cerrado. Esses fragmentos foram individualizados, isto é, passaram a receber identificadores únicos.

\subsubsection{3 Área nuclear dos fragmentos de floresta}

A área nuclear é definida como a área de um fragmento sem considerar a faixa de sua borda, que é a região do fragmento sob maior influência das ações antrópicas. Nesse trabalho, foi considerada como borda uma faixa com largura de $20 \mathrm{~m}$ (1 pixel), julgada adequada às características gerais dos fragmentos da bacia.

O plano de informação área nuclear dos fragmentos de floresta foi produzido a partir do plano fragmentos de floresta, no próprio SIG, por meio do módulo de operador de distâncias.

Primeiramente foram eliminados os fragmentos com área menor que 1 ha, considerando a afirmação de Valente (2001) que os fragmentos de floresta nativa da Bacia do Rio Corumbataí com área total menor que 1 ha não apresentaram área nuclear (considerando borda de $20 \mathrm{~m}$ ). 
Para o restante dos fragmentos, com a eliminação da faixa com largura de $20 \mathrm{~m}$ a partir de suas respectivas bordas, obteve-se a área nuclear desses fragmentos.

Os fragmentos de floresta nativa e de cerrado que estavam unidos (total de 112 fragmentos), para esse plano foram considerados como um único fragmento para, assim, não produzir uma faixa de borda entre eles que no campo não se observa.

A área nuclear dos fragmentos foi calculada no software FRAGSTATS 3.3, com o índice CORE (em escala de fragmentos).

\subsubsection{Centros urbanos}

Os centros urbanos foram extraídos do mapa de uso e cobertura do solo.

\subsubsection{Declividade}

O plano de informação declividade (em porcentagem) foi produzido a partir do Modelo Digital do Terreno da bacia (Projeto PiraCena, 2000).

\subsubsection{Mapas de fatores}

A definição dos fatores e, posteriormente, a de seus pesos de compensação (item 3.2.4.1), foi feita com base em revisão de literatura, projetos desenvolvidos e na Técnica Participatória.

Para a aplicação dessa técnica optou-se por, ao invés de uma reunião com todos os especialistas, enviar uma mensagem eletrônica convidando pesquisadores a contribuir com o projeto, sugerindo fatores (características/atributos da paisagem) que seriam importantes aos objetivos do trabalho, assim como explicando o motivo dessa escolha. Nessa mensagem foram enviados: (i) o resumo do projeto inicial, sem os fatores previamente escolhidos; e (ii) uma tabela a ser preenchida com os fatores considerados e pesos (escala de 1 a 10) que deveriam ser atribuídos, a cada um desses fatores.

Foram selecionados dez nomes de pesquisadores que representassem diferentes áreas de interesse (Ecologia da Paisagem, Conservação da Natureza, Hidrologia 
Florestal e Geoprocessamento). Fez-se um primeiro contato (telefônico) e, em seguida, enviou-se a mensagem eletrônica. Desses dez pesquisadores, cinco enviaram suas sugestões.

Ao final do processo (revisão de literatura, avaliação de projetos desenvolvidos e Técnica Participatória) foram, à principio, eleitos os fatores apresentados a seguir.

\subsubsection{Proximidade entre fragmentos de maior área nuclear}

A área nuclear é afetada diretamente pela forma e borda do fragmento e, segundo Temple (1986), é um melhor indicativo da qualidade dos fragmentos do que sua área total. Para Turner \& Gardner (1990), um fragmento pode ser grande o suficiente para ter algumas espécies, mas não conter área nuclear suficiente para suportar essas espécies e, sobretudo, manter a integridade de sua estrutura natural.

Os fragmentos de floresta com maior área nuclear são, dessa forma, os componentes básicos da estrutura de uma paisagem que visa manter a integridade de sua cobertura florestal natural (Geneletti, 2004). Quando esses fragmentos estão conectados existe, portanto, um ganho para a biodiversidade regional, porque aumenta a capacidade desses fragmentos de abrigar espécies e populações, em contrapartida à tendência de extinção (espécies, populações e o próprio fragmento) dos fragmentos pequenos e isolados (Noss et al., 1997; Farina,1998).

Com esse mapa de fator, as regiões de maior importância, na bacia, foram aquelas com os fragmentos com maior área nuclear e, ainda, mais próximos uns aos outros. Para ter-se essa relação de importância, primeiramente os fragmentos foram divididos em classes, de acordo com o tamanho de sua área nuclear (Tabela 8), tendo por base o plano de informação área nuclear dos fragmentos de floresta.

Para a definição dessas classes considerou-se: (i) que os fragmentos com área nuclear entre 1 ha e 5 ha (equivalem a fragmentos com área total variando entre 2 ha e 10 ha, aproximadamente) são os de maior freqüência na bacia e que se encontram mais distribuídos por sua paisagem, mas que, para esse fator, são os de menor interesse; e (ii) 
a freqüência de fragmentos nas classes com área nuclear acima de 5 ha. Procurou-se ter classes com números semelhantes de fragmentos.

Deve-se ressaltar que cada classe de área nuclear passou a constituir um novo mapa, a partir dos quais foram gerados mapas com as distâncias entre as áreas nucleares dos fragmentos de floresta. Cada mapa foi associado ao limite da bacia para ter-se essas distâncias somente dentro da área da bacia.

A etapa seguinte foi a normalização (padronização para uma única escala, nesse caso, variando de 0 a 255 bytes, desses mapas de distâncias, necessária para a posterior combinação (item 3.2.4.3) de todos os mapas de fatores.

Para que os fragmentos com maior área nuclear tivessem sua proximidade priorizada em relação aos menores, foram estabelecidas faixas de variação, entre 0 a 255 bytes, para a normalização de cada um dos mapas de distância. Pode-se dizer que houve um fatiamento dos valores dessa escala, que varia de 0 a 255 bytes, e que foram associados os maiores valores aos mapas de distâncias, que continham as classes de fragmentos de maior área nuclear, conforme indica a Tabela 8.

Tabela 8. Classes de área nuclear dos fragmentos de floresta e intervalos de normalização dos valores de distância

\begin{tabular}{cc}
\hline $\begin{array}{c}\text { Área nuclear } \\
\text { dos fragmentos (ha) }\end{array}$ & $\begin{array}{c}\text { Escala } \\
(0-255 \text { bytes })\end{array}$ \\
\hline $1-5$ & $0-41$ \\
$5-30$ & $42-83$ \\
$30-55$ & $84-125$ \\
$55-80$ & $126-169$ \\
$80-105$ & $170-211$ \\
$>105$ & $212-255$ \\
\hline
\end{tabular}

Para a normalização dos valores de distâncias, para suas respectivas faixas de variação (Tabela 8), foi empregada uma função linear decrescente. Essa função tem a propriedade de inverter a escala de importância do mapa original. Dessa forma foram 
obtidos os maiores valores (ex.:255), ou seja maior prioridade, próximos à área nuclear dos fragmentos de floresta.

Para compor o mapa de fator, todos esses mapas foram novamente unidos. Com essa união foram obtidos valores acima de 255 bytes, tornando necessária uma nova normalização de valores para gerar o mapa final do fator proximidade entre fragmentos de maior área nuclear (Figura 6). Dessa vez foi utilizada uma função linear crescente, que tem a propriedade de manter a escala de importância do mapa original.

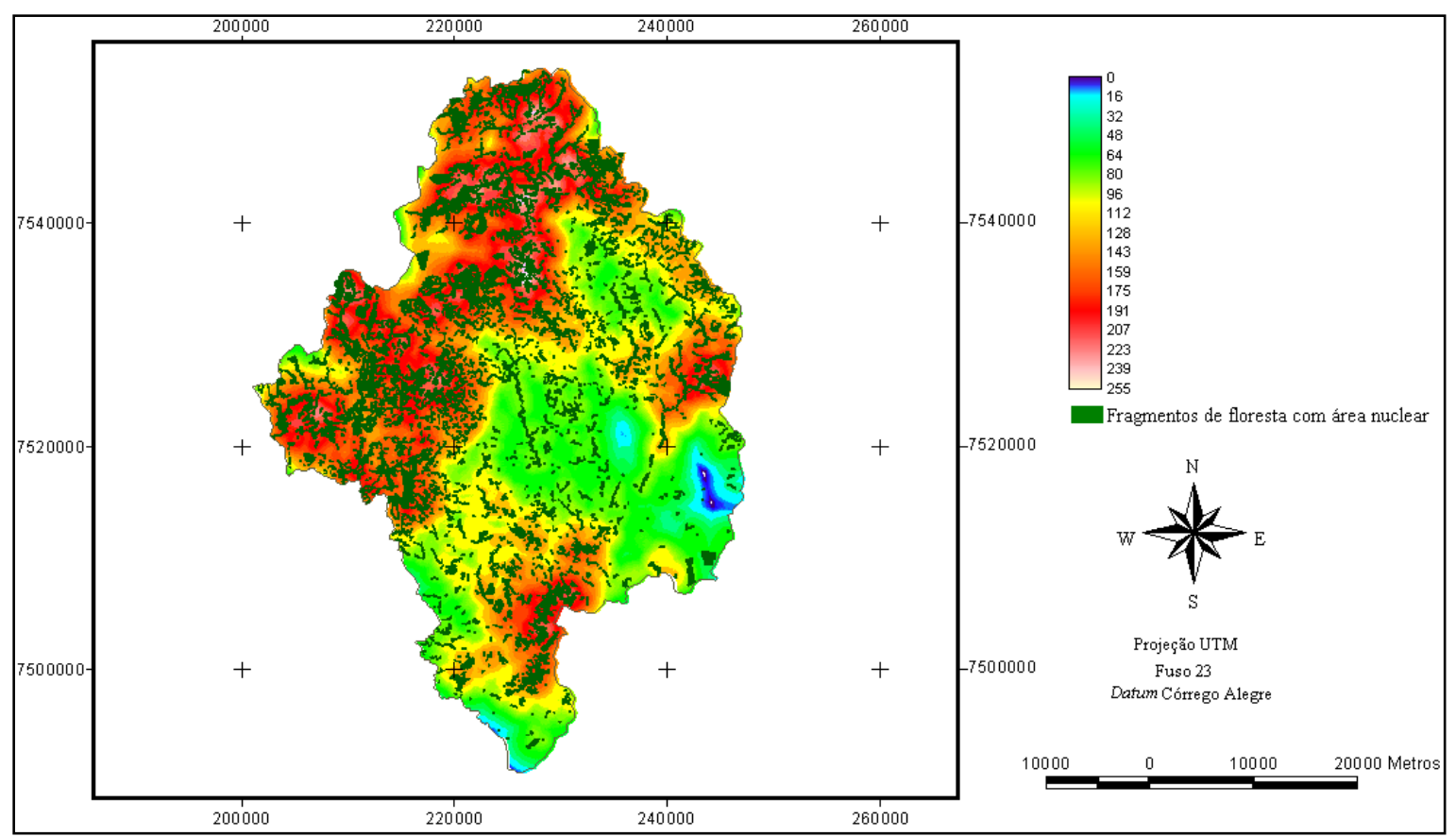

Figura 6 -Proximidade entre fragmentos de maior área nuclear

\subsubsection{Proximidade à cobertura florestal}

A distância entre os fragmentos de uma paisagem contribui para a caracterização de sua configuração e fornece um indicativo sobre seu nível de fragmentação florestal (Turner \& Gardner, 1990; Yong \& Merrian, 1994).

A fragmentação de habitats é considerada uma das mais sérias ameaças à biodiversidade, sendo a principal causa da extinção de espécies, pois gera efeitos físicos e biológicos variados, modificando padrões de predação, dispersão e migração, redução 
de populações e alterações nos fluxos de entrada e saída de energia dos ecossistemas (Tabarelli \& Mantovani, 1997; Kageyama et al., 1998). Nessas condições são formadas verdadeiras "ilhas" de florestas continentais das mais variadas dimensões (Lima, 1993).

Para a conservação e preservação florestal é necessário que essas "ilhas" sejam novamente conectadas, o que será facilitado se houver fragmentos próximos uns aos outros (Kindvall \& Petersson, 2000). Atendida essa condição, o estabelecimento ou incremento da estrutura interna do "novo fragmento" será alcançada em menor tempo e esses remanescentes de floresta passarão a contribuir para o restabelecimento da integridade natural da paisagem (Roy \& Tomar, 2000).

Com esse mapa foram priorizadas as uniões entre os fragmentos de floresta, independentemente de seus tamanhos. A partir do plano de informação fragmentos de floresta gerou-se uma mapa com as distâncias entre os fragmentos. Esse mapa foi associado ao limite da bacia e, em seguida, foi normalizado (escala 0 a 255 bytes) com uma função linear decrescente. Dessa forma ficou garantido que quanto mais próximo à cobertura florestal maior a importância (prioridade) da distância. O mapa do fator proximidade à cobertura florestal, normalizado, pode ser observado na Figura 7.

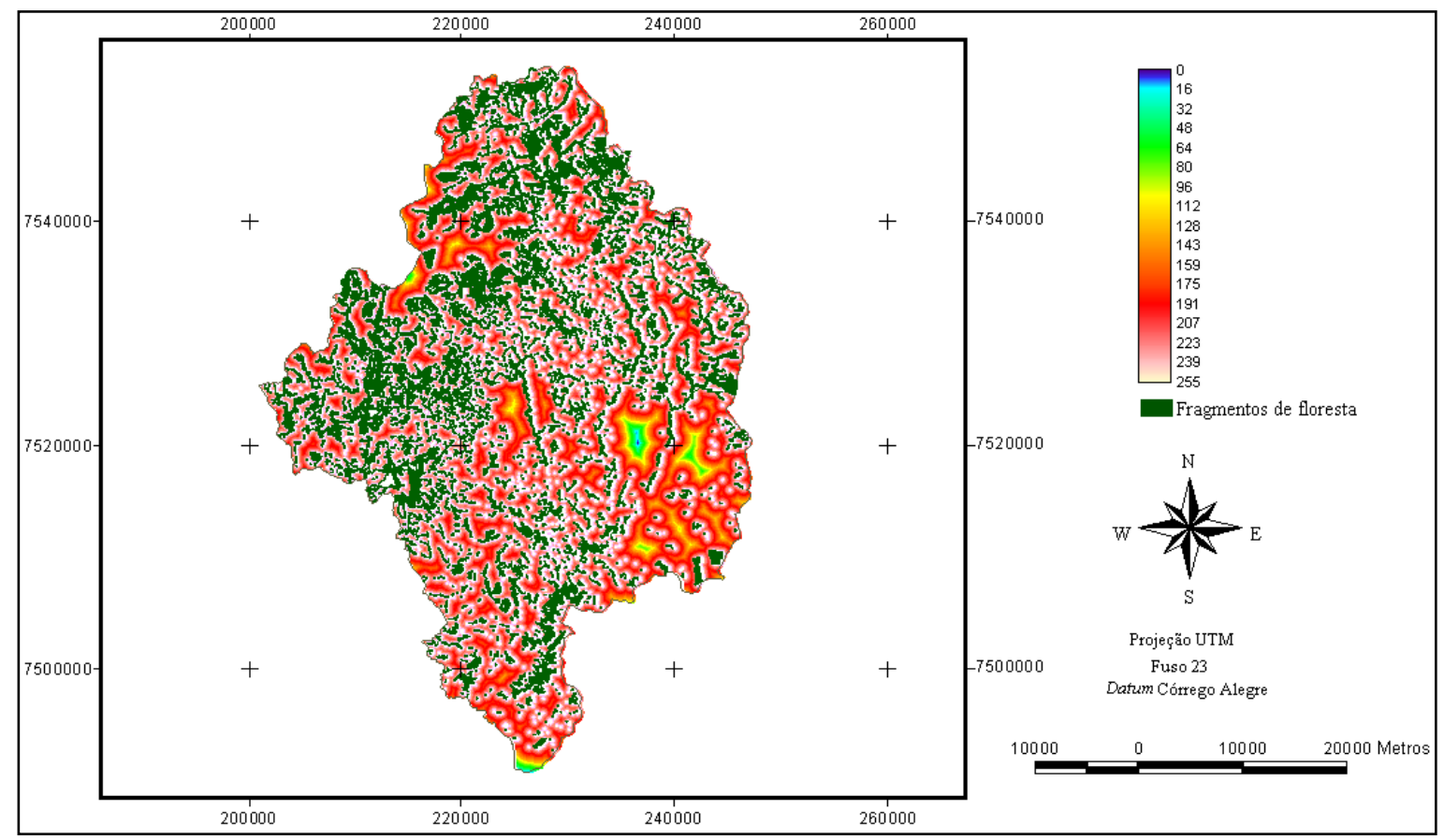

Figura 7 - Proximidade à cobertura florestal 


\subsubsection{Proximidade à rede hidrográfica}

A importância da existência de florestas ao longo dos rios e ao redor de lagos e reservatórios fundamenta-se no amplo espectro de benefícios que este tipo de vegetação traz ao ecossistema, exercendo função protetora sobre os recursos naturais bióticos e/ou abióticos (Durigan \& Silveira, 1999).

As espécies animais, de maneira geral, utilizam-se e necessitam dos corpos d'água. Dessa maneira, as áreas de floresta próximas a esses corpos d'água passam a ter uma grande importância ecológica na dinâmica da paisagem, pois possibilitam o movimento dessas espécies animais, ao longo da paisagem, e contribuem para a dispersão vegetal que, por sua vez, irá auxiliar no incremento da qualidade da estrutura dessa paisagem (conexão florestal) (Harper et al., 1992; Forman \& Collinge, 1997).

A conexão florestal promovida pela união entre fragmentos que margeiam os corpos d'água pode ser incorporada em paisagens com matriz predominantemente agrícola. Elas podem coexistir, mesmo sem grandes alterações na estrutura dessas paisagens (Forman \& Collinge, 1997; Forman, 1997)

Para esse mapa de fator produziu-se o mapa de distância aos corpos d'água, a partir do plano de informação rede hidrográfica. Esse, associado aos limites da bacia, possibilitou ter as distância somente dentro dos limites da Bacia do Rio Corumbataí. O mapa final (Figura 8) foi normalizado (escala 0 - 255 bytes) com uma função linear decrescente. Desse modo obtiveram-se valores iguais e/ou próximos a 255 quanto mais próximo da rede hidrográfica. 


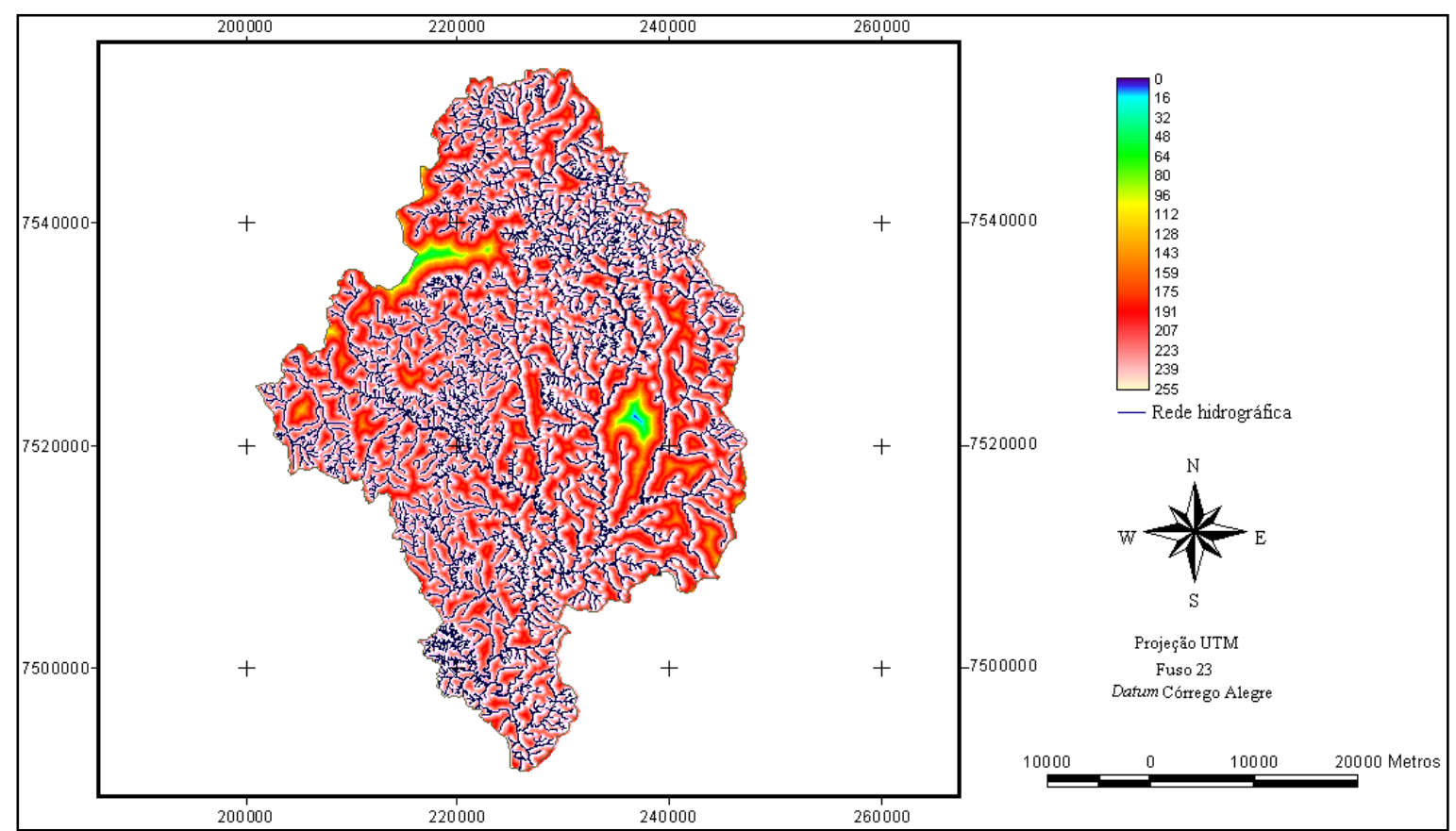

Figura 8 - Proximidade à rede hidrográfica

\subsubsection{Distância aos centros urbanos}

Numa paisagem, a matriz representa o elementos de maior conectividade, que ocupa a maior extensão e que, por esse motivo, tem maior influência no funcionamento dos outros ecossistemas (McGarigal \& Marks, 1995). No que diz respeito aos elementos que constituirão uma matriz, Forman \& Godron (1986) mencionam que dependerá da escala de investigação.

As matrizes que permitem a maior conectividade entre os fragmentos florestais são consideradas as de maior porosidade, fator que terá influência direta na conservação e preservação dos remanescentes florestais (Forman, 1997). Quando a paisagem tem predominância de culturas agrícolas, o grau de porosidade pode variar com a implantação, por exemplo, de corredores florestais, o que não ocorre quando se tem a presença de centros urbanos (Forman \& Collinge,1997).

Os fragmentos próximos aos centros urbanos sofrem com a constante ameaça de redução de sua área ou mesmo de sua extinção total, em função do uso inadequado dessas áreas (Gutzwiller \& Barrow, 2003), aumento do risco de incêndios (Chen et al., 
2001) e pela própria expansão das áreas urbanas (Saunders et al., 1991), dentre outros fatores.

Para a manutenção da biodiversidade e sucesso das ações de conservação e preservação florestal é, portanto, interessante que sejam priorizadas as áreas mais distantes dos centros urbanos.

As distâncias aos centros urbanos foram determinadas tendo por referência o plano de informação centros urbanos. Em seguida, utilizando o limite da bacia, produziu-se um mapa com as distâncias aos centros urbanos somente para a área de estudo.

Como para esse fator, quanto mais próximo a um centro urbano menor a importância (prioridade) da distância e para a sua normalização empregou-se uma função linear crescente. O mapa final desse fator é apresentado na Figura 9.

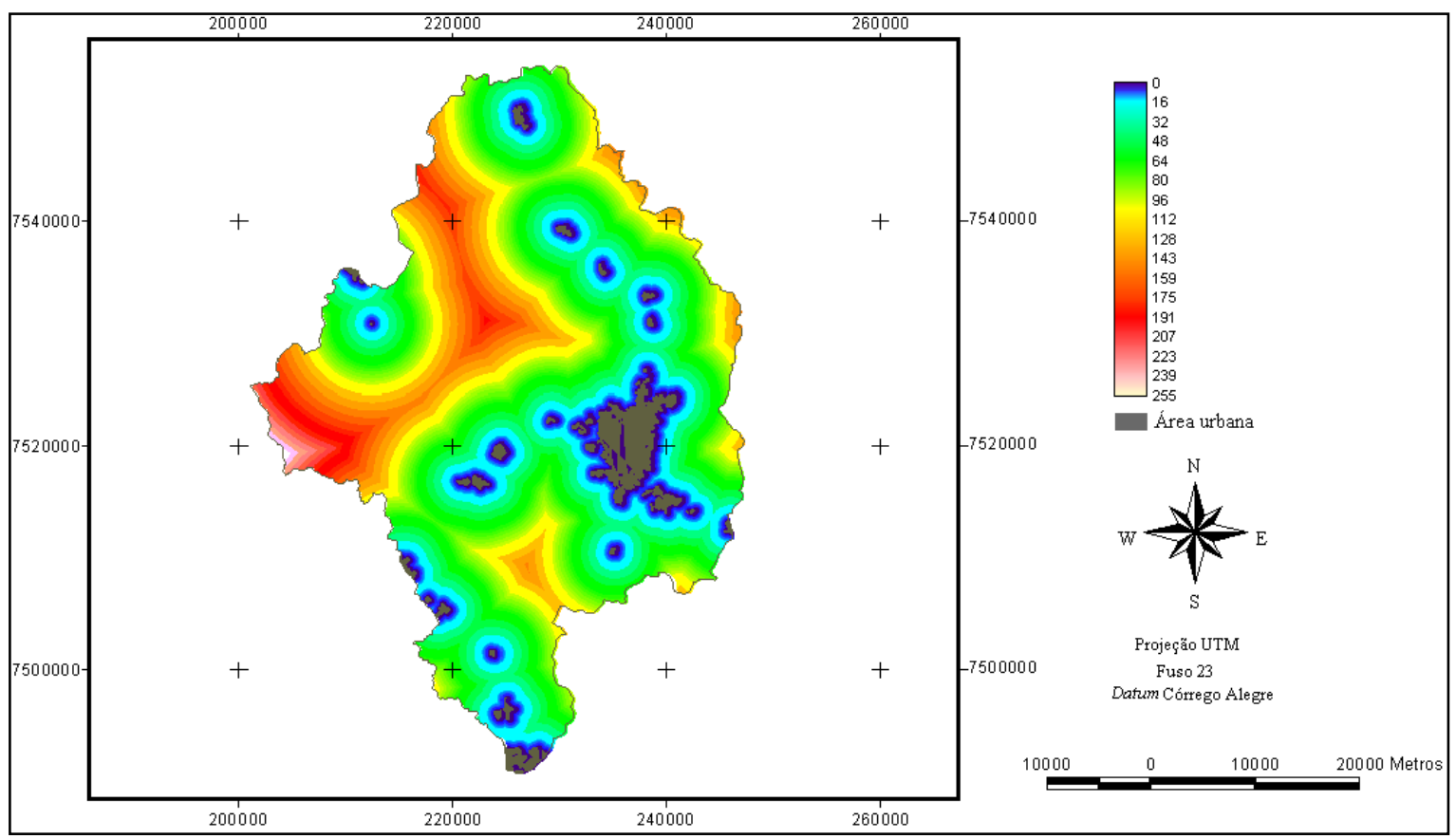

Figura 9-Distância aos centros urbanos 


\subsubsection{Distância à malha viária}

Os fragmentos florestais próximos à malha viária estão sob as mesmas influências negativas que os fragmentos próximos aos centros urbanos (uso inadequado do entorno, risco de incêndios etc), com o agravante que, conforme citado por Lima (2000), se o traçado da malha viária não considera os atributos da bacia hidrográfica, constitui-se em um foco permanente de erosão, principalmente em solos mais sensíveis.

Para algumas regiões a malha viária, em função de sua estrutura linear, afeta mais as áreas naturais que outros focos de desenvolvimento, como por exemplo as áreas urbanas, parques industriais etc. (Geneletti, 2004). Ela é a causa direta e indireta da redução de habitats. A direta refere-se à redução da área total do ecossistema, causada pela própria presença dessa infraestrutura e pela conversão da cobertura original em superfícies artificiais. A indireta refere-se a efeitos como a fragmentação (ecossistema fracionado em fragmentos pequenos e mais distantes uns dos outros) e a degradação do ecossistema (alterações biofísicas induzindo a barulho, poluição do ar e água, luz artificial etc.). Esses efeitos causam uma perda indireta do habitat e a redução da capacidade do ecossistema de sustentar sua biodiversidade original (Geneletti, 2003).

Para garantir o sucesso das ações de conservação e preservação florestal é interessante, portanto, que sejam priorizadas as regiões mais distantes da malha viária.

Com base no plano de informação malha viária gerou-se o mapa de distâncias que, por sua vez, foi associado ao limite da bacia para ter-se essas distância somente dentro área da bacia. Para a normalização desse mapa de fator (Figura 10) foi utilizada uma função linear crescente. Desse modo, quanto mais próximos às estradas, menores os valores assumidos (escala 0 a 255 bytes). 


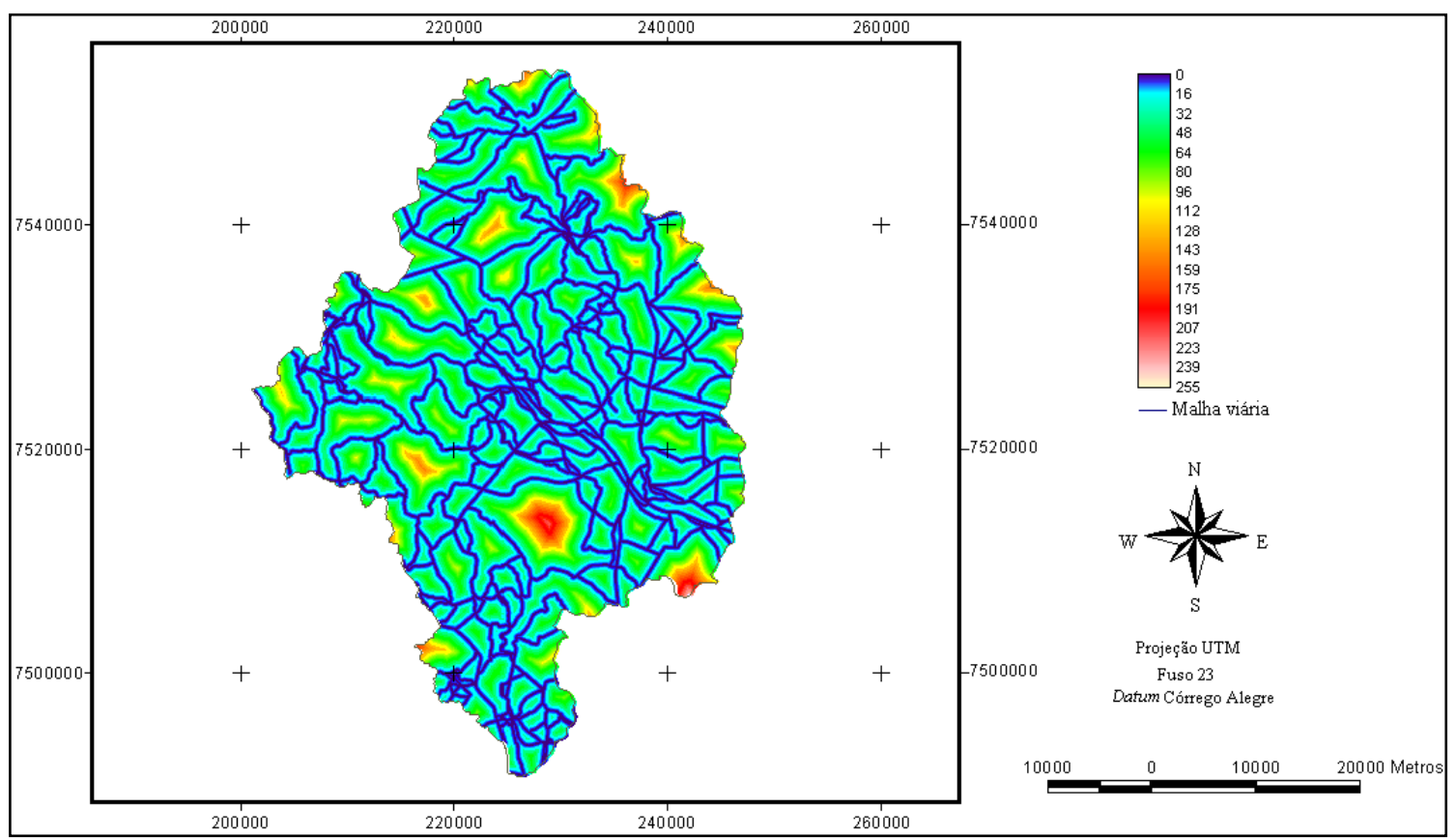

Figura 10 - Distância à malha viária

\subsubsection{Vulnerabilidade à erosão}

O mapa do fator vulnerabilidade à erosão é resultado da combinação de dois aspectos da paisagem: a erodibilidade do solo e a declividade do terreno.

A erodibilidade é uma propriedade inerente ao solo, sendo importante na previsão das perdas por erosão. Trata-se de uma propriedade complexa, que depende da combinação de fatores individuais de cada solo, especialmente aqueles que determinam a velocidade de infiltração da água no perfil e aqueles que determinam a resistência à dispersão e ao arraste de partículas durante a chuva e o escoamento superficial (Wischmeier \& Mannering, 1969).

As características de um determinado solo podem levá-lo a ser mais erodível que outros, mesmo quando se têm fatores similares (condições climáticas, intensidade de chuva, declividade, taxa de cobertura vegetal e práticas de manejo) que influenciam na taxa de erosão (Bertoni \& Lombardi, 1990).

Com este fator foi dada maior atenção aos solos mais erodíveis e em maiores declividades. Nessa condição eles estarão mais suscetíveis à erosão, podendo ser uma 
ameaça à conservação e sobretudo à preservação florestal (Rosa et al., 2000). Essa ameaça é melhor entendida considerando-se que esses solos, com cobertura inadequada ou descobertos, podem ser os causadores de deslizamentos, produzindo sedimentos que, juntamente com outros danos, podem afetar as áreas florestais que já alcançaram a estabilidade de sua estrutura interna ou a outras que estão caminhando nesse sentido. Quando recobertos por floresta, essa suscetibilidade pode ser amenizada, contribuindo para a estabilidade dessas regiões e mesmo para o sucesso das ações de conservação e preservação florestal (Khan et al., 2001).

Outro problema, associado a regiões da paisagem com solos mais sensíveis (mais suscetíveis à erosão e maiores declividades), principalmente na regiões tropicais, são os danos causados a um possível "banco de sementes" dessa área (Farina, 1998).

Forman (1997) cita que, no planejamento de ações de conservação e preservação florestal, não se pode deixar de considerar a localização da vegetação existente, o aspecto, a declividade, a direção dos ventos, o tipo de solo e, principalmente, os mais suscetíveis à erosão. Esses atributos, além de afetarem os fragmentos de floresta, podem afetar a estrutura e os processos de uma paisagem (Swanson et al., 1990).

A produção desse mapa de fator teve por base os planos de informação declividade (\%) e erodibilidade do solo (t.ha.ha/ha Mj.mm).

Para o plano de informação declividade foram adotados os intervalos de classe (Tabela 9) baseados nos propostos por Bertoni \& Lombardi (1990), para a determinação de classes de capacidade de uso. Deve-se ressaltar que cada um desses intervalos de declividade foi separado em um novo mapa. Dessa maneira continuou-se tendo uma representação contínua da declividade e, também, pode-se fazer a normalização (função linear crescente) de maneira a ter maior prioridade para os maiores valores de declividade. Os intervalos de escala (entre 0 e 255 bytes) utilizados para normalização de cada uma das classes de declividade também são apresentados na Tabela 9. Após a normalização, as classes de declividade foram novamente reunidas em um único mapa $(0-255$ bytes $)$. 
Tabela 9. Intervalos de normalização: classes de declividade

\begin{tabular}{cc}
\hline $\begin{array}{c}\text { Classes de declividade } \\
(\%)\end{array}$ & $\begin{array}{c}\text { Escala } \\
(0-255 \text { bytes })\end{array}$ \\
\hline $0-2,5$ & $0-41$ \\
$2,5-10$ & $42-83$ \\
$10-25$ & $84-125$ \\
$25-50$ & $126-169$ \\
$50-100$ & $170-211$ \\
$>100$ & $212-255$ \\
\hline
\end{tabular}

Para o mapa de erodibilidade foram adaptados os intervalos de classes (Tabela 10) propostos por Foster (1981) e Levy (1995), que classificaram os valores de erodibilidade em muito baixo, baixo, médio e alto. Assim como se procedeu com a declividade, os intervalos de erodibilidade foram separados em diferentes mapas. Em seguida, esses mapas foram normalizados (entre 0 a 255 bytes) para os intervalos apresentados na Tabela 10, com uma função linear crescente. Obteve-se, dessa maneira, a relação de prioridade desejada (maior a erodibilidade, maior a importância) com uma representação contínua do fator erodibilidade do solo. Os mapas (classes de erodibilidade) normalizados foram reunidos em um único mapa ( 0 - 255 bytes).

Tabela 10. Intervalos de normalização: classes de erodibilidade

\begin{tabular}{cc}
\hline $\begin{array}{c}\text { Classes de erodibilidade } \\
\text { (t.ha.ha/ha Mj.mm) }\end{array}$ & $\begin{array}{c}\text { Escala } \\
(0-255 \text { bytes })\end{array}$ \\
\hline $0,0125-0,0247$ & $0-64$ \\
$0,0247-0,0318$ & $65-128$ \\
$0,0318-0,0424$ & $129-191$ \\
$0,0424-0,053$ & $192-255$
\end{tabular}

Para o mapa de fator vulnerabilidade foram combinados os mapas, já normalizados, de declividade e erodibilidade do solo. Com essa combinação foram 
gerados valores maiores que 255 bytes. Com uma nova normalização (função linear crescente) obteve-se o mapa final de vulnerabilidade à erosão (Figura 11) variando entre 0 e 255 bytes.

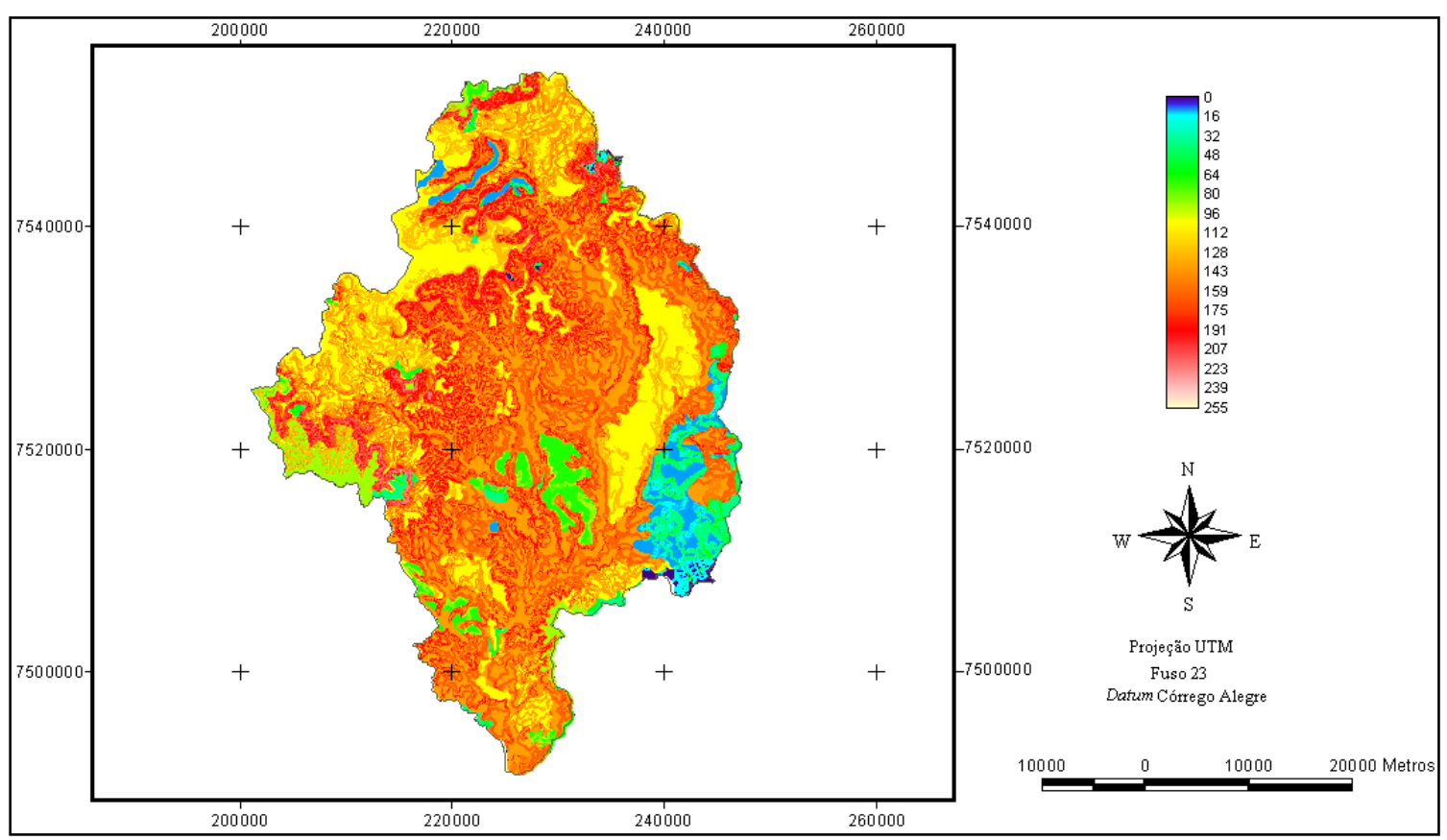

Figura 11 - Vulnerabilidade à erosão

\subsubsection{Mapa de restrições}

Como restrições foram considerados os limites da bacia, as áreas urbanas e as áreas de mineração. Isto significa que o mapa final de áreas prioritárias considerou apenas o território dentro dos limites da bacia, exceto as áreas ocupadas por área urbanas e de mineração. Desse modo, para a elaboração do mapa de restrições associou-se o plano de informação limite da bacia com o plano contendo as feições área urbana e mineração, extraídas do mapa de uso e cobertura do solo. 


\subsubsection{Abordagem multicriterial}

$\mathrm{Na}$ combinação dos mapas de fatores foi empregado o Método da Média Ponderada Ordenada. Esse método foi escolhido pela flexibilidade que possui de assumir soluções em qualquer ponto, entre os extremos AND e OR, no espaço de estratégia de decisão (Figura 12).

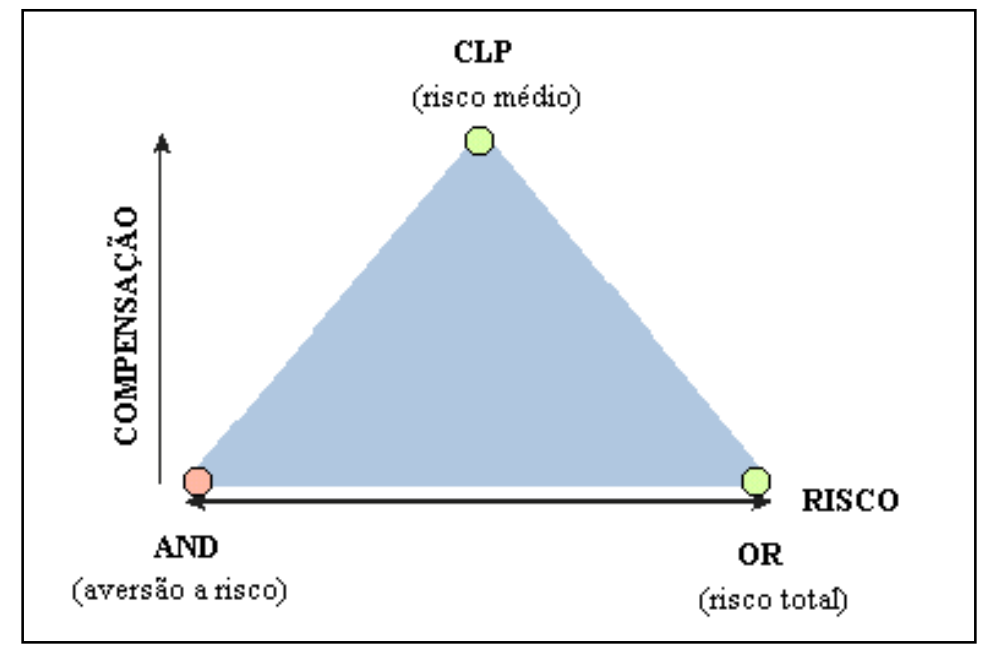

Figura 12 - Espaço de estratégia para a tomada de decisão.

Fonte: adaptada de Eastman (2001)

Para a aplicação desse método, no próprio SIG empregado nesse trabalho, foram necessárias as etapas descritas a seguir.

\subsubsection{Definição dos pesos de compensação}

Os pesos de compensação, que expressam a importância, ou ordem de importância, dos fatores no processo de tomada de decisão, foram determinados com base na revisão de literatura, em projetos desenvolvidos, na Técnica Participatória (item 3.2.2) e utilizando o Método da Comparação Pareada, proposto por Saaty (1977) no contexto do Processo Hierárquico Analítico. Esse método baseia-se na elaboração de uma matriz de comparação entre os fatores, de acordo com a importância relativa entre pares de fatores (Eastman, 2001). 
Para a elaboração da matriz de comparação os fatores foram comparados, dois a dois, utilizando como referência a escala contínua de nove pontos (Figura 13) e classificados segundo a importância relativa entre eles.

\begin{tabular}{|c|c|c|c|c|c|c|c|c|}
\hline $1 / 9$ & $1 / 7$ & $1 / 5$ & $1 / 3$ & $\overline{11}$ & $\overline{3}$ & $\overline{5}$ & $\overline{77}$ & $\bar{~} 9$ \\
\hline \multirow[t]{2}{*}{$\begin{array}{c}\text { Extrema- } \\
\text { mente }\end{array}$} & Muito & $\begin{array}{l}\text { Forte- } \\
\text { mente }\end{array}$ & $\begin{array}{l}\text { Modera- } \\
\text { damente }\end{array}$ & Igualmente & $\begin{array}{l}\text { Modera- } \\
\text { damente }\end{array}$ & $\begin{array}{l}\text { Forte- } \\
\text { mente }\end{array}$ & Muito & $\begin{array}{c}\text { Extrema- } \\
\text { mente }\end{array}$ \\
\hline & \multicolumn{3}{|c|}{ Menos importante } & \multicolumn{5}{|c|}{ Mais importante } \\
\hline
\end{tabular}

Figura 13 - Escala contínua para elaboração da matriz de comparação pareada.

Fonte: Eastman (2001)

Foram propostas várias matrizes de comparação pareada (Anexo A) sendo escolhida a apresentada na Tabela 11.

Tabela 11. Matriz de comparação pareada entre os mapas de fatores

\begin{tabular}{|c|c|c|c|c|c|c|c|}
\hline Fatores & Vulner. & Dist. urb. & Dist. malha & Prox. rede & Prox. frag. & Prox. área & $\begin{array}{c}\text { Pesos de } \\
\text { compensação }\end{array}$ \\
\hline Vulner. & 1 & & & & & & 0,0725 \\
\hline Dist. urb. & 2 & 1 & & & & & 0,1171 \\
\hline Dist. malha & 2 & 1 & 1 & & & & 0,1171 \\
\hline Prox. rede & 2 & 2 & 2 & 1 & & & 0,1736 \\
\hline Prox. frag. & 2 & 2 & 2 & 1 & 1 & & 0,1736 \\
\hline Prox. área & 4 & 2 & 2 & 3 & 3 & 1 & 0,3462 \\
\hline Taxa de C & $\hat{e n c i}$ & C) $=0$ & & & & Total & 1,0000 \\
\hline
\end{tabular}

\section{Onde:}

Vulner. : vulnerabilidade à erosão;

Dist. urb. : distância aos centros urbanos;

Dist. malha : distância à malha viária;

Prox. rede : proximidade à rede hidrográfica;

Prox. frag. : proximidade à cobertura florestal;

Prox. área : proximidade entre os fragmentos de maior área nuclear. 


\subsubsection{Definição dos pesos de ordenação}

Os pesos de ordenação, que controlam a maneira pelo qual os fatores são agregados e o nível de compensação entre eles, foram determinados dentro do espaço de estratégia de decisão (Figura 12).

Deve-se ressaltar que em uma primeira etapa foi atribuído mesmo peso de ordenação para todos os mapas de fatores, com o intuito de avaliar se os pesos de compensação, além de expressarem a ordem desejada dos fatores, estavam coerentes com a realidade da paisagem estudada.

Como o grau de compensação (Figura 12) é governado pela distribuição relativa de pesos de ordenação entre os fatores ranqueados, se a soma dos pesos de ordenação for uniformemente distribuída entre os fatores, há uma forte compensação. Nesse caso, observa-se o mesmo resultado que seria obtido utilizando a Combinação Linear Ponderada (CLP). Na situação contrária, com todo o peso assinalado a um único fator, não há compensação (semelhante aos operadores AND e OR), conforme ilustra a Figura 12.

A maneira como os fatores serão compensados é que controla, portanto, o modo de como o operador (média ponderada ordenada) agrega os fatores, no continuum entre os extremos (AND e OR) (Eastman \& Jiang, 1996). Se a maior parte dos pesos de ordenação (Figura 12) for assinalada à esquerda, à direita ou ao centro, isto irá determinar a posição na dimensão de risco assumido, no processo de tomada de decisão (Malczewski, 1999).

Os parâmetros ANDness e ORness (risco assumido) e compensação caracterizam, segundo Jiang \& Eastman (2000) a natureza da média ponderada ordenada (form. 7, 8 e 9) :

$$
\begin{aligned}
& \text { ANDness }=\frac{1}{n-1} \sum[(n-i) W i] \\
& \text { ORness }=1-\text { ANDness } ; \mathrm{e}
\end{aligned}
$$




$$
\text { Compensação }=1-\sqrt{\frac{\sum(W i-1 / n)^{2}}{n-1}}
$$

Onde:

n : número total de fatores;

i : ordem do fator; e

$\mathrm{W}$ : peso de ordenação do fator.

$\mathrm{Na}$ determinação dos melhores pesos de ordenação, numa segunda etapa, foi considerado o risco $(\mathrm{R})$ assumido no processo de tomada de decisão determinado a partir da fórmula de ANDness. Procurou-se distribuir o peso de ordenação de maneira a obterse soluções com risco médio (combinação linear ponderada), risco baixo ou médio baixo e risco alto ou médio alto. Considerou-se duas vezes o intervalo de confiança de $10 \%$ a partir do risco médio (equivale a 0,5 no continuum de risco - Figura 12) para caracterizar os intervalos de risco, conforme a Tabela 12.

Tabela 12. Risco assumido para a tomada de decisão

\begin{tabular}{ll}
\hline Intervalo de Risco & Risco assumido \\
\hline $0,00-0,40$ & Alto \\
$0,40-0,50$ & Médio alto \\
$0,50-0,60$ & Médio baixo \\
$0,60-1,00$ & Baixo \\
\hline
\end{tabular}

Foram propostos alguns grupos de pesos de ordenação (Anexo B), para a matriz de comparação pareada (Tabela 11), sendo os escolhidos apresentados na Tabela 13. 
Tabela 13. Pesos de ordenação para a matriz de comparação pareada

\begin{tabular}{lccc}
\hline Fatores & \multicolumn{3}{c}{ Peso de ordenação } \\
& Risco médio & Risco baixo & Risco alto \\
\hline Vulner. & 0,1667 & 0,1200 & 0,0800 \\
Dist. urb. & 0,1667 & 0,2200 & 0,1800 \\
Dist. malha & 0,1667 & 0,2200 & 0,1800 \\
Prox. rede & 0,1667 & 0,0500 & 0,0800 \\
Prox. frag. & 0,1667 & 0,0500 & 0,0800 \\
Prox. área & 0,1667 & 0,3400 & 0,4000 \\
Total & 1,000 & 1,0000 & 1,0000 \\
\hline Risco & 0,5000 & 0,6200 & 0,4000 \\
Compensação & 1,0000 & 0,7000 & 0,7800 \\
\hline
\end{tabular}

Para auxiliar na definição dos pesos de ordenação foi necessário entender o comportamento (ordem de ranqueamento) de cada fator. Com esse intuito foram produzidos dois mapas (Figura 14), o primeiro assinalando todo peso ao fator de "menor ranqueamento" e o segundo assinalando todo peso ao fator de "maior ranqueamento", ou seja, foram aplicados, respectivamente, os operadores AND e OR. Esse mapas assemelharam-se, como observado na Figura 14, aos mapas de fatores de distância à malha viária (AND) e de proximidade à rede hidrográfica (OR). Esses são, portanto, os fatores de menor e maior ranqueamento, respectivamente. Associando todo o peso (total $=1$ ) a cada um dos mapas de fatores foi sendo obtido, sucessivamente, o ranqueamento dos fatores (entre os fatores distância à malha viária e proximidade à rede hidrográfica): distância aos centros urbanos; vulnerabilidade à erosão; proximidade entre fragmentos de maior área nuclear; e proximidade à cobertura florestal.

A importância de entender o ranqueamento dos fatores está relacionada ao quanto cada fator será compensado, isto considerando, também, sua importância no processo de tomada de decisão. 


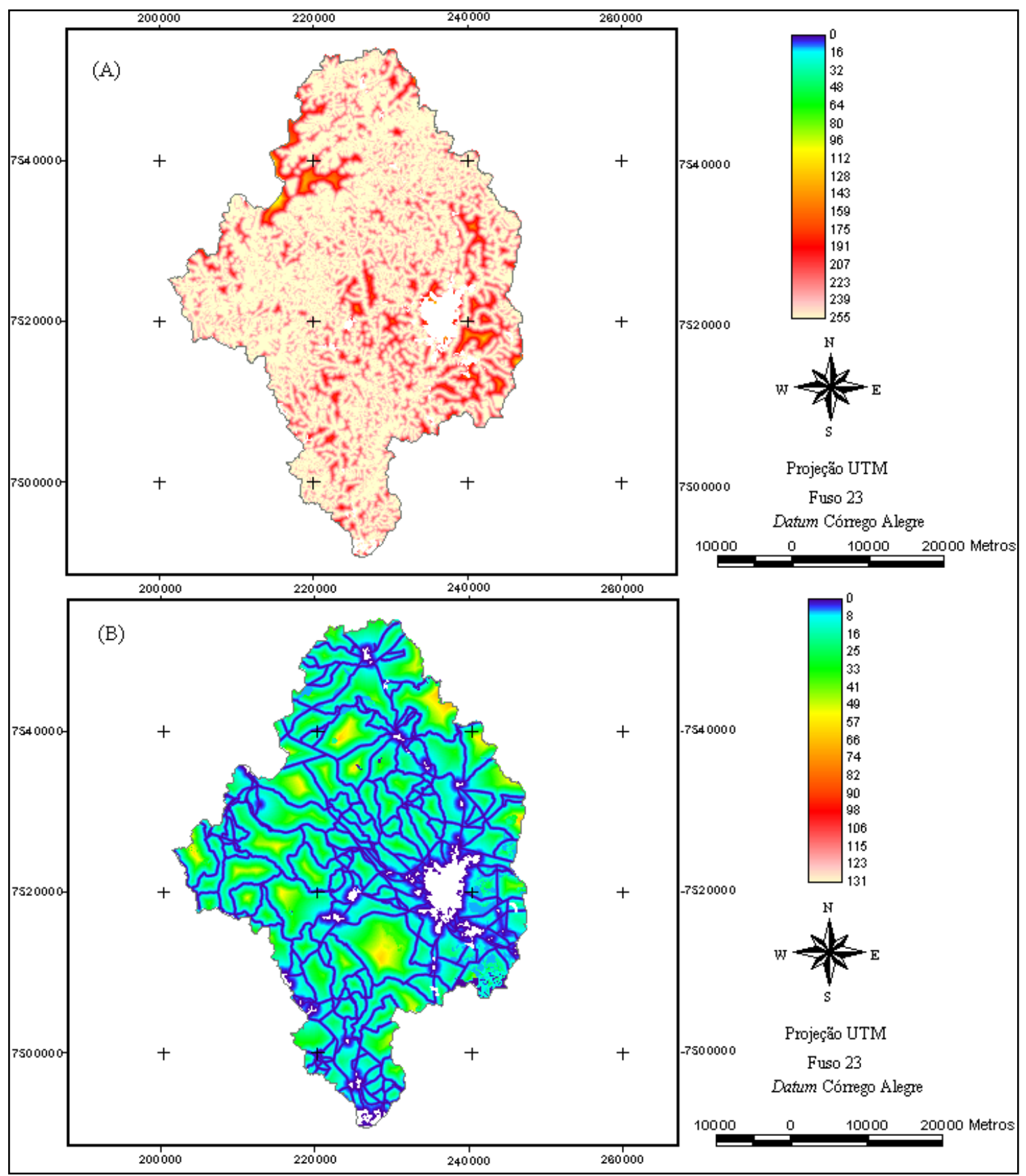

Figura 14 - Mapas de prioridades: operador OR (A) e operador AND (B)

\subsubsection{Método da Média Ponderada Ordenada}

Com os pesos de compensação e ordenação foi possível combinar os mapas de fatores utilizando o método da Média Ponderada Ordenada, cuja conceituação 
matemática foi estabelecida por Yager (1988). Foram produzidos mapas para os três grupos de pesos de ordenação (Tabela 13), tendo assim mapas de áreas prioritárias para a conservação e preservação florestal com riscos médio, alto e baixo.

\subsubsection{Avaliação dos pesos de ordenação}

Para definir qual grupo de pesos de ordenação (Tabela 13) melhor representava, na paisagem, as interações entre os fatores, foram analisados os mapas produzidos com o Método da Média Ponderada Ordenada.

Com esse intuito, produziu-se uma malha com 52 pontos, distribuídos de forma estratificada ao acaso. O número de pontos foi determinado a partir do número inicial empregado na verificação da exatidão do mapa de uso e cobertura do solo (item 3.2.1.1). Desse número inicial eles foram sendo reduzidos até eliminar-se a sobreposição de pontos na área da bacia.

A malha de pontos foi sobreposta a cada um dos mapas de fatores e aos mapas de prioridades o que, por sua vez, possibilitou avaliar a prioridade atribuída a cada ponto e a contribuição de cada fator para essa prioridade. Essa malha de pontos também foi empregada na seleção dentre os grupos de pesos de ordenação (Anexo B e Tabela 13), no entendimento do comportamento dos fatores (ordem de ranqueamento), na análise de sensibilidade e na avaliação da melhor alternativa para a definição de áreas prioritárias.

\subsubsection{Análise de sensibilidade}

A análise de sensibilidade foi feita para avaliar a importância dos fatores no processo de tomada de decisão. Ela foi realizada somente para o mapa de prioridades referente ao grupo de pesos de ordenação mais adequado a esse processo de tomada de decisão, dentre os apresentados na Tabela 13.

A matriz de comparação pareada foi sendo reorganizada à medida que se eliminava um fator. A princípio mantinham-se as mesmas relações de importância (comparação pareada) para os fatores que restavam na matriz. Esperava-se que, desse 
modo, o peso de compensação antes atribuído ao fator eliminado fosse igualmente distribuído entre os demais fatores. Quando essa distribuição resultava em peso de compensação muito alto para algum dos fatores ou em Taxa de Consistência acima do aceitável, a matriz era reorganizada.

Para a atribuição dos pesos de ordenação, o peso atribuído ao fator eliminado era, de modo similar, distribuído igualmente entre os demais fatores, independentemente do risco assumido no processo de tomada de decisão. Para alguns casos foram avaliadas opções de pesos de ordenação para analisar se, com essa alteração, seria possível eliminar o fator no processo de tomada de decisão. Em caso positivo ele não era considerado importante. Essas opções de pesos de ordenação também foram empregadas nos casos em que o novo conjunto de pesos causava alterações no mapa de prioridades, na ordem de importância dos fatores.

Nas Tabelas 14 a 19 estão as matrizes de comparação pareada, os pesos de compensação e a ordenação utilizados para a priorização de áreas sem os mapas de fatores, respectivamente: proximidade entre os fragmentos de maior área nuclear; vulnerabilidade à erosão; proximidade à cobertura florestal; proximidade à rede hidrográfica; distância a malha viária; e distância aos centros urbanos.

Mantiveram-se as mesmas relações de importância (matriz de comparação pareada) e pesos de ordenação proporcionais, dos demais fatores, com a eliminação dos mapas de proximidade entre fragmentos de maior área nuclear (Tabela 14) e vulnerabilidade à erosão (Tabela 15). Com a eliminação dos mapas de proximidades à cobertura florestal (Tabela 16) e à rede hidrográfica (Tabela 17) mantiveram-se as mesmas relações de importância (matriz de comparação), mas houve a necessidade de outros pesos de ordenação (não proporcionais aos que se tinha com a presença de todos os fatores). Na eliminação dos mapas de distâncias à malha viária (Tabela 18) e aos centros urbanos (Tabela 19) foi necessária a reorganização da matriz e dos pesos de ordenação. 
Tabela 14. Matriz de comparação pareada: sem proximidade entre fragmentos de maior área nuclear

\begin{tabular}{lccccccc}
\hline \multicolumn{1}{c}{ Fatores } & Vulner. & $\begin{array}{c}\text { Dist. } \\
\text { urb. }\end{array}$ & $\begin{array}{c}\text { Dist. } \\
\text { malha }\end{array}$ & $\begin{array}{c}\text { Prox. } \\
\text { rede }\end{array}$ & $\begin{array}{c}\text { Prox. } \\
\text { frag. }\end{array}$ & $\begin{array}{c}\text { Pesos de } \\
\text { compensação }\end{array}$ & $\begin{array}{c}\text { Pesos de } \\
\text { ordenação }\end{array}$ \\
\hline Vulner. & $\mathbf{1}$ & & & & & 0,1092 & 0,1600 \\
Dist. urb. & 2 & $\mathbf{1}$ & & & 0,1628 & 0,2600 \\
Dist. malha & 2 & 1 & $\mathbf{1}$ & & & 0,1628 & 0,2600 \\
Prox. rede & 2 & 2 & 2 & $\mathbf{1}$ & & 0,2826 & 0,1600 \\
Prox. frag. & 2 & 2 & 2 & 1 & $\mathbf{1}$ & 0,2826 & 0,1600 \\
\hline Taxa de Consistência $(T C)=0,04$ & & & Total & 1,0000 & 1,0000 \\
\hline
\end{tabular}

Risco : 0,58

Compensação: 0,88

Tabela 15. Matriz de comparação pareada entre os fatores: sem vulnerabilidade à erosão

\begin{tabular}{lccccccc}
\hline \multicolumn{1}{c}{ Fatores } & $\begin{array}{c}\text { Dist. } \\
\text { urb. }\end{array}$ & $\begin{array}{c}\text { Dist. } \\
\text { malha }\end{array}$ & $\begin{array}{c}\text { Prox. } \\
\text { rede }\end{array}$ & $\begin{array}{c}\text { Prox. } \\
\text { frag. }\end{array}$ & $\begin{array}{c}\text { Prox. } \\
\text { área }\end{array}$ & $\begin{array}{c}\text { Pesos de } \\
\text { compensação }\end{array}$ & $\begin{array}{c}\text { Pesos de } \\
\text { ordenação }\end{array}$ \\
\hline Dist. urb. & $\mathbf{1}$ & & & & & 0,1191 & 0,1945 \\
Dist. malha & 1 & $\mathbf{1}$ & & & 0,1191 & 0,1945 \\
Prox. rede & 2 & 2 & $\mathbf{1}$ & & & 0,1890 & 0,0945 \\
Prox. frag. & 2 & 2 & 1 & $\mathbf{1}$ & & 0,1890 & 0,0945 \\
Prox. área & 2 & 2 & 3 & 3 & $\mathbf{1}$ & 0,3837 & 0,4222 \\
\hline Taxa de Consistência $(T C)=0,04$ & & & Total & 1,0000 & 1,0000 \\
\hline
\end{tabular}

Risco : 0,58

Compensação: 0,70

No Anexo C estão os pesos de ordenação resultantes da eliminação dos mapas de proximidades à cobertura florestal e à rede hidrográfica e a simples distribuição de seus respectivos pesos de ordenação entre os demais fatores. Outras opções de pesos de ordenação avaliadas, também podem ser observadas no Anexo C. 
Tabela 16. Matriz de comparação pareada: sem proximidade à cobertura florestal

\begin{tabular}{lccccccc}
\hline \multicolumn{1}{c}{ Fatores } & Vulner. & $\begin{array}{c}\text { Dist. } \\
\text { urb. }\end{array}$ & $\begin{array}{c}\text { Dist. } \\
\text { malha }\end{array}$ & $\begin{array}{c}\text { Prox. } \\
\text { rede }\end{array}$ & $\begin{array}{c}\text { Prox. } \\
\text { área }\end{array}$ & $\begin{array}{c}\text { Pesos de } \\
\text { compensação }\end{array}$ & $\begin{array}{c}\text { Pesos de } \\
\text { ordenação }\end{array}$ \\
\hline Vulner. & $\mathbf{1}$ & & & & & 0,0867 & 0,0800 \\
Dist. urb. & 2 & $\mathbf{1}$ & & & 0,1520 & 0,1800 \\
Dist. malha & 2 & 1 & $\mathbf{1}$ & & & 0,1520 & 0,1800 \\
Prox. rede & 2 & 2 & 2 & $\mathbf{1}$ & & 0,2198 & 0,1600 \\
Prox. área & 4 & 2 & 2 & 3 & $\mathbf{1}$ & 0,3895 & 0,4000 \\
\hline \multicolumn{2}{l}{ Taxa de Consistência $(T C)=0,03$} & & & Total & 1,0000 & 1,0000 \\
\hline
\end{tabular}

Risco : 0,46

Compensação: 0,73

Tabela 17. Matriz de comparação pareada: sem proximidade à rede hidrográfica

\begin{tabular}{lccccccc}
\hline \multicolumn{1}{c}{ Fatores } & Vulner. & $\begin{array}{c}\text { Dist. } \\
\text { urb. }\end{array}$ & $\begin{array}{c}\text { Dist. } \\
\text { malha }\end{array}$ & $\begin{array}{c}\text { Prox. } \\
\text { frag. }\end{array}$ & $\begin{array}{c}\text { Prox. } \\
\text { área }\end{array}$ & $\begin{array}{c}\text { Pesos de } \\
\text { compensação }\end{array}$ & $\begin{array}{c}\text { Pesos de } \\
\text { ordenação }\end{array}$ \\
\hline Vulner. & $\mathbf{1}$ & & & & & 0,0867 & 0,0800 \\
Dist. urb. & 2 & $\mathbf{1}$ & & & 0,1520 & 0,1800 \\
Dist. malha & 2 & 1 & $\mathbf{1}$ & & & 0,1520 & 0,1800 \\
Prox. frag. & 2 & 2 & 2 & $\mathbf{1}$ & & 0,2198 & 0,1600 \\
Prox. área & 4 & 2 & 2 & 3 & $\mathbf{1}$ & 0,3895 & 0,4000 \\
\hline \multicolumn{2}{l}{ Taxa de Consistência $(T C)=0,03$} & & & Total & 1,0000 & 1,0000 \\
\hline
\end{tabular}

Risco : 0,46

Compensação: 0,73

As matrizes, sem alteração das relações de importância (comparação pareada), com a eliminação dos mapas de distâncias à malha viária e aos centros urbanos, seus respectivos pesos de compensação e ordenação (distribuição dos pesos dos eliminados entre os demais fatores) também podem ser observadas no Anexo C. 
Tabela 18. Matriz de comparação pareada: sem distância à malha viária

\begin{tabular}{|c|c|c|c|c|c|c|c|}
\hline Fatores & Vulner. & $\begin{array}{l}\text { Dist. } \\
\text { urb. }\end{array}$ & $\begin{array}{l}\text { Prox. } \\
\text { rede }\end{array}$ & $\begin{array}{l}\text { Prox. } \\
\text { frag. }\end{array}$ & $\begin{array}{l}\text { Prox. } \\
\text { área }\end{array}$ & $\begin{array}{c}\text { Pesos de } \\
\text { compensação }\end{array}$ & $\begin{array}{l}\text { Pesos de } \\
\text { ordenação }\end{array}$ \\
\hline Vulner. & 1 & & & & & 0,0941 & 0,1200 \\
\hline Dist. urb. & 2 & 1 & & & & 0,1498 & 0,2700 \\
\hline Prox. rede & 2 & 2 & 1 & & & 0,1986 & 0,0800 \\
\hline Prox. frag. & 2 & 2 & 1 & 1 & & 0,1986 & 0,0800 \\
\hline Prox. área & 3 & 1,5 & 2,5 & 2,5 & 1 & 0,3589 & 0,4500 \\
\hline \multicolumn{5}{|l|}{ Taxa de C } & Total & 1,0000 & 1,0000 \\
\hline
\end{tabular}

Risco : 0,61

Compensação: 0,64

Tabela 19. Matriz de comparação pareada: sem distância aos centro urbanos

\begin{tabular}{|c|c|c|c|c|c|c|c|}
\hline Fatores & Vulner. & $\begin{array}{l}\text { Dist. } \\
\text { malha. }\end{array}$ & $\begin{array}{l}\text { Prox. } \\
\text { rede }\end{array}$ & $\begin{array}{l}\text { Prox. } \\
\text { frag. }\end{array}$ & $\begin{array}{c}\text { Prox. } \\
\text { área }\end{array}$ & $\begin{array}{c}\text { Pesos de } \\
\text { compensação }\end{array}$ & $\begin{array}{l}\text { Pesos de } \\
\text { ordenação }\end{array}$ \\
\hline Vulner. & 1 & & & & & 0,0941 & 0,1160 \\
\hline Dist. malha & 2 & 1 & & & & 0,1498 & 0,2160 \\
\hline Prox. rede & 2 & 2 & 1 & & & 0,1986 & 0,1160 \\
\hline Prox. frag. & 2 & 2 & 1 & 1 & & 0,1986 & 0,1160 \\
\hline Prox. área & 3 & 1,5 & 2,5 & 2,5 & 1 & 0,3589 & 0,4360 \\
\hline Tax & &, 04 & & & Total & 1,0000 & 1,0000 \\
\hline
\end{tabular}

Risco : 0,55

Compensação: 0,69

\subsubsection{Alternativa na definição de áreas prioritárias}

Como conseqüência da análise de sensibilidade observou-se a possibilidade de uma nova alternativa (opção, solução) para a definição de áreas prioritárias, que foi com a eliminação do fator proximidade à rede hidrográfica.

Para essa alternativa também foram produzidos mapas de áreas prioritárias com pesos de ordenação que possibilitassem a tomada de decisão com riscos médio e baixo. 
Nesse caso, não foi necessário um mapa com risco alto, pois para a análise de sensibilidade já tinha sido gerado um mapa com risco médio-alto.

Utilizou-se, dessa maneira, a mesma matriz de comparação (Tabela 17) empregada na análise de sensibilidade (item 3.2.4.5). Os pesos de ordenação do mapa de risco médio-alto e dos outros dois mapas de prioridades (risco médio e baixo) podem ser observados na Tabela 20.

Tabela 20. Pesos de ordenação *: sem proximidade à rede hidrográfica

\begin{tabular}{lccc}
\hline Fatores & \multicolumn{3}{c}{ Peso de ordenação } \\
& Risco médio & Risco baixo & Risco médio-alto \\
\hline Vulner. & 0,1667 & 0,0800 & 0,0800 \\
Dist. urb. & 0,1667 & 0,2300 & 0,1800 \\
Dist. malha & 0,1667 & 0,2300 & 0,1800 \\
Prox. frag. & 0,1667 & 0,1300 & 0,1600 \\
Prox. área & 0,1667 & 0,3300 & 0,4000 \\
Total & 1,000 & 1,0000 & 1,0000 \\
\hline Risco & 0,5000 & 0,5400 & 0,4600 \\
Compensação & 1,0000 & 0,7800 & 0,7300
\end{tabular}

*matriz de comparação pareada da Tabela 17.

\subsubsection{Definição das classes de áreas prioritárias}

Foram definidas, para os todos mapas produzidos, cinco classes de prioridades: muito baixa, baixa, média, alta e muito alta. O intervalo de classe foi determinado a partir da avaliação do histograma dos mapas ( 0 - 255 bytes $)$ e definição dos limites inferior e superior de variação (todos os mapas).

O mapa final de áreas prioritárias (melhor alternativa) foi reclassificado em sete classes de prioridades para melhor avaliar a relação das áreas prioritárias para a conservação e preservação florestal da bacia com os fatores utilizados. 


\section{RESULTADOS E DISCUSSÃO}

\subsection{Uso e cobertura do solo}

O mapa de uso e cobertura do solo da Bacia do Rio Corumbataí é apresentado na Figura 15. A verificação da exatidão desse mapa pode ser observada na Tabela 21.

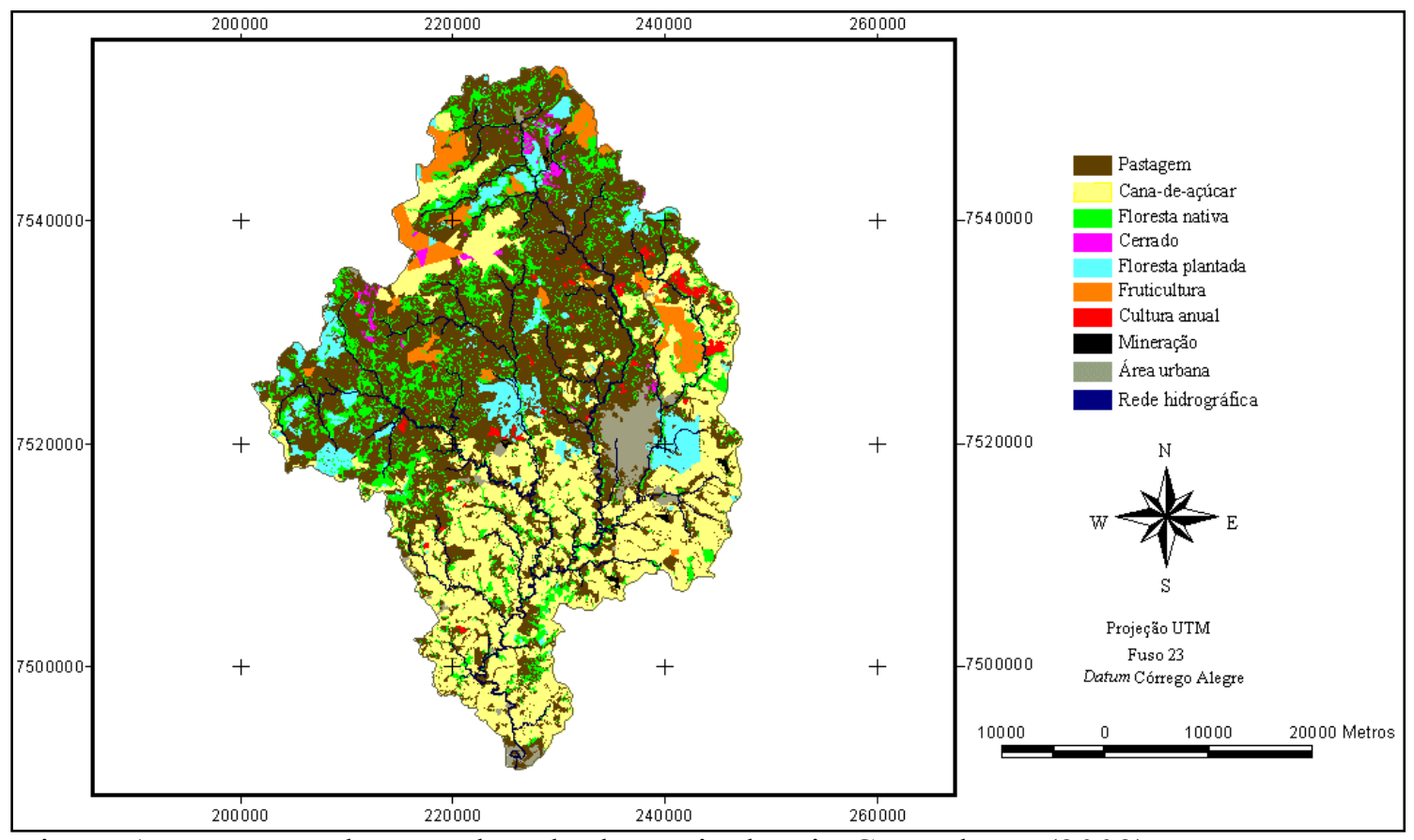

Figura 15 - Uso e cobertura do solo da Bacia do Rio Corumbataí (2003)

$\mathrm{Na}$ matriz de confusão, a diagonal indica o número de pontos onde houve coincidência entre o mapa temático e a verdade terrestre. A partir dessa matriz obteve-se uma porcentagem de acerto global de $92,96 \%$ e o valor de 0,97 para o índice Kappa (K) global. As porcentagens de acerto para as classes de uso e cobertura do solo da bacia podem ser observadas na Tabela 22. 
Tabela 21. Matriz de confusão: mapa de uso e cobertura do solo

\begin{tabular}{|c|c|c|c|c|c|c|c|c|c|}
\hline MAPA & & & & $\overline{\text { VERI }}$ & ADE TER & ESTRE & & & \\
\hline & pastagem & $\begin{array}{l}\text { cana-de- } \\
\text { açúcar }\end{array}$ & $\begin{array}{c}\text { floresta } \\
\text { nativa }\end{array}$ & cerrado & $\begin{array}{l}\text { floresta } \\
\text { plantada }\end{array}$ & fruticultura & $\begin{array}{l}\text { cultura } \\
\text { anual }\end{array}$ & $\begin{array}{c}\text { área } \\
\text { urbana }\end{array}$ & TOTAL \\
\hline pastagem & 42 & 2 & 1 & & & & & & 45 \\
\hline cana-de-açúcar & 2 & 38 & & & & 1 & 1 & & 41 \\
\hline floresta nativa & & & 27 & & 1 & & & & 28 \\
\hline cerrado & & & 1 & 9 & & & & & 10 \\
\hline floresta plantada & & & & 1 & 9 & & & & 10 \\
\hline fruticultura & & & & & & 8 & & & 9 \\
\hline cultura anual & 1 & 1 & & & & & 3 & & 4 \\
\hline área urbana & & & & & & & & 4 & 4 \\
\hline total & 45 & 41 & 28 & 10 & 10 & 9 & 4 & 4 & 152 \\
\hline
\end{tabular}

Pontos coincidentes

A exatidão para o mapa de uso e cobertura foi superior ao valor tido como mínimo aceitável (85\%), por autores como Anderson et al. (1979) e Eastman (1995), para classificações empregando imagens orbitais de média resolução espacial. A qualidade da classificação, tendo por base os intervalos do índice Kappa (K) propostos por Landis \& Koch (1977), pode ser classificada como excelente.

Tabela 22. Exatidão de classificação para as classes de uso e cobertura do solo

\begin{tabular}{lc}
\hline \multicolumn{1}{c}{ Uso e cobertura do solo } & Exatidão (\%) \\
\hline Pastagem & 93,33 \\
Cana-de-açúcar & 92,68 \\
Floresta nativa & 96,43 \\
Cerrado & 90,00 \\
Floresta plantada & 90,00 \\
Fruticultura & 88,89 \\
Cultura anual & 75,00 \\
Área urbana & 100,00 \\
\hline
\end{tabular}


Para a classe área urbana, o reduzido número de pontos utilizados para a verificação de sua exatidão foi o responsável por $100 \%$ de acerto.

Com a matriz de confusão (Tabela 21) e os valores de exatidão de classificação obtidos para as classes floresta nativa e cerrado constatou-se que o Índice de Vegetação da Diferença Normalizada (NDVI) foi eficiente na distinção essas duas categorias. Shimabukuro et al. (1999) e Ferreira et al. (2004) também constataram a capacidade do NDVI, produzido a partir de imagens de média resolução espacial, na distinção entre o cerrado e outras formações florestais.

Com o mapa de uso e cobertura do solo (Figura 15) observou-se que na bacia continua existindo uma predominância do uso agrícola do solo com, conforme a Tabela 23 , aproximadamente $42 \%$ de sua área ocupada por pastagem e $28 \%$ por cana-de-açúcar. A pastagem concentra-se predominantemente nas partes superior e média da bacia e a cana-de-açúcar nas partes média e baixa. A floresta nativa e o cerrado correspondem, respectivamente, a apenas $11 \%$ e $0,7 \%$, sendo que as maiores manchas de vegetação florestal estão associadas às regiões com predomínio de pastagem. Com os planos de informação fragmentos de floresta e área nuclear dos fragmentos de floresta constatou-se que na bacia existem 3438 fragmentos de floresta nativa (2036 fragmentos menores que 1 ha e 1402 maiores que 1 ha) e apenas 156 fragmentos de cerrado (72 fragmentos menores que 1 ha e 84 maiores que 1 ha).

A estrutura da paisagem dessa bacia (Figura 16) não sofreu, portanto, grandes alterações desde o mapeamento de 2000 (Valente \& Vettorazzi, 2003). Continua ocorrendo o predomínio das culturas agrícolas; contudo, nota-se no mapa de 2003 uma diminuição das áreas ocupadas por pastagem e, em contrapartida, um aumento das áreas ocupadas por cana-de-açúcar.

A área ocupada por floresta nativa manteve-se, nesses dois mapeamentos, praticamente inalterada, assim como ocorreu para a cultura anual e para a área urbana. Para o cerrado e para a floresta plantada houve, no mapeamento atual, uma diminuição de suas áreas, enquanto que para a fruticultura ocorreu um aumento de área. Para o cerrado essas diferenças são conseqüência, principalmente, da utilização do NDVI, que possibilitou distinguir o cerrado das demais formações florestais. 
Tabela 23. Uso e cobertura do solo para a Bacia do Rio Corumbataí (2003)

\begin{tabular}{lcr}
\hline Uso e cobertura do solo & \multicolumn{2}{c}{ Área } \\
& (ha) & $(\%)$ \\
\hline Pastagem & 72228,48 & 42,29 \\
Cana-de-açúcar & 47431,92 & 27,77 \\
Floresta nativa & 19234,84 & 11,26 \\
Cerrado & 1217,20 & 0,71 \\
Floresta plantada & 9713,84 & 5,69 \\
Fruticultura & 6848,80 & 4,01 \\
Cultura anual & 1575,48 & 0,92 \\
Mineração & 323,92 & 0,19 \\
Área urbana & 4937,72 & 2,89 \\
Outros* & 7263,40 & 4,25 \\
\hline Total & 170775,60 & 100,00
\end{tabular}

* área ocupada pela rede hidrográfica e pela malha viária.

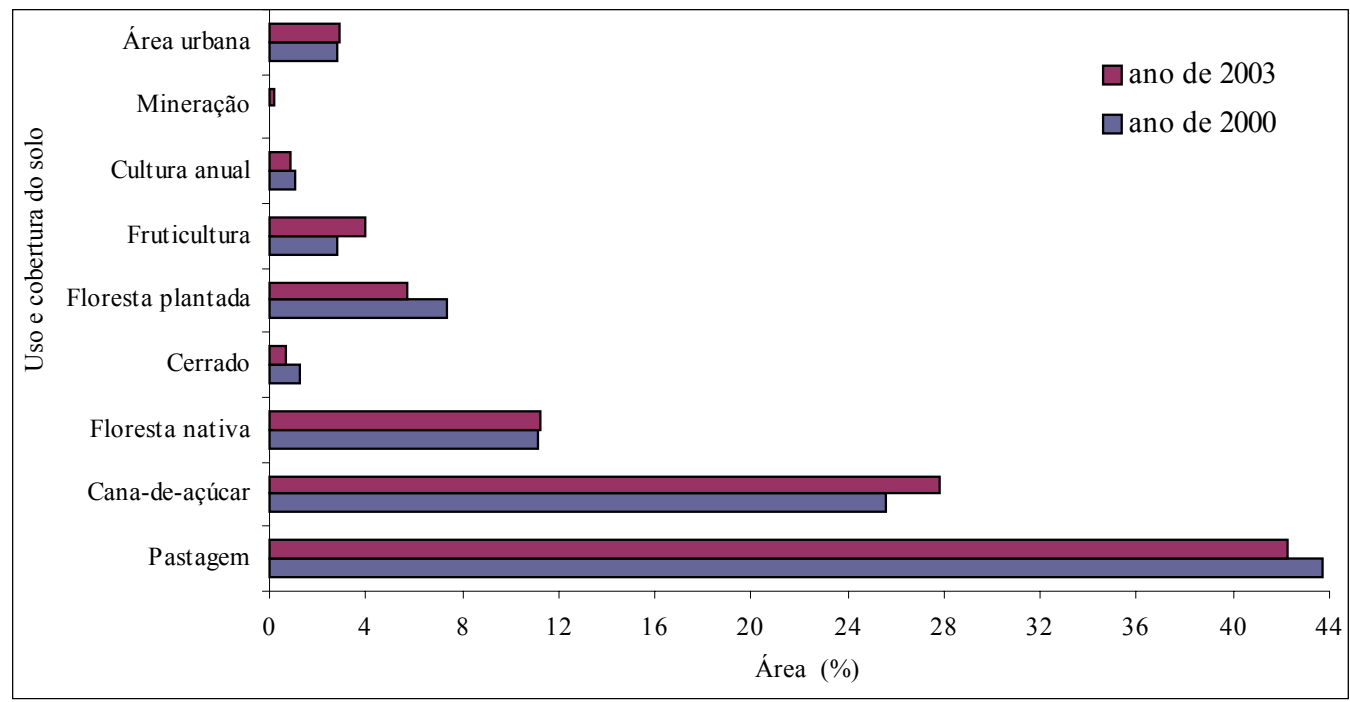

Figura 16 - Uso e cobertura do solo: áreas ocupadas nos anos de 2000 e 2003 


\section{2 Áreas prioritárias para a conservação e a preservação florestal}

\subsubsection{Método da Média Ponderada Ordenada}

O mapa de áreas prioritárias produzido a partir da combinação de todos os mapas de fatores, que se mostrou mais adequado para esse processo de tomada de decisão foi o que apresentou risco alto $(\mathrm{R}=0,40$; Tabela 13$)$ e compensação de $78 \%$ entre os fatores.

Malczewski (1999) afirma que nem sempre a melhor solução é aquela de menor risco. Deve-se avaliar as características da paisagem e as soluções propostas para determinar-se qual a melhor alternativa.

Com esse mapa (Figura 17) observou-se que existe correspondência entre a concentração de fragmentos de floresta com área nuclear e os valores da escala de prioridades ( 0 - 255 bytes). As regiões da bacia onde esses fragmentos são praticamente inexistentes foram associadas aos menores valores de prioridade e, em contrapartida, as marcadas pela maior concentração desses fragmentos foram associadas aos maiores valores de prioridade. Existe, ainda, uma terceira região com freqüência intermediária desses fragmentos e com valores também intermediários na escala de prioridade.

Como conseqüência dessa definição de regiões, esse mapa de prioridades, dentre os três (com riscos: médio, baixo e alto), foi o que apresentou uma melhor definição em suas classes de prioridades, principalmente a da classe com prioridade muito alta. No mapa de prioridades em classes (Figura 18) notou-se, ainda, que houve uma tendência de interligação entre as regiões de cada subclasse de prioridade (muito baixa, baixa, média, alta e muito alta). 


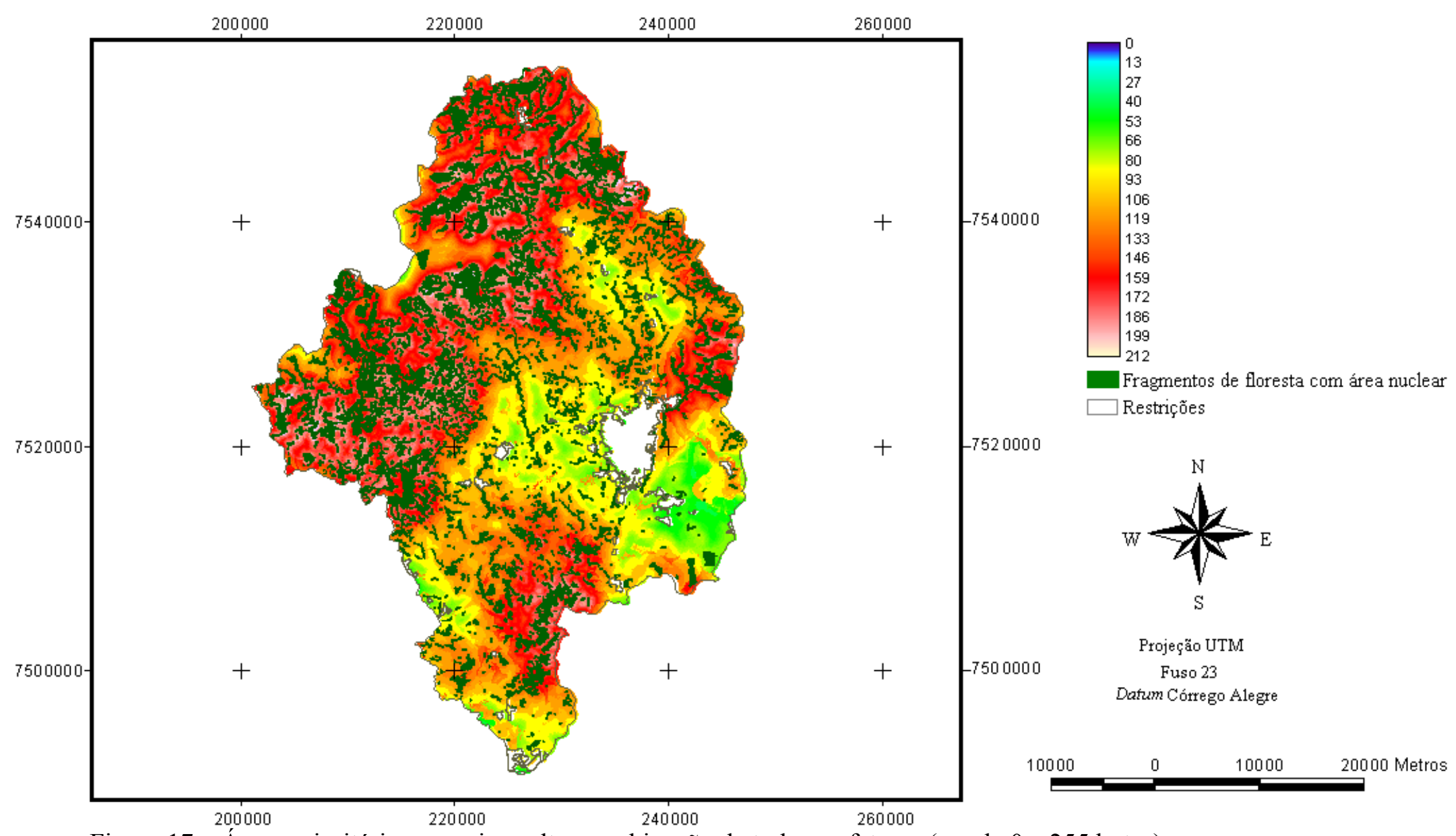

Figura 17 - Áreas prioritárias com risco alto: combinação de todos os fatores (escala 0 a 255 bytes) 


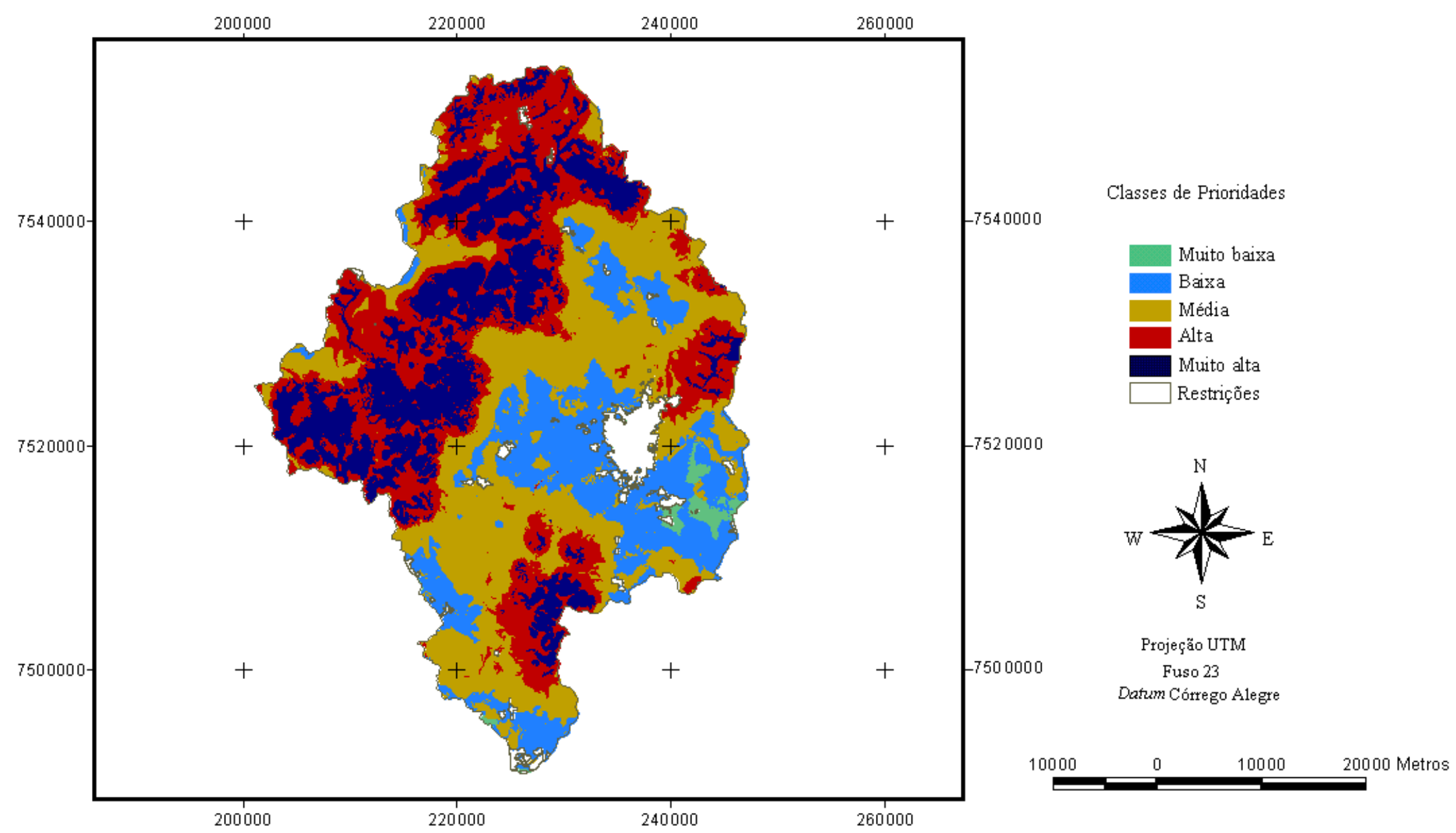

Figura 18 - Áreas prioritárias com risco alto: combinação de todos os fatores (classes de prioridades) 
A priorização de áreas (Figuras 17 e 18) é realizada com esse mapa, de maneira a promover, de modo geral, primeiro a união dos fragmentos de floresta com maior área nuclear (prioridade muito alta) e, a partir dessa união, a sucessiva expansão dessas regiões de prioridade muito alta (classes alta a muito baixa), respeitando-se, de maneira geral, a importância dos fatores no processo de tomada de decisão. Com a conecção entre os fragmentos com maior área nuclear está, segundo Lathrop et al. (1998) e Geneletti (2004) favorecendo-se as ações de conservação e preservação florestal porque, de acordo com os autores, essa conecção contribui para a reestruturação da paisagem e incremento de sua biodiversidade.

Com base no mapa de prioridades, em classes (Figura 18), 34\% da área da bacia apresenta média prioridade, $26 \%$ alta, $21 \%$ muito alta, $18 \%$ baixa e $1 \%$ muito baixa prioridade. Dentre os três mapas, conforme a Figura 19, este foi o que apresentou maior percentual da bacia com prioridades média e muito alta.

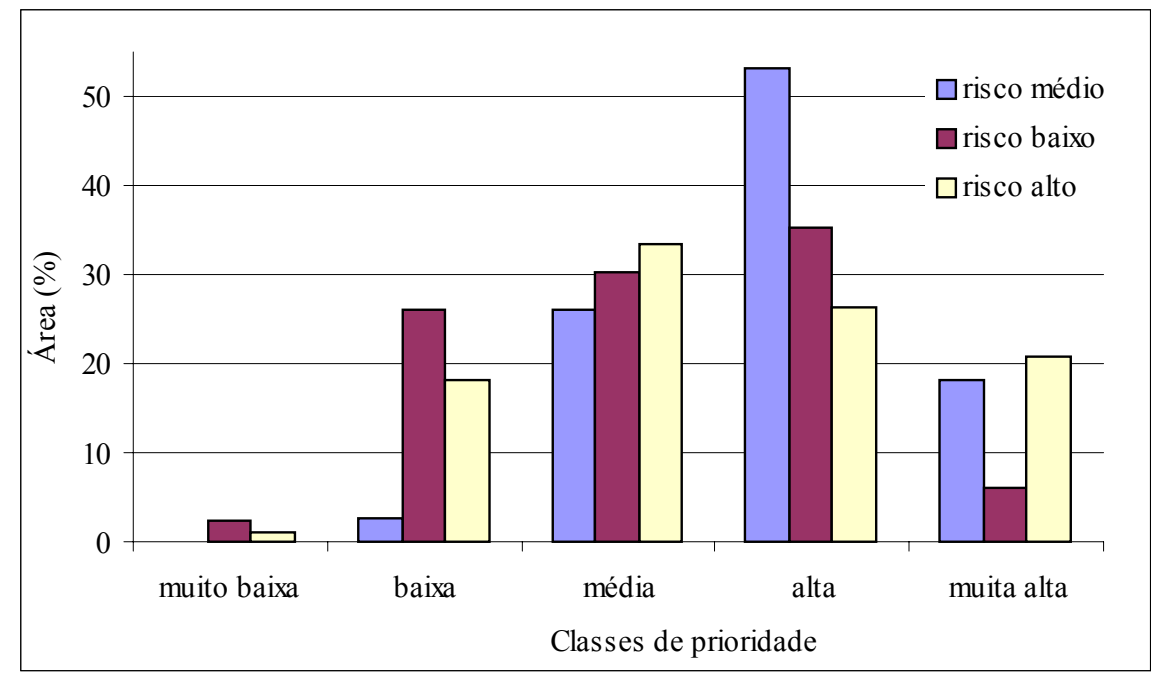

Figura 19 - Área (\%) ocupada por classes de prioridades: mapas com riscos médio, baixo e alto (todos os fatores)

A respeito dos pesos de ordenação (Tabela 13), pode-se dizer que possibilitaram a priorização considerando as relações de importância dos fatores, para esse processo de tomada de decisão. 
O mapa de áreas prioritárias que apresentou risco médio $(\mathrm{R}=0,5$; Tabela 13) e compensação total (100\%) entre os fatores pode ser observado na Figura 20.

A maior parte da bacia, de acordo com esse mapa, foi associada a valores (escala 0 a 255 bytes) próximos entre sí, tendo como conseqüência a priorização de quase toda a paisagem, exceto para aquela região onde os fragmentos de floresta com área nuclear são praticamente inexistentes (sudeste da cidade de Rio Claro). Esse fato ocorre porque o mapa com risco médio (todos os fatores com igual peso de ordenação) reflete uma influência excessiva dos fatores de "maior ranqueamento", nesse caso, os mapas de proximidades à rede hidrográfica e à cobertura florestal. Por esses motivos o mapa com risco médio não se mostrou adequado à priorização de áreas para a conservação e a preservação florestal na Bacia do Rio Corumbataí.

No que diz respeito aos mapas de proximidades, eles estão associados ao primeiro (proximidade à rede hidrográfica) e segundo (proximidade à cobertura florestal) fatores de maior ranqueamento, pela própria distribuição que suas respectivas feições apresentam. Observa-se corpos d'água distribuídos por toda a área. Como para esse fator quanto mais próximo se está dos corpos d'água maior é a prioridade associada (maior valor na escala 0 a 255 bytes), houve priorização na maior parte da bacia. Associado ao fato desse fator ser, à princípio, um dos mais importantes (peso de compensação $=17,36 \%$; Tabela 11 ) no processo de tomada de decisão, obteve-se essa forte influência do fator no mapa de prioridade com risco médio.

Com o fator proximidade à cobertura florestal o mesmo raciocínio pode ser seguido. Os fragmentos de floresta, independentemente de seus tamanhos, estão distribuídos por toda a paisagem. Para esse fator, quanto mais próximo a esses fragmentos maior a prioridade (valores próximos a 255 bytes). Como foi atribuído a ele um dos maiores pesos de compensação (17,36\%; Tabela 11), ele passou a exercer forte influência no mapa de prioridades com risco médio. 


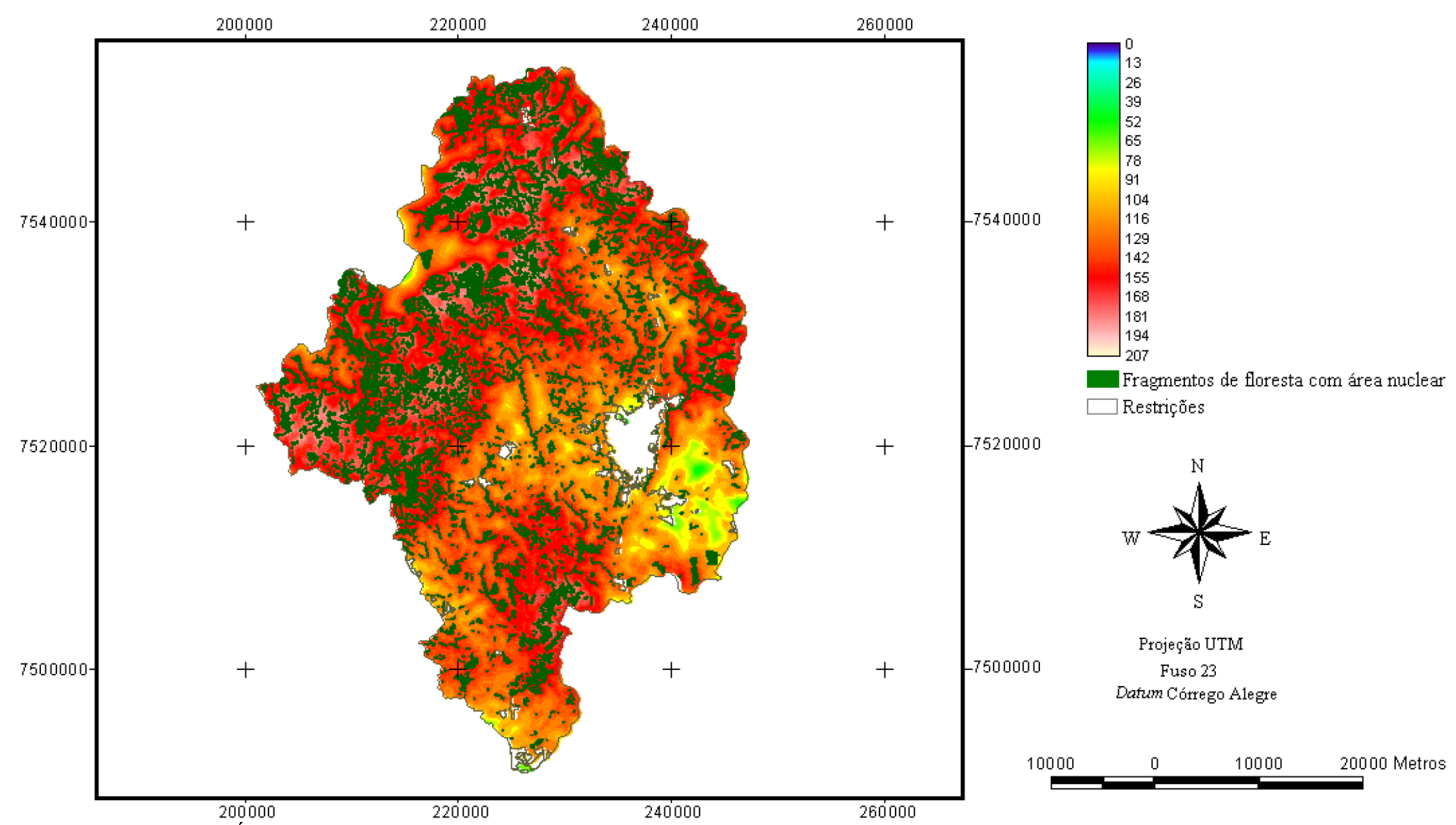

Figura 20 - Áreas prioritárias com risco médio: combinação de todos os fatores (escala 0 - 255 bytes) 
Jiang \& Eastman (2000) citam que os mapas com risco médio que apresentam compensação total entre os fatores (todos os fatores com igual peso de ordenação) equivalem aos obtidos pelo método da Combinação Linear Ponderada. Araújo (1999), comparando os métodos da Combinação Linear Ponderada e da Média Ponderada Ordenada também constatou que, em geral, mapas com risco médio $(100 \%$ de compensação entre fatores) têm forte influência de seus fatores de maior ranqueamento e que o primeiro método possibilita apenas a definição de grandes regiões.

A partir do mapa com risco médio em classes (Figura 21), contatou-se que 53\% da área da bacia foi classificada como sendo de alta prioridade; $26 \%$ de média; $18 \%$ de muita alta; 3\% de baixa, não tendo áreas na classe muito baixa.

O mapa de áreas prioritárias com risco baixo $(\mathrm{R}=0,62$; Tabela 13) e compensação de $70 \%$ entre os fatores pode ser observado na Figura 22. As diferenças observadas entre esse mapa e os demais (com riscos médio e alto) estão associadas aos pesos de ordenação.

Nesse caso, do mapa com risco baixo, o mapa de fator que recebeu o maior peso de ordenação foi o de proximidade entre os fragmentos de maior área nuclear, tendo como conseqüência uma região bem definida (associada à maior freqüência dos fragmentos com área nuclear). Na seqüência tem-se os mapas de fatores distância à malha viária e distância aos centros urbanos, ambos com peso de ordenação de 0,22 (Tabela 13). Esses dois fatores (item 3.2.4.2) ocuparam, respectivamente, a primeira e a segunda posições no ranqueamento dos fatores.

Como os mapas de distâncias possuíam um dos menores pesos de compensação e passaram a ter um dos maiores pesos de ordenação, pode-se dizer que foram fortemente compensados e passaram a ter maior influência no mapa de prioridades, ou seja, passouse a priorizar algumas regiões classificadas como de "baixo risco". A conseqüência desse fato foi uma maior extensão da bacia associada a menores valores de prioridade (Figura 21) e o mapa de prioridades em classes com maior área, dentre os três mapas, na classe de baixa prioridade, conforme indicam as Figuras 19 e 21. 


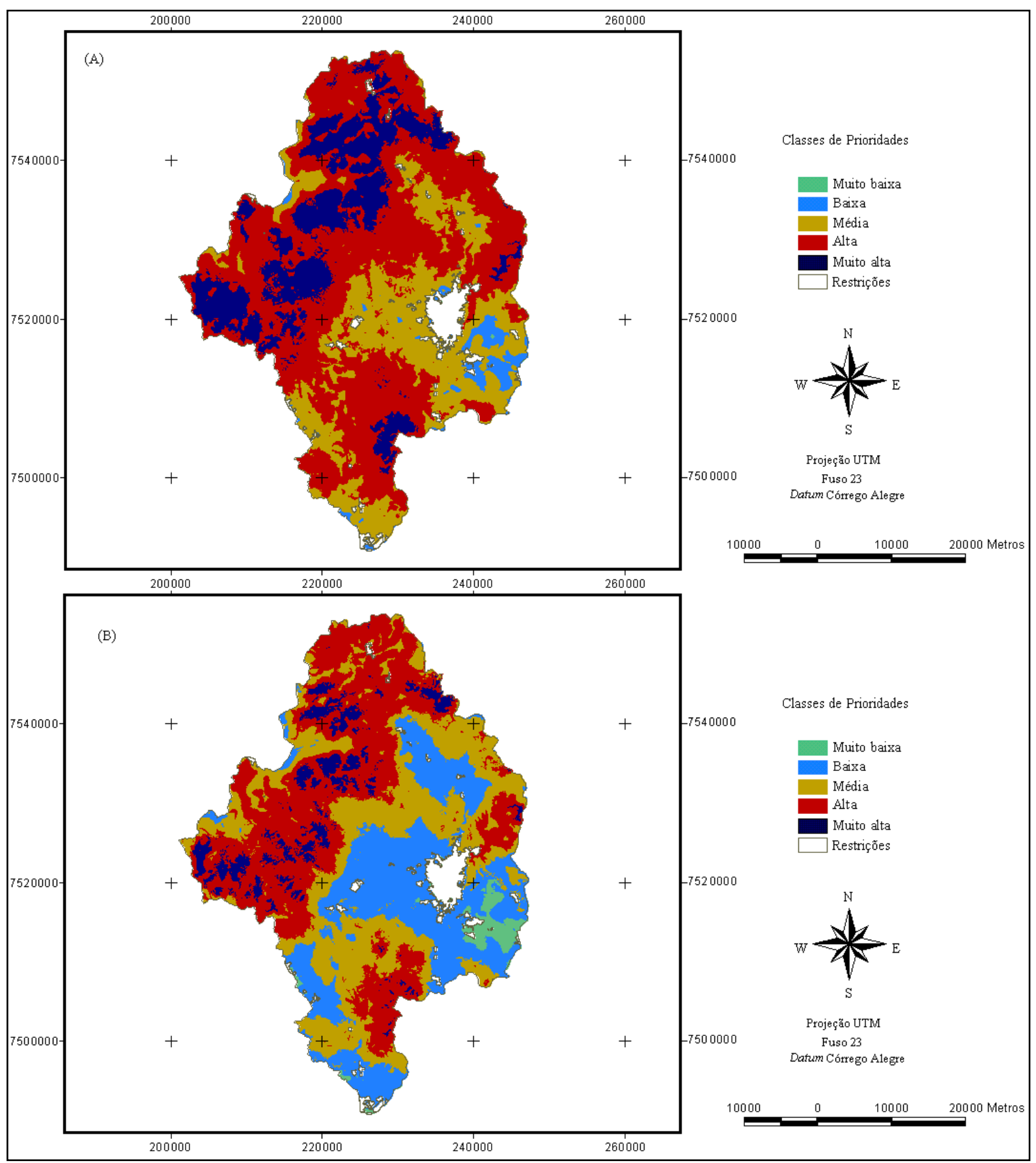

Figura 21 - Mapas com riscos médio (A) e baixo (B): combinação de todos os fatores (classes de prioridades) 


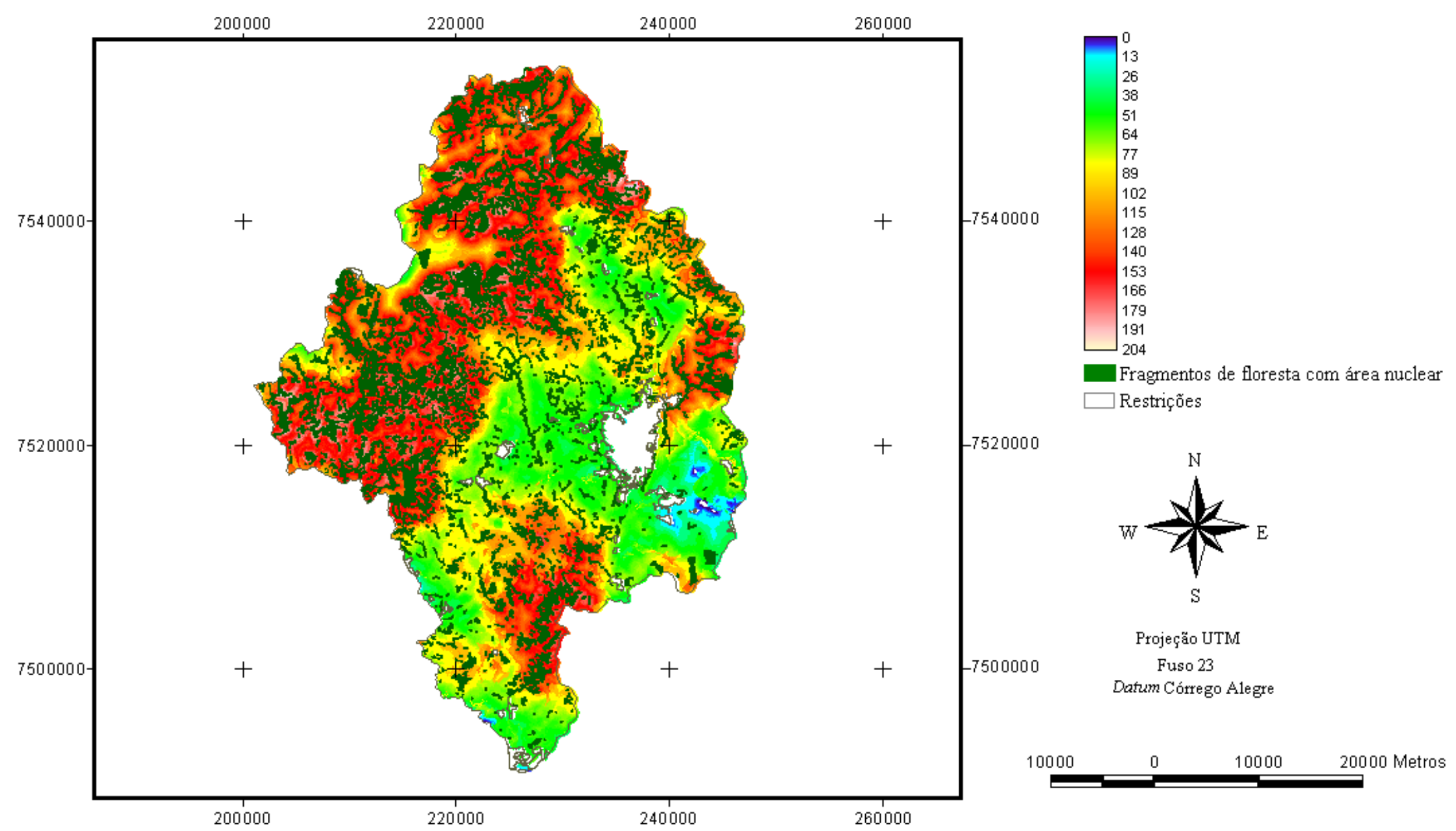

Figura 22 - Áreas prioritárias com risco baixo: combinação de todos os fatores (escala 0 - 255 bytes) 
Com base no mapa em classes (Figura 21) tem-se 35\% da área da bacia com alta prioridade; $30 \%$ com média prioridade; $26 \%$ com baixa prioridade; $6 \%$ com muita alta prioridade; e apenas $2 \%$ com muito baixa prioridade

Quanto aos mapas de proximidades à cobertura florestal e, principalmente, à rede hidrográfica, que receberam os menores pesos de ordenação, eles tiveram sua influência reduzida no mapa de prioridades.

Avaliando o mapa de risco baixo concomitantemente com os mapas de fatores observou-se que, para algumas regiões da bacia, não houve a priorização de áreas segundo a importância dos fatores, para o processo de tomada de decisão.

Para algumas regiões, principalmente quando se estava distante de uma grande concentração de estradas e/ou áreas urbanas, notou-se que foram priorizadas áreas mesmo sem a presença de fragmentos de floresta. Pode-se dizer que houve uma excessiva compensação dos fatores distância à malha viária e distância aos centros urbanos em detrimento dos fatores proximidade à cobertura florestal e proximidade à rede hidrográfica. Com esses pesos de ordenação, a relação mapa de prioridades e objetivos do processo de tomada de decisão foram alterados.

\subsubsection{Análise de sensibilidade}

Os mapas utilizados nessa análise e resultantes das matrizes de comparação pareada, pesos de compensação e ordenação (Tabelas 14 a 19 - item 3.2.4.5) podem ser observados nas Figuras 23 a 28 (escala 0 a 255 bytes e em classes).

\subsubsection{Proximidade entre fragmentos de maior área nuclear}

Com a eliminação desse fator, o mapa de prioridades (Figura 23) assumiu risco médio-baixo $(\mathrm{R}=0,58)$ e compensação de $89 \%$ entre os demais fatores. Esse mapa de prioridades é bem semelhante ao mapa de risco médio (todos os fatores), ou seja, também possui predominância de valores próximos entre si (escala 0 a 255 bytes) e, ainda, esse fato ocorreu como conseqüência da grande influência dos mapas de 
proximidades à rede hidrográfica e à cobertura florestal (fatores de "maiores ranqueamento").

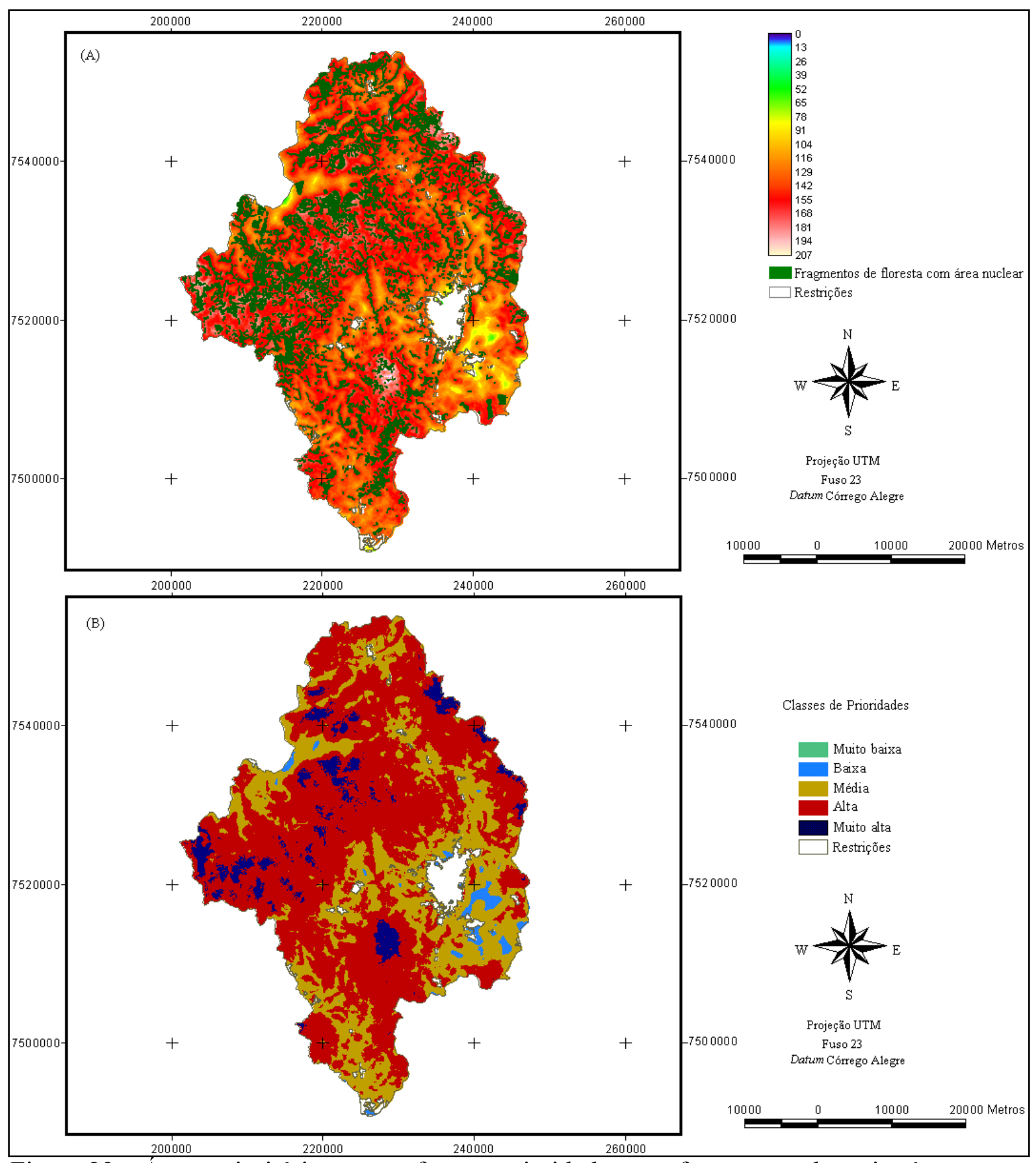

Figura 23 - Áreas prioritárias, sem o fator proximidade entre fragmentos de maior área nuclear : risco médio-baixo (escala $0-255$ bytes (A) e em classes (B)) 
Outro ponto a ser considerado é que, com a eliminação do fator proximidade entre fragmentos de maior área nuclear, a priorização de áreas passou a promover a união entre fragmentos de floresta independentemente de seus tamanhos. Não se tem mais a priorização de maneira a preservar e a conservar os fragmentos que já apresentam uma estrutura interna estabelecida que, conforme citado por Geneletti (2004), são os componentes básicos da estrutura de uma paisagem que visa manter a integridade de sua cobertura natural por sua capacidade, dentre outras, de manter as espécies típicas de formação florestal a que pertencem.

$\mathrm{Na}$ Figura 23 pode-se observar esse mapa de prioridades em classes. Como resultado dessa generalização, causada pela exclusão do mapa de proximidade entre fragmentos de maior área nuclear, $62 \%$ da área da bacia foi classificada como de alta prioridade. Com base nesse mapa obteve-se, ainda, 31\% da bacia com média prioridade; $5 \%$ com muito alta; e $2 \%$ com baixa.

Pode-se assim dizer que o fator proximidade entre fragmentos de maior área nuclear é importante e deve continuar no processo de tomada de decisão.

\subsubsection{Vulnerabilidade à erosão}

O mapa de prioridades sem o fator vulnerabilidade à erosão (Figura 24) assumiu risco médio-baixo $(\mathrm{R}=0,58)$ e compensação de $70 \%$ entre os demais fatores. Muitas semelhanças são observadas entre esse mapa e o mapa com risco alto (Figura 17), produto da combinação de todos os fatores. As semelhanças ocorrem tanto na espacialização quanto na área ocupada (Figura 29) pelas classes de prioridades. A partir desse mapa obteve-se $32 \%$ da área da bacia com média prioridade; $25 \%$ com muito alta, $24 \%$ com alta; $18 \%$ com baixa; e apenas $1 \%$ com muito baixa prioridade(Figura 24).

Avaliando o mapa de prioridades em conjunto com os mapas de fatores, notou-se que a priorização foi feita segundo a importância dos fatores preestabelecida para esse processo de tomada de decisão. Constatou-se, contudo, que áreas com características semelhantes (demais fatores), mas com vulnerabilidades distintas, passaram a receber a 
mesma prioridade com a exclusão desse fator, conforme pode ser observado na região em evidência da Figura 24.

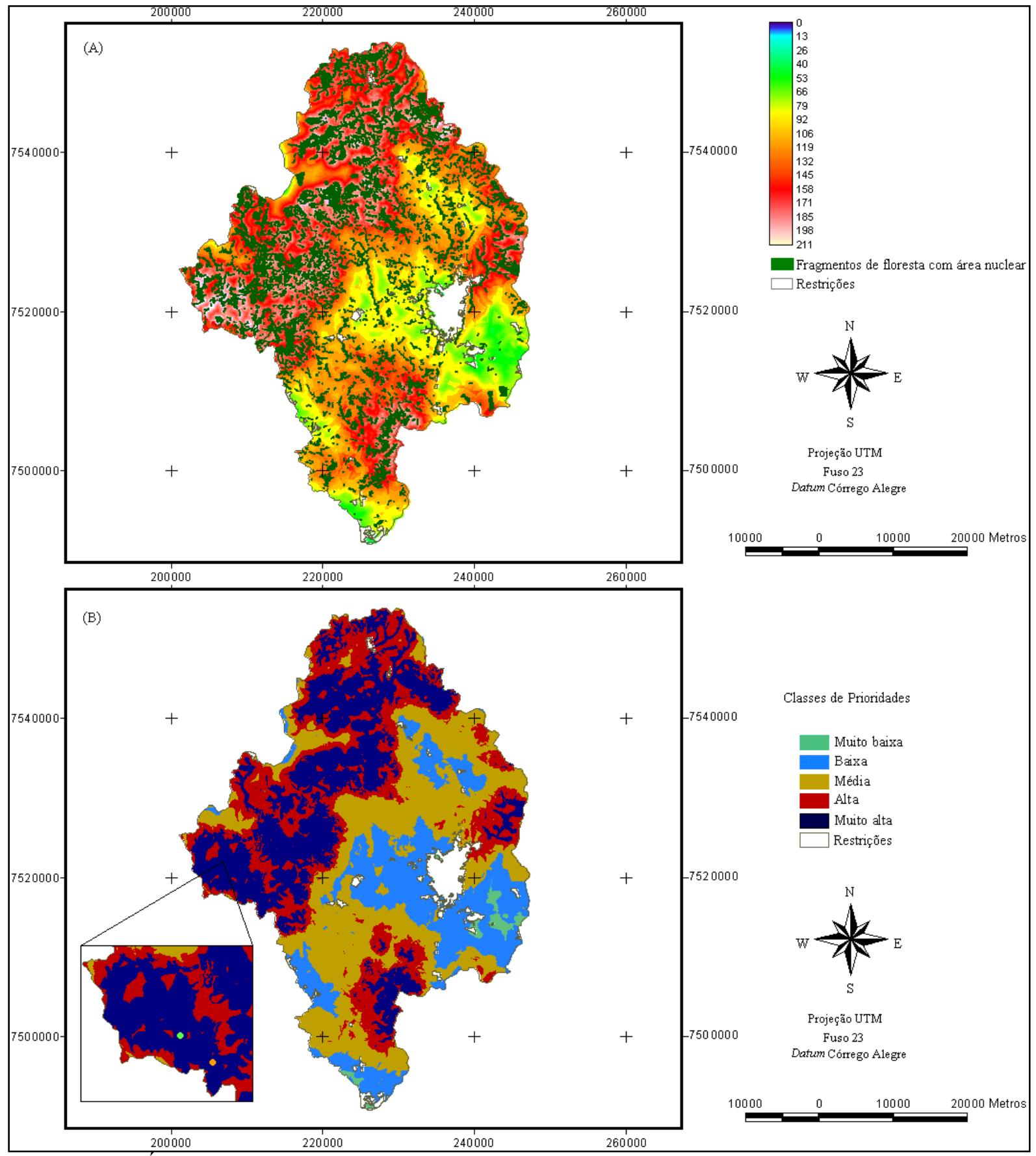

Figura 24 - Áreas prioritárias, sem o fator vulnerabilidade à erosão: risco médio-baixo (escala $0-255$ bytes (A) e em classes (B)) 
A eliminação desse fator afeta, portanto, a priorização apenas em nível de áreas prioritárias (local) pois, no geral, mantém-se as regiões prioritárias semelhantes (mesma relação de importância dos demais fatores), o que explica algumas semelhanças entre os mapas com e sem esse fator.

A influência local é, por sua vez, conseqüência dos baixos pesos de compensação e de ordenação atribuídos à vulnerabilidade à erosão; e, ainda, por esse fator apresentar concordância de suas áreas com maior valor (escala 0 - 255 bytes) com as de maior valor dos mapas de proximidades (entre fragmentos de maior área nuclear, à cobertura florestal e à rede hidrográfica), que são os de maior "importância" na estrutura desse processo. Isto é, áreas de maior prioridade, desses quatro fatores, coincidem. Por esse motivo, também, quando se elimina o fator vulnerabilidade à erosão não se altera muito a espacialização das classes de prioridade.

Por outro lado, quando se exclui a vulnerabilidade à erosão, do processo de tomada de decisão, tem-se generalização quanto à priorização, ou seja, são priorizadas áreas que atendem as demais características (fatores) mas não as "mais sensíveis" (maiores valores de declividade e de erodibilidade do solo), que segundo Forman (1997), Farina (1998) e Khan et al. (2001), devem ser consideradas quando se tem em vista a restruturação de toda a paisagem. Por esse motivo, sem o fator, regiões da bacia antes classificadas como de média e alta prioridades (Figura 29) na presença do fator, passaram à classe de muito alta prioridade (conversão total de 4\% em área).

Considerando, com relação à presença do fator vulnerabilidade à erosão, os benefícios à estrutura da paisagem (Farina, 1998; Khan et al., 2001), a espacialização dessas áreas (comparada àquelas priorizadas sem o fator) e, ainda, que as ações de conservação e preservação florestal da bacia devem favorecer a reestruturação de toda a paisagem e que essa será garantida com a priorização, quando possível, de suas áreas mais sensíveis (maior erodibilidade do solo e maiores declividades) deve-se manter o fator vulnerabilidade à erosão no processo de tomada de decisão. 


\subsubsection{Proximidade à cobertura florestal}

Eliminando-se esse fator o mapa de prioridades apresentou risco médio-alto $(\mathrm{R}=$ 0,46) e compensação de 73\% entre os demais fatores (Figura 25). Esse mapa, como no caso anterior, apresenta algumas semelhanças com o mapa produto da combinação de todos os fatores (risco alto). Obteve-se, sem o fator proximidade à cobertura florestal (Figura 25), 36\% de área da bacia com média prioridade, 30\% com alta, 18\% com baixa, $14 \%$ com muito alta e $1 \%$ com muito baixa. Comparado ao mapa de risco alto (todos os fatores) houve, conforme indica a Figura 29, um aumento nas áreas ocupadas pelas classes com média e alta prioridades e uma diminuição das regiões com muito alta prioridade.

Avaliando os mapas, com e sem esse fator, constatou-se que as semelhanças entre eles são conseqüência: (i) do fator proximidade entre fragmentos de maior área nuclear ter recebido, nos dois mapas, os maiores pesos de compensação e ordenação; e (ii) como os mapas de proximidades à cobertura florestal e à rede hidrográfica priorizam áreas semelhantes, com a exclusão do primeiro manteve-se semelhanças na priorização de algumas regiões.

As diferenças entre eles existem, por sua vez, por dois motivos. Primeiro, porque para as regiões em que a distribuição dos corpos d'água não está concentrada, com a eliminação do fator proximidade à cobertura florestal, elas deixaram de receber uma alto valor na escala de prioridades $(0-255$ bytes $)$. Deixou-se, dessa maneira, de priorizar regiões em que a conexão de grandes fragmentos (maiores áreas nucleares) é reforçada/facilitada pela presença de fragmentos de floresta (independentemente de seus tamanhos) em relação àquelas em que só existem os grandes fragmentos.

Os fragmentos de floresta, mesmo os menores, não podem ser desconsiderados na reestruturação de uma paisagem. Conforme citado por Metzger (2003), para a conservação biológica, além de ter-se os grandes fragmentos é necessária a presença de uma rede de fragmentos menores para que se aumente a conectividade funcional de uma paisagem. 


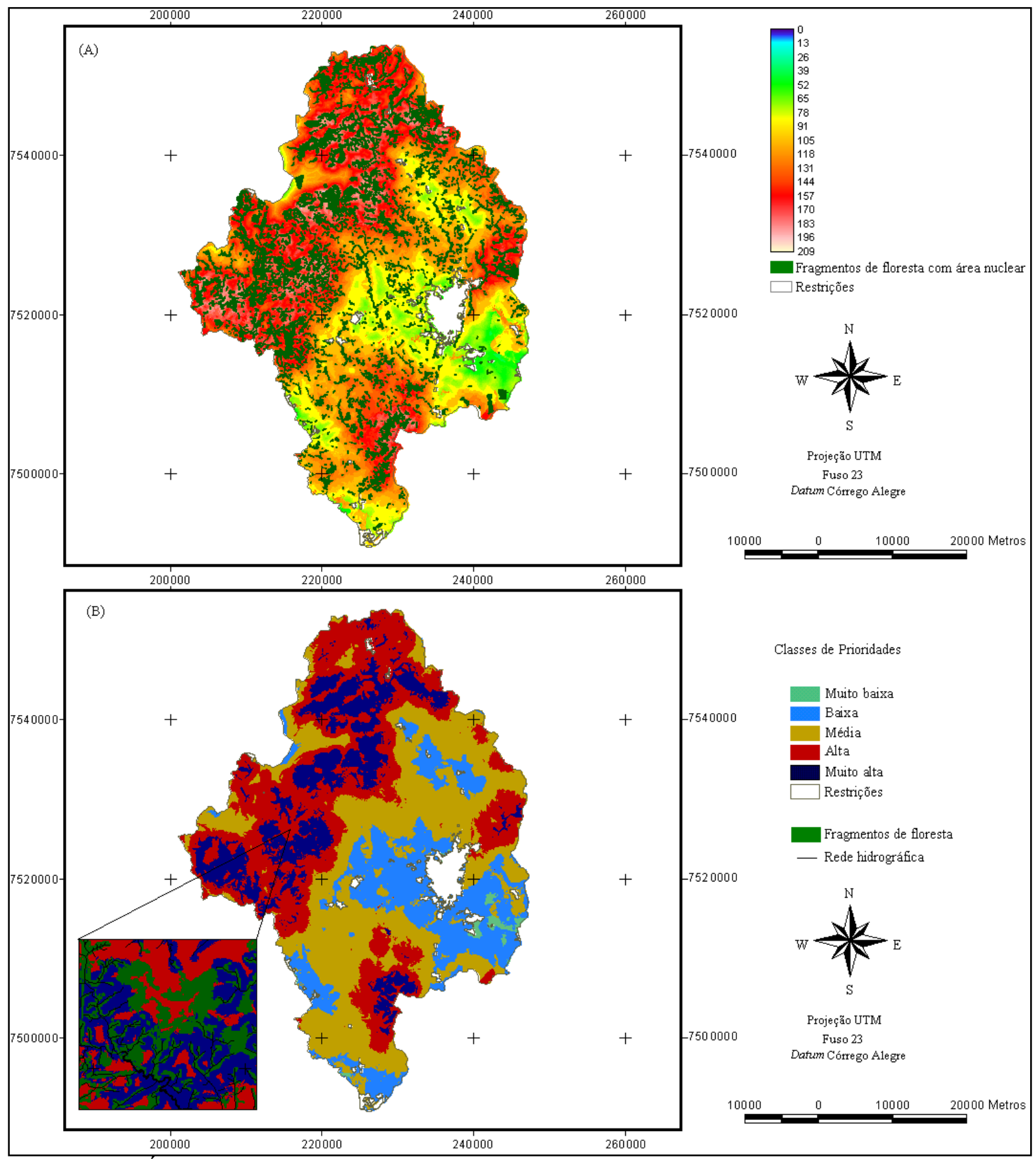

Figura 25 - Áreas prioritárias, sem o fator proximidade à cobertura florestal: risco médioalto (escala 0 - 255 bytes (A) e em classes (B))

O segundo motivo, e de maior importância, acontece em função dos corpos d'água apresentarem-se distribuídos por toda a Bacia do Rio Corumbataí e, como já 
discutido, por esse fator ser o que apresenta maior ranqueamento entre os demais. Com a exclusão do fator proximidade à cobertura florestal, o fator proximidade à rede hidrográfica passou a apresentar excessiva influência no mapa de prioridades. Na maior parte da bacia passou a ocorrer a priorização praticamente em função da presença dos corpos d'água, independentemente da presença dos fragmentos de floresta e, ainda, dos fragmentos com maior área nuclear, como pode ser observado na Figura 25 (região em evidência).

A presença do fator proximidade à cobertura florestal possibilita, dessa maneira, que as regiões de maior prioridade da bacia contenham, além dos seus fragmentos com maior área nuclear, uma grande concentração de floresta natural.

A análise de sensibilidade indicou, portanto, que é importante manter o fator proximidade à cobertura florestal no processo de tomada de decisão.

\subsubsection{Proximidade à rede hidrográfica}

O mapa de prioridades sem o fator proximidade à rede hidrográfica (Figura 26) apresentou risco médio-alto $(\mathrm{R}=0,46)$ e compensação de $73 \%$ entre demais fatores. De acordo com esse mapa, em classes (Figura 26), a bacia apresentou 35\% de sua área com média prioridade, $28 \%$ com alta, $18 \%$ com baixa, $17 \%$ com muito alta e $1 \%$ com muito baixa prioridade. A classe com prioridade muito alta apresentou redução em área ocupada e espacialização diferente em relação ao mapa produto da combinação de todos os fatores, conforme indica a Figura 29.

Comparando-se os mapas, com e sem esse fator, foram constatadas algumas alterações na estrutura de priorização de áreas. No mapa com o fator, pontos amostrados apresentaram-se sempre com maiores valores de prioridade do que no mapa sem esse fator, como conseqüência do fator eliminado ser o primeiro na ordem de ranqueamento. Ainda, pela influência desse fator, observou-se que para duas regiões, sendo a primeira marcada pela presença de grandes fragmentos, próximos uns ao outros, e a segunda por fragmentos um pouco menores, com demais características (fatores) semelhantes à anterior, porém com esses fragmentos próximos à rede hidrográfica, eram atribuídos 
valores mais altos na escala de prioridades $(0-255$ bytes $)$ para a região mais próxima aos corpos d'água. Quando esse fator foi eliminado passou a priorizar-se a primeira região em relação à segunda. Pode-se dizer que passaram a ter maior prioridade as regiões associadas à presença dos fragmentos de floresta e, principalmente, daqueles com maiores áreas nucleares, conforme indica a Figura 26 (região em evidência).

A importância de ações nas regiões ao longo dos corpos d'água é amplamente discutida na literatura (Forman \& Collinge, 1997; Forman, 1997; Durigan \& Silveira, 1999), contudo, quando se deseja incremento da biodiversidade por meio de ações de conservação e/ou preservação não se pode desconsiderar os fragmentos de floresta e, sobretudo, os fragmentos com uma estrutura definida. Esses últimos são, segundo McNeely et al. (1990), os retentores de maior diversidade em uma paisagem e quando conectados (espacialmente ou por meio de outros fragmentos menores) é que irão subsidiar a restruturação de toda a paisagem.

No caso da Bacia do Rio Corumbataí, o principal problema da priorização em função, principalmente, da rede hidrográfica, está em algumas de suas regiões onde corpos d'água não possuem vegetação ciliar ou então somente fragmentos pequenos e distantes uns dos outros.

Pode-se, assim, dizer que o fator proximidade a rede hidrográfica não é importante, nesse caso específico, em função da distribuição dos corpos d'água na bacia, podendo ser eliminado do processo de tomada de decisão.

Ressalta-se que tanto para esse fator como para o proximidade à cobertura florestal, os pesos de ordenação propostos inicialmente e apresentados no Anexo C também não se mostraram adequados, em função dos pesos excessivos associados aos mapas de distâncias à malha viária e aos centros urbanos. Mesmo nessas condições o mapa de proximidade à rede hidrográfica (pesos de ordenação I - Tabela 34, Anexo C) apresentou comportamento semelhante ao mapa de prioridades empregado na análise de sensibilidade. 


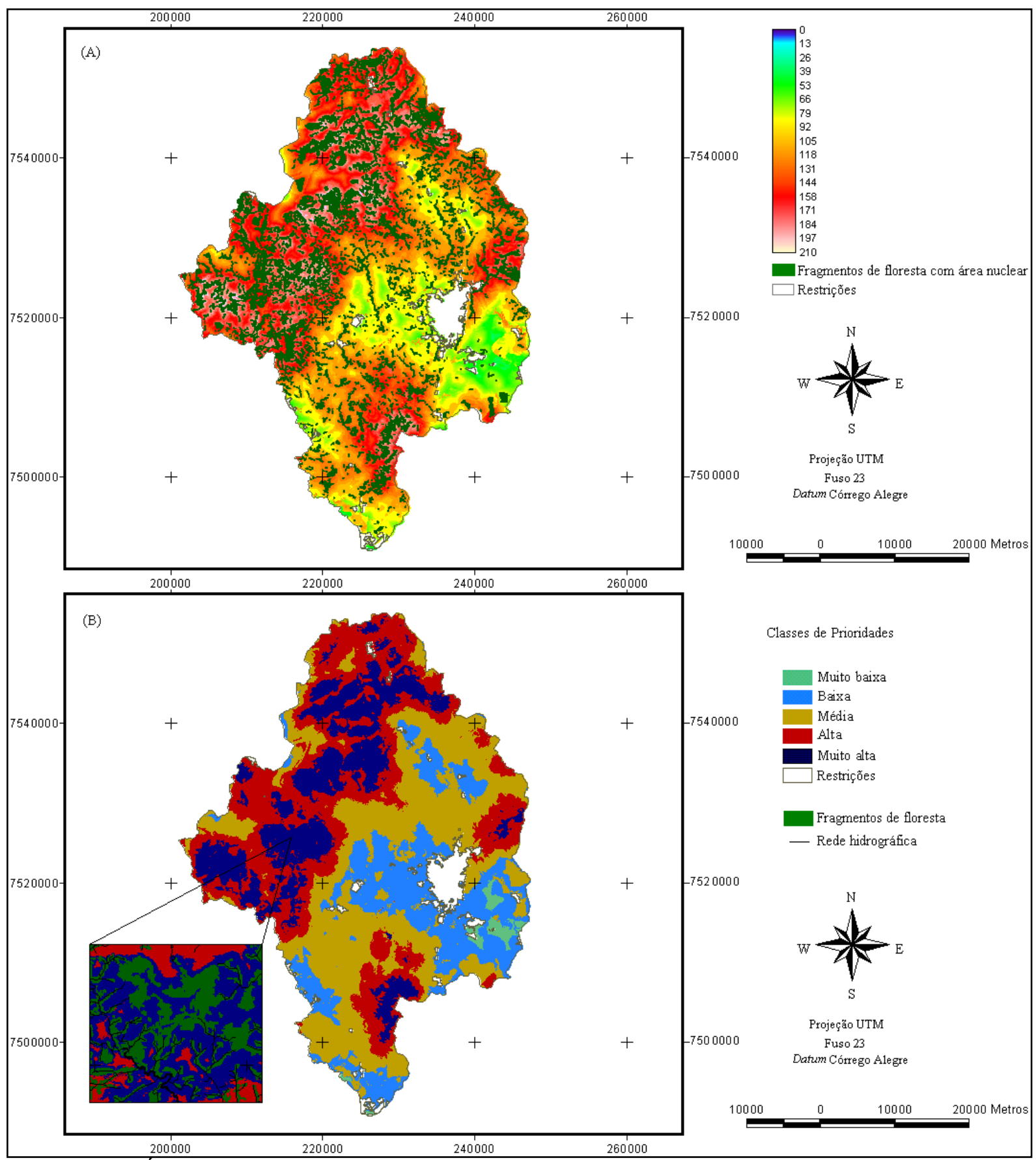

Figura 26 - Áreas prioritárias, sem o fator proximidade à rede hidrográfica: risco médioalto (escala $0-255$ bytes (A) e em classes (B)) 


\subsubsection{Distância à malha viária}

Com a eliminação desse fator, o mapa de prioridades (Figura 27) assumiu risco baixo $(\mathrm{R}=0,58)$ e compensação entre os demais fatores de $64 \%$. Obteve-se, a partir desse mapa em classes, $36 \%$ da bacia classificada com média prioridade, $26 \%$ com muito alta, $25 \%$ com alta, $12 \%$ com baixa e $1 \%$ com muito baixa prioridade. Em relação ao mapa com todos os fatores houve, em área ocupada, aumento das classes com muito alta e média prioridades e diminuição da classe com baixa prioridade (Figura 29).

A malha viária foi o fator que, por sua distribuição associada a sua importância no processo de tomada de decisão, menor influência (primeiro no ranqueamento) exerceu no mapa de prioridades (todos os fatores). Essa baixa influência das estradas, no

processo de tomada de decisão, também foi constatada comparando-se os mapas com e sem esse fator.

Dessa forma, sua eliminação não alterou as relações de prioridade, ou seja, houve semelhanças nas regiões prioritárias (com e sem o fator). Com o aumento da escala de investigação e avaliação de locais com características semelhantes, exceto pela presença e ausência de estradas, contatou-se que localmente esse fator exerce influência no mapa de prioridades.

A conexão florestal foi associada a maiores valores (escala e classes de prioridades) quando se tinha fragmentos mais distantes da malha viária (mapa com todos os fatores). Por outro lado, quando esse fator foi eliminado houve a priorização independentemente da presença das estradas, conforme pode ser observado na região em evidência da Figura 27.

A influência local do fator distância à malha viária passa a ser importante, para esse processo de tomada de decisão, quando se considera que o sucesso das ações de conservação e preservação florestal pode estar seriamente comprometido quando se está próximo a fontes de distúrbios (ex. estradas). Como citado por Geneletti (2003), os resultados de efeitos diretos (redução da área total do fragmento) e indiretos (fragmentação e degradação do ecossistema) da presença de fontes de distúrbios, podem 
variar desde a redução da capacidade do ecossistema de sustentar sua biodiversidade original à sua total extinção.

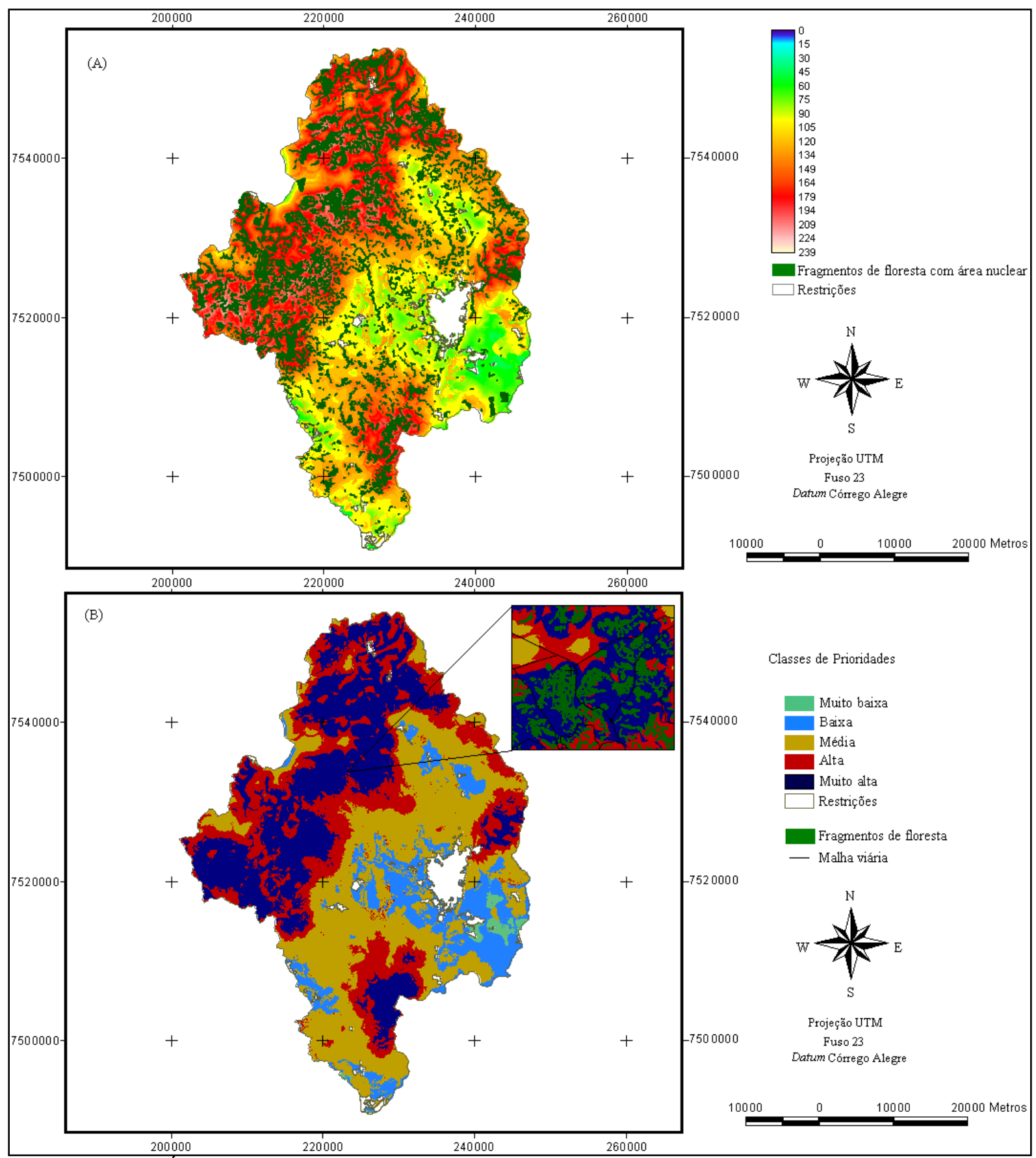

Figura 27 - Áreas prioritárias, sem o fator distância à malha viária: risco baixo (escala 0 - 255 bytes (A) e em classes (B)) 
Com variações nos pesos de ordenação (Tabelas 27 e Anexo C) houve uma tentativa de compensar a ausência desse fator, atribuindo maiores pesos aos mapas de proximidades à cobertura florestal e entre fragmentos de maior área nuclear, mas não houve sucesso.

Nesse contexto, a análise de sensibilidade confirmou que é importante manter o fator distância à malha viária no processo de tomada de decisão.

\subsubsection{Distância aos centros urbanos}

O mapa de prioridades sem o fator distância aos centros urbanos (Figura 28) apresentou risco médio-baixo $(\mathrm{R}=0,55)$ e compensação de $69 \%$ entre demais fatores. Como outros mapas que apresentaram risco médio $(\mathrm{R}=0,50)$ ou próximos ao médio, ele mostrou uma extensa área da bacia associada a valores semelhantes (escala $0-255$ bytes). De acordo com esse mapa em classes (Figura 28), a bacia apresentou 38\% de sua área com média prioridade; $28 \%$ com alta; $26 \%$ com muito alta; e $8 \%$ com baixa.

Áreas consideradas como de baixa ou muito baixa prioridade, com a eliminação desse fator, tiveram suas prioridades alteradas (classes média à muito alta). Eliminandose esse fator houve a priorização de áreas, estando distantes ou não de fontes de perturbação. Como exemplo fácil de ser visualizado existe a cidade de Rio Claro. Áreas vizinhas à essa cidade pertenciam, predominantemente, a categoria baixa prioridade (mapa com todos os fatores) e, com a eliminação do fator distância ao centros urbanos, passaram a ser classificadas como de média prioridade (Figura 28).

Para a conservação e preservação florestal os efeitos de ter-se fragmentos priorizados próximos às cidades são semelhantes aos que se tem quando se está próximo de estradas. Como citado por Gutzwiller \& Barrow (2003), as áreas naturais próximas aos centros urbanos estão sob constante ameaças, em função do uso inadequado dessas áreas. Outro aspecto negativo a ser considerado é que centros urbanos, segundo Metzger (2003), funcionam com barreiras aos fluxos biológicos. 


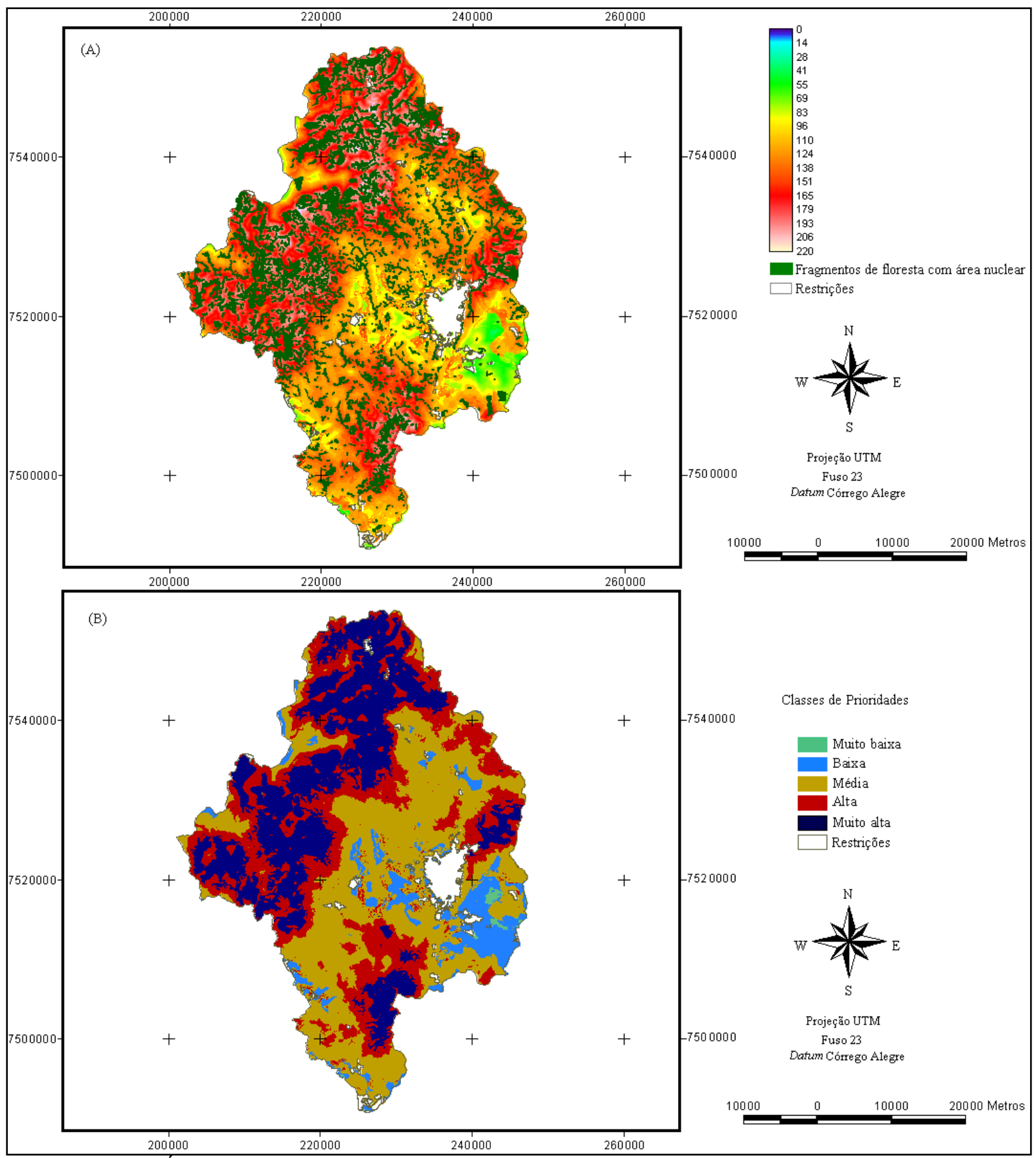

Figura 28 - Áreas prioritárias, sem o fator distância aos centros urbanos: risco médiobaixo (escala $0-255$ bytes (A) e em classes (B)) 
Quando se tem em vista o incremento de biodiversidade é interessante que as ações de reestruturação da paisagem iniciem-se longe dessas fontes de distúrbio. Assim, tem-se uma melhor expectativa quanto ao sucesso.

Desse modo, o fator distância aos centros urbanos influencia no processo de tomada de decisão e é importante que continue a ser utilizado.

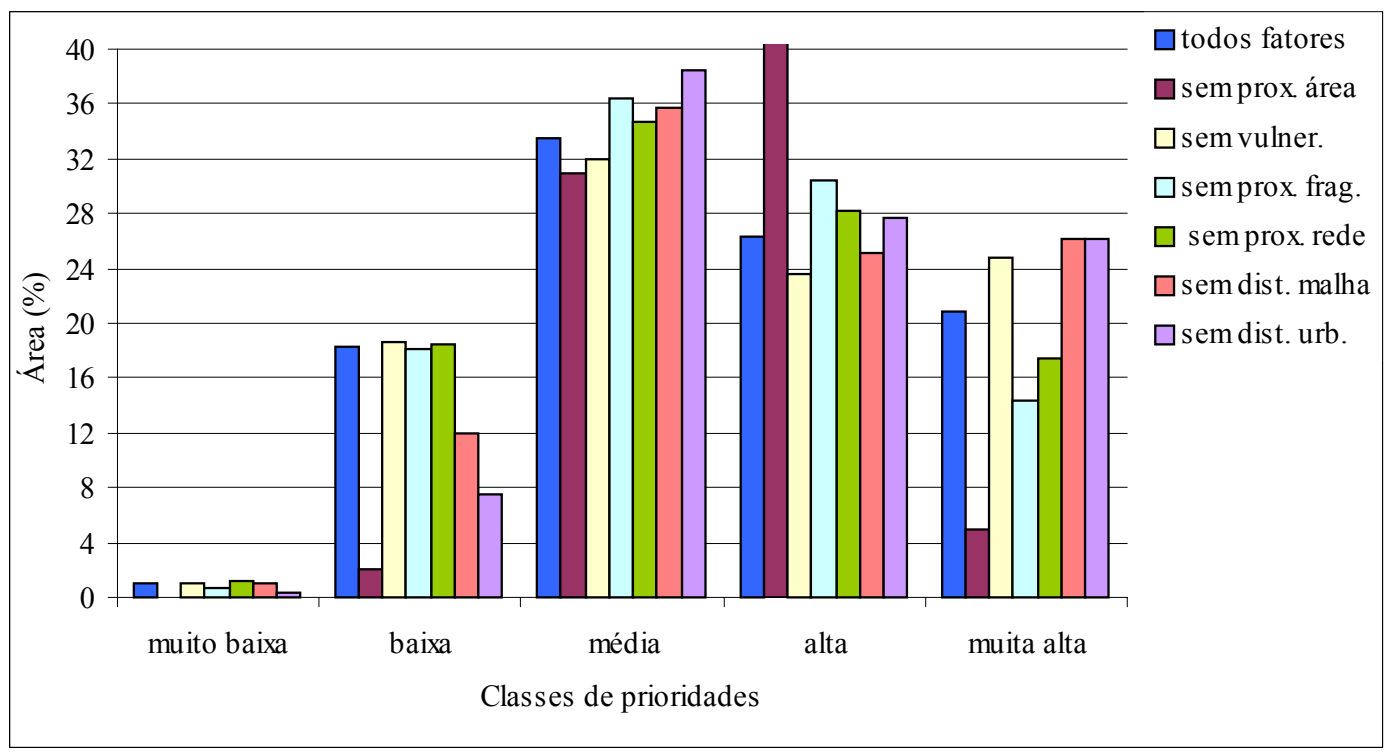

Figura 29 - Análise de sensibilidade: área (\%) das classes de prioridades

\subsubsection{Avaliação da alternativa proposta para a definição de áreas prioritárias}

A análise de sensibilidade indicou como a melhor alternativa, para a priorização de áreas para a conservação e a preservação florestal na Bacia do Rio Corumbataí, a eliminação do mapa de fator proximidade à rede hidrográfica. Na análise avaliou-se essa alternativa (solução) somente com risco médio-alto $(\mathrm{R}=0,46)$. Nas Figuras 30 e 32 estão, respectivamente, os mapas de prioridades referentes à essa alternativa, que apresentaram riscos médio $(R=0,50)$ e médio-baixo $(R=0,54)$, conforme indicado na Tabela 20.

O mapa de prioridades com risco médio apresentou 100\% de compensação entre os demais fatores (igual peso de ordenação dos fatores). 


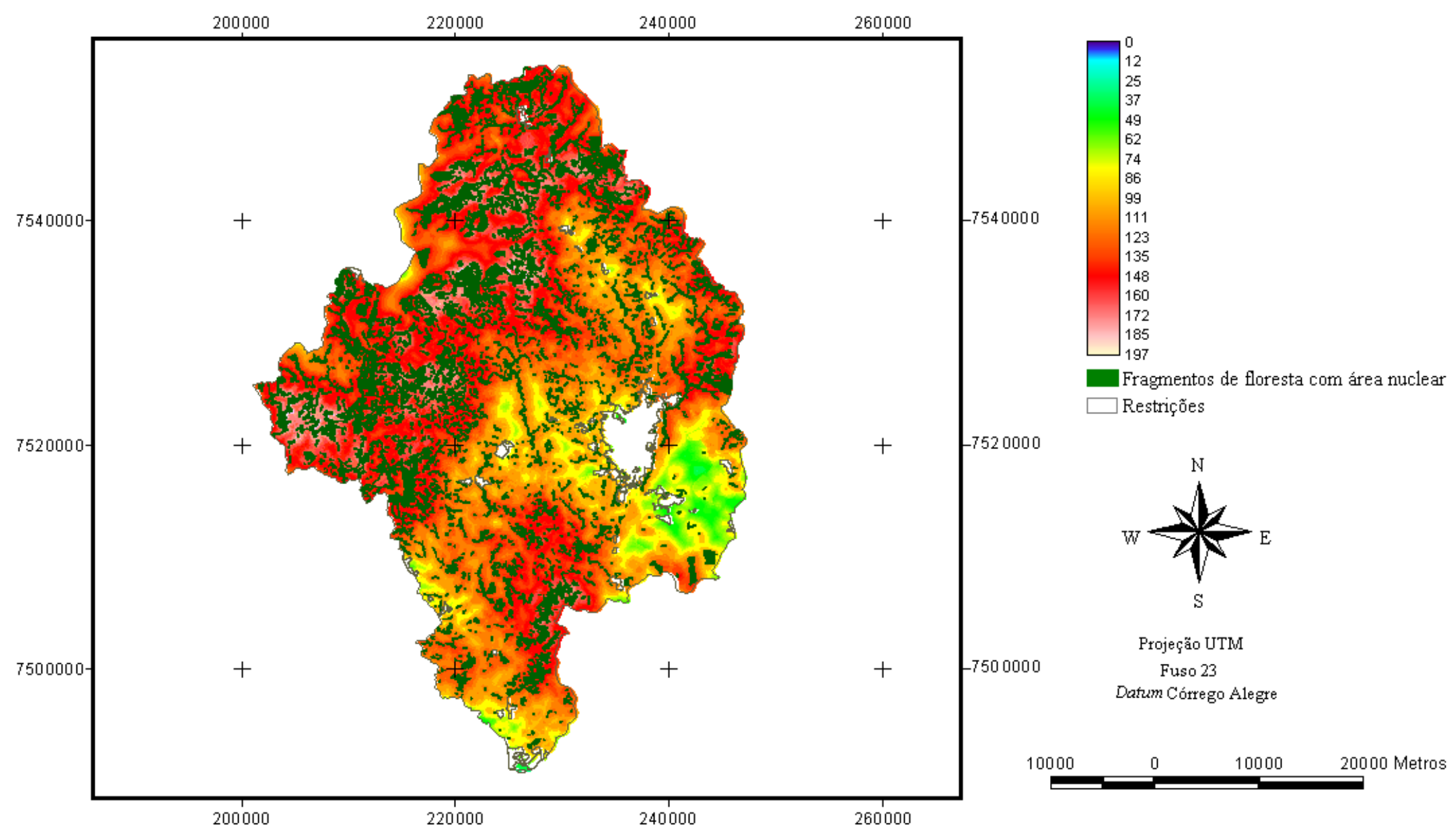

Figura 30 - Áreas prioritárias com risco médio: sem o fator proximidade à rede hidrográfica (escala 0 - 255 bytes) 
Como já discutido e também citado por Araújo (1999) e Malczewski (1999), o mapa com risco médio apresenta excessiva influência de seus fatores com maior ranqueamento, nesse caso os mapas de proximidades à cobertura florestal e entre fragmentos de maior área nuclear. Pela influência desse último (maiores pesos de compensação e ordenação) houve a melhor definição (comparação aos demais mapas com risco médio) de uma região, associada à concentração dos fragmentos de maior área nuclear. No mapa em classes (Figura 31) observa-se que essa região foi, de maneira geral, classificada como de alta prioridade e representou $43 \%$ da área da bacia. A média prioridade ocupou $40 \%$ da área da bacia; a baixa $11 \%$; a muito alta $5 \%$; e a muito baixa $1 \%$.

Mesmo nessas condições, houve predominância da influência do mapa de proximidade entre fragmentos, que para essa alternativa (sem proximidade à rede hidrográfica) é o fator de maior ranqueamento. A relação mapa de prioridades e importância dos fatores foi, portanto, alterada. Nesse mapa com risco médio obteve-se a priorização considerando, na maioria das situações, a proximidade entre fragmentos mas não a proximidade entre fragmentos de maior área nuclear, que são necessários para o incremento da biodiversidade de uma paisagem (McNeely et al. 1990; Metzger, 2003; Genelletti 2004).

$\mathrm{Na}$ classe de muito alta prioridade notou-se, por exemplo, a concentração de fragmentos de floresta, que nem sempre pertencem ao grupo dos maiores fragmentos dessa paisagem.

O mapa com risco médio (compensação total entre os fatores) caracteriza-se por apresentar soluções nem arriscadas e nem aversas a risco, porque suas soluções sempre estão entre os extremos (AND e OR), conforme citado por Malczewski (2000). Nem sempre suas soluções são as ideais porque, conforme visto nesse caso, ele tem a tendência de generalização, ou melhor, sofre muito influência do fator de maior ranqueamento (solução arriscada e generalizada).

Pode-se dizer que o mapa de prioridades com risco médio não se mostrou adequado à priorização de áreas, de acordo com a importância dos fatores para esse processo de tomada de decisão. 


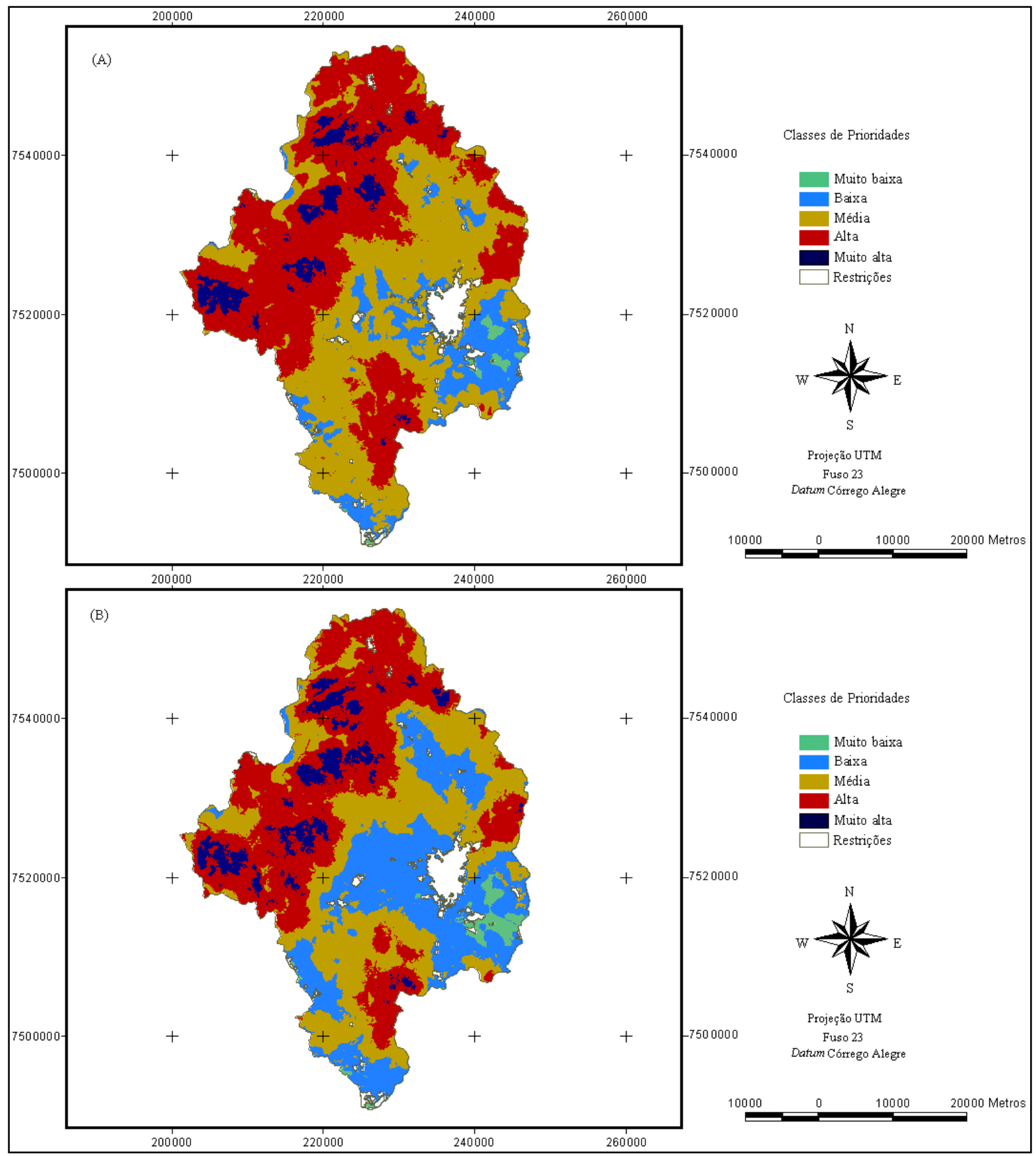

Figura 31 - Mapas com riscos médio (A) e médio-baixo (B): sem o fator proximidade à rede hidrográfica (classes de prioridades) 
Quanto ao mapa de prioridades com risco médio-baixo (Figura 32), ele apresentou compensação de $78 \%$ entre seus fatores. Como seu principal problema temse a excessiva influência dos mapas de distâncias à malha viária e aos centros urbanos.

Para que o mapa de prioridades obtivesse risco baixo (ou próximo ao baixo) foi necessária uma alta compensação (baixo peso de compensação e alto peso de ordenação) dos mapas de distâncias. Dessa maneira, houve a priorização de regiões de "baixo risco", semelhante às que seriam priorizadas com a aplicação do operador AND.

Áreas classificadas como de média prioridade, no mapa com risco médio, passaram à categoria baixa, principalmente pela influência da cidade de Rio Claro (Figura 31). Houve, no mapa com risco-médio, aproximadamente o dobro de áreas com prioridades baixa e muito baixa em relação ao com risco médio. A bacia apresentou 34\% de sua área classificada com alta prioridade; $33 \%$ com média prioridade; $25 \%$ com baixa prioridade; $6 \%$ com muito alta prioridade; e $2 \%$ com muito baixa prioridade, de acordo com o mapa em classes (Figura 31).

Apesar da influência do mapa de fator proximidade entre fragmentos de maior área nuclear (maiores pesos de compensação e ordenação), quando se avaliaram conjuntamente os mapas de fatores e prioridades, notou-se que (i) algumas regiões da bacia receberam alta/muito alta prioridade, mesmo sem a presença e/ou proximidade de fragmentos de floresta (independentemente de seu tamanho); e (ii) a priorização de algumas regiões, independentemente se estão distantes ou não de fontes de distúrbios (estradas e centros urbanos). Esses duas situações são, ainda, conseqüência da influência dos mapas de distâncias à malha viária e aos centros urbanos.

Quando se priorizam áreas sem a presença de fragmentos de floresta e próximas a fontes de distúrbios não se está caminhando no sentido contrário a fragmentação (Geneletti, 2004).

O mapa de prioridades com risco médio-baixo foi o que apresentou, dentre os três (riscos médio, médio-alto e médio-baixo), menor risco para essa alternativa. Contudo, seus pesos de ordenação não propõem a solução mais adequada à priorização de áreas. Nem sempre a melhor solução é aquela associada ao menor risco (Malczewski, 1999). 


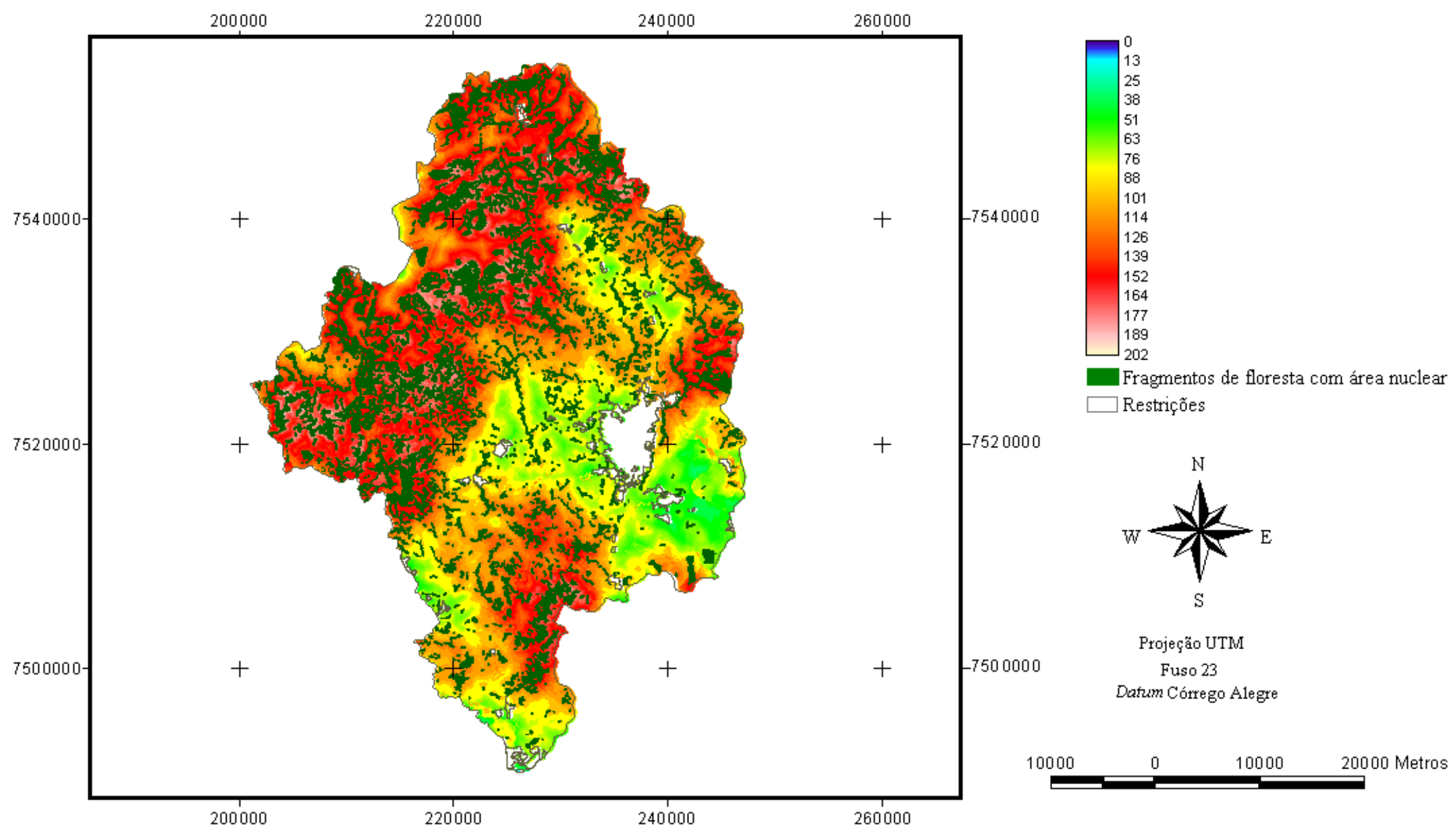

Figura 32 - Áreas prioritárias com risco médio-baixo: sem o fator proximidade à rede hidrográfica (escala 0 - 255 bytes) 
A avaliação desses mapas de prioridades com riscos médio e médio-baixo, assim como a análise de sensibilidade, indicaram que a melhor solução para a priorização de áreas para a conservação e preservação florestal na Bacia do Rio Corumbataí, tendo em vista o incremento de sua biodiversidade foi o mapa sem o fator proximidade à rede hidrográfica, com risco médio-alto $(\mathrm{R}=0,46$; Tabela 20) e que apresentou compensação entre seus fatores de $73 \%$.

A respeito dessa alternativa, a análise de sensibilidade demonstrou, ainda, que tanto o ranqueamento proposto para os mapas de fatores como a alternativa (solução) apresentaram robustez. Isto porque, conforme citado por Malczewski (1999), não houve alterações na priorização, mesmo com a eliminação desse fator, ou seja, os demais fatores continuaram a possuir a mesma importância (ou ordem de importância) inicialmente proposta, para o processo de tomada de decisão.

Malczewski (1999) e Calijuri et al. (2002) também obtiveram como melhores soluções mapas com risco médio-alto e compensação parcial entre os fatores. No primeiro estudo, para a determinação de áreas adequadas à urbanização no México, e no segundo para a identificação de áreas para a implantação de aterros sanitários no Espírito Santo. Nos dois casos, utilizando-se o método da Média Ponderada Ordenada.

\subsubsection{Mapa de áreas prioritárias para a conservação e a preservação florestal}

O mapa de áreas prioritárias que representou a melhor alternativa nesse processo de tomada de decisão pode ser observado na Figura 33, agora em sete classes de prioridades. Ele possibilita o melhor entendimento entre as alterações necessárias na estrutura da paisagem e as classes de prioridade ("ordem de prioridades").

Foi possível esse detalhamento, em especial das classes de maior prioridade, em função dos pesos de ordenação atribuídos aos fatores. Jiang \& Eastman (2000) também comprovaram a possibilidade de aumento no número de classes à medida que se obtêm soluções mais arriscadas.

A priorização de áreas na bacia, de acordo com esse mapa, promove inicialmente a melhoria na forma e na união dos maiores fragmentos com área nuclear. 


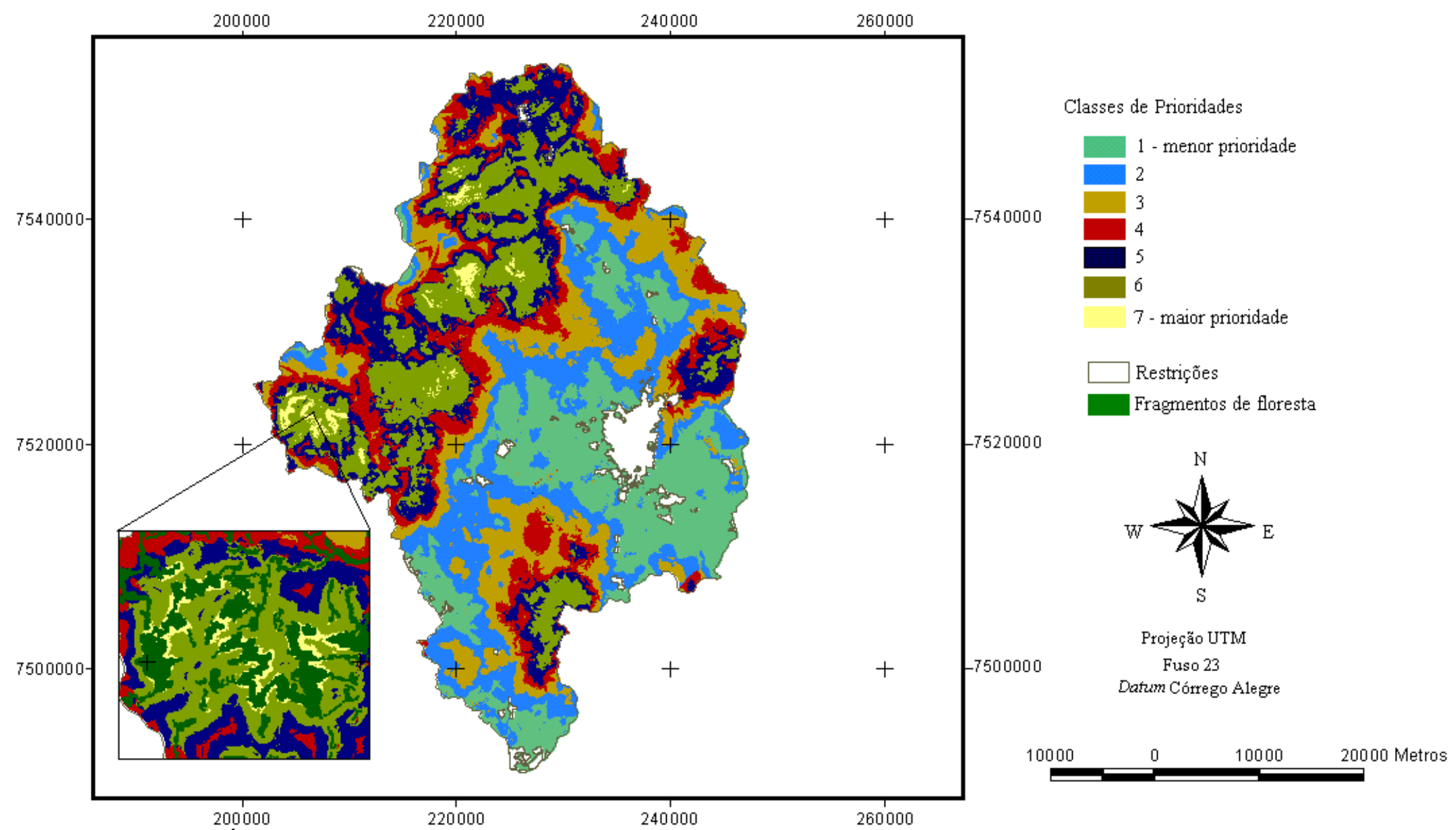

Figura 33 - Áreas prioritárias para conservação e preservação florestal na Bacia do Rio Corumbataí 
A forma de um fragmento está interligada ao seu tamanho e a sua área nuclear (Temple, 1986). Quando se tem a melhora na forma de um fragmento há, conseqüentemente, um incremento em sua área nuclear e a diminuição do efeito de borda.

Geneletti (2004) cita que, dessa maneira, está se caminhando no sentido contrário ao da fragmentação, que promove um aumento no isolamento dos fragmentos, a diminuição de seu tamanho e o aumento de seu efeito de borda. Esses efeitos promovem, por sua vez, a redução da biodiversidade, da estabilidade dos ecossistemas e a sua habilidade de recuperação mediante distúrbios (Saunders et al., 1991; Baskent, 1999).

Para fragmentos que estão bem próximos uns dos outros, como ocorre com os localizados na classe de maior prioridade, a melhora da forma já contribui para a conexão entre eles, conforme pode ser observado na Figura 33 (região em evidência).

Farina (1998) cita que dessa maneira restabelece-se a conectividade entre os fragmentos, ou seja, sub-populações passam a estar interconectadas em uma nova unidade. Tabarelli et al. (1999) complementam que esse beneficio é possível quando as barreiras físicas à dispersão, à migração e ao fluxo de energia entre os fragmentos, dentre outros fatores, são eliminadas e/ou amenizadas.

Fragmentos com maiores áreas nucleares e conectados, como nesse caso propõem as classes de maior prioridade (Figura 33), são tipicamente melhores para a conservação da biodiversidade, de acordo com Noss et al. (1997). Eles são, ainda segundo Geneletti (2004), os componentes básico da estrutura de uma paisagem que visa a manter a integridade de sua cobertura florestal natural. Para Lovejoy et al. (1986) eles são detentores de parte da biodiversidade da formação florestal à que pertencem.

Azevedo et al. (2003) comentam que na sub-bacia do Rio Passa-Cinco, os fragmentos maiores que 60 ha são os que apresentam o melhor estado de conservação e preservação, isto com base em características fisionômicas da vegetação.

Com a conservação e a preservação desses maiores fragmentos tem-se, portanto, um incremento na biodiversidade de toda a paisagem. Para a expansão dessas áreas "focos" de biodiversidade é interessante, como proposto no mapa de prioridades 
(classes 5 e 6), que exista a expansão da conectividade entre os maiores fragmentos com área nuclear (mesmo que menores do que os presentes na classe 7).

Para os casos em que não é possível, à principio, a união física entre os maiores fragmentos, como ocorre em algumas regiões da bacia, a conectividade pode ser feita por meio de fragmentos menores (independentemente de sua área nuclear). Ressalta-se, dessa maneira, a importância do fator proximidade entre fragmentos para esse mapa de prioridades.

O fator proximidade à cobertura florestal além de possibilitar a conexão florestal colaborou, juntamente com o fator proximidade entre fragmentos de maior área nuclear, para que houvesse a definição de grande parte das áreas com maior prioridade em regiões da bacia que concentram as maiores áreas de floresta nativa. Essas regiões (subbacias do rio Passa-Cinco e Alto Corumbataí), segundo Valente \& Vettorazzi (2002), além da concentração de floresta nativa, possuem os melhores fragmentos (maiores, mais próximos uns dos outros, com melhor forma e maior área nuclear) da Bacia do Rio Corumbataí.

Malczewski (2003), na definição de áreas a serem reabilitadas/restauradas em uma bacia hidrográfica do Canadá, também obteve em seu mapa final a indicação de que as atividades de restauração deveriam iniciar onde já existiam áreas naturais.

Vários autores (Trani \& Giles, 1999; Kindvall \& Petersson, 2000; Geneletti, 2003) têm empregado a proximidade entre fragmentos como um dos critérios, em seus trabalhos de conservação e preservação florestal.

Metzger (1997) ressalta a importância da proximidade entre remanescentes de floresta e cita que os fragmentos com área superior a 0,72 ha têm condições de assumir uma função na conexão florestal, por serem úteis a locomoção de animais e dispersão de sementes na paisagem.

Na Bacia do Rio Corumbataí, como na maioria das paisagens brasileiras, não se pode desconsiderar as influências negativas, nos fragmentos de florestas naturais, causadas pela proximidade que essas áreas encontram-se de centros urbanos, rodovias e parques industriais, dentre outras fontes de distúrbio. 
Observando os mapas de distâncias à malha viária (Figura 9) e aos centros urbanos (Figura 10) e o mapa de prioridades (Figura 33), nota-se que as classes de maior prioridade possuem menor concentração de estradas e centros urbanos. Isto, como uma maneira de tentar garantir o sucesso das ações de conservação e preservação florestal.

Lathrop et al. (1998) e Geneletti (2004) obtiveram resultados semelhantes com a utilização, respectivamente, dos fatores distância à malha viária e distância a fontes de distúrbio. O primeiro, na região metropolitana de Nova York, para determinar áreas prioritárias para a conservação florestal (Floresta de Sterling) e o segundo, na província de Trento, Itália, para a definição de áreas prioritárias para a conservação de ecossistemas típicos de sua região.

No mapa de áreas prioritárias não se pode desconsiderar a influência (mesmo que local) do fator vulnerabilidade à erosão. Conforme discutido, são coincidentes as áreas com maiores valores ( 0 -255 bytes) de vulnerabilidade à erosão com as classes de maior prioridade, no caso as classes 6 e 7.

Rosa et al. (2000) concluíram que os solos com maior vulnerabilidade à erosão não se mostram adequados a todas as práticas agrícolas, podendo causar diversos problemas à estrutura da paisagem como um todo, se não estiverem com a cobertura adequada.

Outra característica a ser ressaltada, ainda, no mapa de áreas prioritárias é a continuidade de suas classes de prioridade. A categoria de maior prioridade acaba sendo conectada pela categoria seguinte (ordem de prioridade) e assim sucessivamente. Para a priorização de toda a bacia seria necessário a união de grandes regiões prioritárias.

Malczewski (2003) cita que essa característica é conseqüência, além dos pesos de compensação e ordenação atribuídos aos fatores, da forma contínua como são representados esses fatores.

Na combinação de fatores, com os métodos da Combinação Linear Ponderada e Média Ponderada Ordenada, quando se tem um ou mais fatores que não possibilitam essa representação contínua, tem-se como produto final (soluções, alternativas) um mapa "mosaicado", ou seja, sem continuidade dentre e entre suas categorias (Malczewski, 1999). 


\section{CONCLUSÕES}

Para as condições específicas em que foi realizado o presente trabalho foi possível concluir que:

(1) A abordagem multicriterial, com o método da Média Ponderada Ordenada, possibilita a definição de áreas prioritárias para a conservação e a preservação florestal, visando ao incremento da biodiversidade regional;

(2) Para utilização desse método deve-se ter um bom conhecimento da paisagem a ser estudada, para que se defina com coerência os pesos de compensação, de ordenação e as alternativas propostas.

(3) O método da Média Ponderada Ordenada é flexível, fácil de ser implementado e permite a interação de conhecimentos (pesquisadores, analistas etc.) e de características da paisagem, no processo de tomada de decisão;

(4) Dos fatores inicialmente propostos, para os objetivos desse trabalho somente a proximidade à rede hidrográfica não é importante;

(5) A análise de sensibilidade é essencial na avaliação dos fatores, de seus pesos (compensação e ordenação) e das soluções propostas; e

(6) A coerência apresentada entre os pesos de compensação, de ordenação e a solução final conferem robustez ao processo de tomada de decisão. 
ANEXOS 


\section{ANEXO A: matriz de comparação pareada, pesos de compensação e ordenação:}

\section{todos os fatores.}

Tabela 24. Matriz de comparação pareada entre os mapas de fatores (A)

\begin{tabular}{|c|c|c|c|c|c|c|c|}
\hline Fatores & Vulner. & Dist. urb. & Dist. malha & Prox. rede & Prox. frag. & Prox. área & $\begin{array}{c}\text { Pesos de } \\
\text { compensação }\end{array}$ \\
\hline Vulner. & 1 & & & & & & 0,0387 \\
\hline Dist. urb. & 4 & 1 & & & & & 0,0834 \\
\hline Dist. malha & 4 & 1 & 1 & & & & 0,0834 \\
\hline Prox. rede & 4 & 3 & 3 & 1 & & & 0,1605 \\
\hline Prox. frag. & 5 & 4 & 4 & 3 & 1 & & 0,2813 \\
\hline Prox. área & 5 & 4 & 4 & 3 & 2 & 1 & 0,3528 \\
\hline \multicolumn{6}{|c|}{ Taxa de Consistência $(T C)=0,06$} & Total & 1,0000 \\
\hline
\end{tabular}

Tabela 25. Matriz de comparação pareada entre os mapas de fatores (B)

\begin{tabular}{|c|c|c|c|c|c|c|c|}
\hline Fatores & Vulner. & Dist. urb. & Dist. malha & Prox. rede & Prox. frag. & Prox. área & $\begin{array}{l}\text { Pesos de } \\
\text { compensação }\end{array}$ \\
\hline Vulner. & 1 & & & & & & 0,0964 \\
\hline Dist. urb. & $1 / 2$ & 1 & & & & & 0,0899 \\
\hline Dist. malha & $1 / 2$ & 1 & 1 & & & & 0,0899 \\
\hline Prox. rede & 2 & $1 / 2$ & $1 / 2$ & 1 & & & 0,0963 \\
\hline Prox. frag. & 4 & 3 & 3 & 2 & 1 & & 0,2377 \\
\hline Prox. área & 6 & 4 & 4 & 3 & 2 & 1 & 0,3898 \\
\hline \multicolumn{6}{|c|}{ Taxa de Consistência $(T C)=0,08$} & Total & 1,0000 \\
\hline
\end{tabular}


Tabela 26. Matriz de comparação pareada entre os mapas de fatores (C)

\begin{tabular}{|c|c|c|c|c|c|c|c|}
\hline Fatores & Vulner. & Dist. urb. & Dist. malha & Prox. rede & Prox. frag. & Prox. área & $\begin{array}{c}\text { Pesos de } \\
\text { compensação }\end{array}$ \\
\hline Vulner. & 1 & & & & & & 0,0415 \\
\hline Dist. urb. & 3 & 1 & & & & & 0,0910 \\
\hline Dist. malha & 3 & 1 & 1 & & & & 0,0910 \\
\hline Prox. rede & 4 & 3 & 3 & 1 & & & 0,1783 \\
\hline Prox. frag. & 4 & 3 & 3 & 2 & 1 & & 0,2345 \\
\hline Prox. área & 5 & 4 & 4 & 3 & 2 & 1 & 0,3637 \\
\hline Taxad & sitn & $=$ & & & & Total & 1,0000 \\
\hline
\end{tabular}

Tabela 27. Matriz de comparação pareada entre os mapas de fatores (D)

\begin{tabular}{lccccccc}
\hline \multicolumn{1}{c}{ Fatores } & Vulner. Dist. urb. & Dist. malha & Prox. rede & Prox. frag. & Prox. área & $\begin{array}{c}\text { Pesos de } \\
\text { compensação }\end{array}$ \\
\hline Vulner. & $\mathbf{1}$ & & & & & & 0,0415 \\
Dist. urb. & 3 & $\mathbf{1}$ & & & & & 0,0910 \\
Dist. malha & 3 & 1 & $\mathbf{1}$ & & & & 0,0910 \\
Prox. rede & 4 & 3 & 3 & $\mathbf{1}$ & & & 0.2345 \\
Prox. frag. & 4 & 3 & 3 & $1 / 2$ & $\mathbf{1}$ & & 0,1783 \\
Prox. área & 5 & 4 & 4 & 3 & 2 & $\mathbf{1}$ & 0,3637 \\
\hline \multicolumn{7}{l}{ Taxa de Consistência $(T C)=0,07$} \\
\hline
\end{tabular}

Tabela 28. Matriz de comparação pareada entre os mapas de fatores (E)

\begin{tabular}{|c|c|c|c|c|c|c|c|}
\hline Fatores & Vulner. & Dist. urb. & Dist. malha & Prox. rede & Prox. frag. & Prox. área & $\begin{array}{c}\text { Pesos de } \\
\text { compensação }\end{array}$ \\
\hline Vulner. & 1 & & & & & & 0,0392 \\
\hline Dist. urb. & 2 & 1 & & & & & 0,0604 \\
\hline Dist. malha & 2 & 1 & 1 & & & & 0,0604 \\
\hline Prox. rede & 4 & 3 & 3 & 1 & & & 0,1308 \\
\hline Prox. frag. & 5 & 4 & 4 & 3 & 1 & & 0,2256 \\
\hline Prox. área & 7 & 6 & 6 & 5 & 4 & 1 & 0,4835 \\
\hline$C c$ & $\hat{e} t_{t}$ & C) & & & & Total & 1,0000 \\
\hline
\end{tabular}


Tabela 29. Matriz de comparação pareada entre os mapas de fatores (F)

\begin{tabular}{|c|c|c|c|c|c|c|c|}
\hline Fatores & Vulner. & Dist. urb. & Dist. malha & Prox. rede & Prox. frag. & Prox. área & $\begin{array}{c}\text { Pesos de } \\
\text { compensação }\end{array}$ \\
\hline Vulner. & 1 & & & & & & 0,0500 \\
\hline Dist. urb. & 2 & 1 & & & & & 0,0803 \\
\hline Dist. malha & 2 & 1 & 1 & & & & 0,1346 \\
\hline Prox. rede & 3 & 2 & 2 & 1 & & & 0,1346 \\
\hline Prox. frag. & 5 & 4 & 4 & 3 & 1 & & 0,2888 \\
\hline Prox. área & 5 & 4 & 4 & 3 & 2 & 1 & 0,3659 \\
\hline Taxa de $C o$ & ct & I $=$ & & & & Total & 1,0000 \\
\hline
\end{tabular}

Tabela 30. Matriz de comparação pareada entre os mapas de fatores $(\mathrm{G})$

\begin{tabular}{lccccccc}
\hline \multicolumn{1}{c}{ Fatores } & Vulner. & Dist. urb. & Dist. malha & Prox. rede & Prox. frag. & Prox. área & $\begin{array}{c}\text { Pesos de } \\
\text { compensação }\end{array}$ \\
\hline Vulner. & $\mathbf{1}$ & & & & & & \\
Dist. urb. & 2 & $\mathbf{1}$ & & & & & 0,0541 \\
Dist. malha & 2 & 1 & $\mathbf{1}$ & & & & 0,0880 \\
Prox. rede & 3 & 2 & 2 & $\mathbf{1}$ & & & 0,0880 \\
Prox. frag. & 4 & 3 & 3 & 2 & $\mathbf{1}$ & & 0,1501 \\
Prox. área & 5 & 4 & 4 & 3 & 2 & $\mathbf{1}$ & 0,3777 \\
\hline \multicolumn{7}{l}{ Taxa de Consistência $(T C)=0,01$} & \\
\hline
\end{tabular}

Tabela 31. Matriz de comparação pareada entre os mapas de fatores $(\mathrm{H})$

\begin{tabular}{lccccccc}
\hline \multicolumn{1}{c}{ Fatores } & Vulner. & Dist. urb. & Dist. malha & Prox. rede & Prox. frag. & Prox. área & $\begin{array}{c}\text { Pesos de } \\
\text { compensação }\end{array}$ \\
\hline Vulner. & $\mathbf{1}$ & & & & & & \\
Dist. urb. & 2 & $\mathbf{1}$ & & & & & 0,0700 \\
Dist. malha & 2 & 1 & $\mathbf{1}$ & & & & 0,1855 \\
Prox. rede & 2 & $1 / 2$ & $1 / 2$ & $\mathbf{1}$ & & & 0,1855 \\
Prox. frag. & 2 & $1 / 2$ & $1 / 2$ & 1 & $\mathbf{1}$ & & 0,1097 \\
Prox. área & 4 & 2 & 2 & 3 & 2 & $\mathbf{1}$ & 0,3349 \\
\hline \multicolumn{7}{l}{ Taxa de Consistência $(T C)=0,04$} &
\end{tabular}


ANEXO B: pesos de compensação e ordenação: todos os fatores.

Tabela 32. Pesos de compensação* e de ordenação, propostos

\begin{tabular}{lccc}
\hline Fatores & Pesos de compensação & \multicolumn{2}{c}{ Pesos de ordenação } \\
& & I & II \\
\hline Vulner. & 0,0725 & 0,0700 & 0,0800 \\
Dist. urb. & 0,1171 & 0,1450 & 0,1850 \\
Dist. malha & 0,1171 & 0,1450 & 0,1850 \\
Prox. rede & 0,1736 & 0,1700 & 0,1000 \\
Prox. frag. & 0,1736 & 0,1700 & 0,1000 \\
Prox. área & 0,3462 & 0,3000 & 0,3500 \\
\hline Total & 1,0000 & 1,0000 & 1,0000 \\
\hline
\end{tabular}

* Matriz de comparação pareada: Tabela 11. 


\section{ANEXO C: pesos de ordenação: eliminação de mapas de fatores}

Tabela 33. Pesos de ordenação* : sem proximidade à cobertura florestal

\begin{tabular}{lcc}
\hline Fatores & \multicolumn{2}{c}{ Peso de ordenação } \\
& I $^{* *}$ & II \\
\hline Vulner. & 0,0960 & 0,0900 \\
Dist. urb. & 0,1960 & 0,1950 \\
Dist. malha & 0,1960 & 0,1950 \\
Prox. rede & 0,0960 & 0,1200 \\
Prox. área & 0,4160 & 0,4000 \\
Total & 1,0000 & 1,0000 \\
\hline Risco & 0,50 & 0,49 \\
Compensação & 0,71 & 0,73 \\
\hline
\end{tabular}

*Matriz de comparação pareada: Tabela 16.

** proporcional aos pesos com esse fator.

Tabela 34. Pesos de ordenação* : sem proximidade à rede hidrográfica

\begin{tabular}{lcc}
\hline Fatores & \multicolumn{2}{c}{ Peso de ordenação } \\
& I** & II \\
\hline Vulner. & 0,0960 & 0,0900 \\
Dist. urb. & 0,1960 & 0,1950 \\
Dist. malha & 0,1960 & 0,1950 \\
Prox. rede & 0,0960 & 0,1200 \\
Prox. área & 0,4160 & 0,4000 \\
Total & 1,0000 & 1,0000 \\
\hline Risco & 0,50 & 0,49 \\
Compensação & 0,71 & 0,73 \\
\hline
\end{tabular}

*Matriz de comparação pareada: Tabela 17. ** proporcional aos pesos com esse fator. 
Tabela 35. Matriz de comparação pareada: sem distância à malha viária

\begin{tabular}{|c|c|c|c|c|c|c|c|}
\hline Fatores & Vulner. & Dist. urb. & Prox. rede & Prox. frag. & Prox. área & $\begin{array}{c}\text { Pesos de } \\
\text { compensação }\end{array}$ & $\begin{array}{l}\text { Pesos de } \\
\text { ordenação }\end{array}$ \\
\hline Vulner. & 1 & & & & & 0,0853 & 0,1160 \\
\hline Dist. urb. & 2 & 1 & & & & 0,1350 & 0,2100 \\
\hline Prox. rede & 2 & 2 & 1 & & & 0,1835 & 0,1160 \\
\hline Prox. frag. & 2 & 2 & 1 & 1 & & 0,1835 & 0,1160 \\
\hline Prox. área & 4 & 2 & 3 & 3 & 1 & 0,4126 & 0,4360 \\
\hline \multicolumn{5}{|c|}{ Taxa de Consistência $(T C)=0,03$} & Total & 1,0000 & 1,0000 \\
\hline \multicolumn{8}{|c|}{$\begin{array}{l}\text { Risco : } 0,54 \\
\text { Compensação: } 0,69\end{array}$} \\
\hline \multicolumn{8}{|c|}{ Tabela 36. Matriz de comparação pareada: sem distância aos centros urbanos } \\
\hline Fatores & Vulner. & $\begin{array}{l}\text { Dist. } \\
\text { malha. }\end{array}$ & Prox. rede & Prox. frag. & Prox. área & $\begin{array}{c}\text { Pesos de } \\
\text { compensação }\end{array}$ & $\begin{array}{l}\text { Pesos de } \\
\text { ordenação }\end{array}$ \\
\hline Vulner. & 1 & & & & & 0,0853 & 0,1160 \\
\hline Dist. malha & 2 & 1 & & & & 0,1350 & 0,2100 \\
\hline Prox. rede & 2 & 2 & 1 & & & 0,1835 & 0,1160 \\
\hline Prox. frag. & 2 & 2 & 1 & 1 & & 0,1835 & 0,1160 \\
\hline Prox. área & 4 & 2 & 3 & 3 & 1 & 0,4126 & 0,4360 \\
\hline Taxa de Co & cia ( & $C)=0,03$ & & & Total & 1,0000 & 1,0000 \\
\hline
\end{tabular}

Risco : 0,54

Compensação: 0,69 


\section{REFERÊNCIAS BIBLIOGRÁFICAS}

ALHO, J.; KANGAS, J. Analyzing uncertainties in expert's opinions of forest plan performance. Forest Science, v.43, p.521-528, 1997.

ANDERSON, J.R.; HARDY, E.E.; ROACH, J.T.; WITMER, R.E. A land use and land cover classification system for use with remote sensor data. Washington: USGS, 1979. 28p.

ARAÚJO, C.C. Aplicação de geoprocessamento na análise de favorabilidade para mineralizações de chumbo, zinco e cobre nas folhas Cerro Azul e Apiaí, Vale do Ribeira, (SP e PR). São Paulo, 1999. 117p. Dissertação (Mestrado) - Instituto de Geociências, Universidade de São Paulo.

AZEVEDO, T.S.; MANZATTO, A.G.; FERREIRA, M.C. As perturbações ambientais sofridas pelos fragmentos de matas ciliares no setor da alta bacia do Rio Passa Cinco, Ipeúna-SP: uma abordagem baseada em ecologia da paisagem e caracterização fisionômica da vegetação. In.: CONGRESSO DE ECOLOGIA DO BRASIL, 6., Fortaleza, 2003. Anais. Fortaleza: Sociedade Brasileira de Ecologia, 2003. p.87-88.

BAKER, W.L.; CAI, Y. The role programs for multiscale analysis of landscape structure using the GRASS geographical information system. Landscape Ecology, v.7, p.291-302, 1992.

BASKENT, E.Z. Controlling spatial structure of forested landscapes: a case study towards landscape management. Landscape Ecology, v.14, p.83-87, 1999.

BERRY, J.K. Cartographic modelling: the analytical capabilities of GIS. In: GOODCHILD, M.; PARKS, B.; STEYAERT, L. Environmental modelling with GIS. Oxford: Oxford University Press, 1993. p.58-74. 
BERTONI, J.; LOMBARDI, F.N. Conservação do solo. São Paulo: Ícone, 1990. 335p. BOJORQUEZTAPIA, L.A.; AZUARA, I.; FLORESVILLELA, O.; Identifying conservation priorities in Mexico through geographic information systems and modelling ecological applications. Ecological Applications, v.5, p.215-231, 1995.

BUTLER, J.; JIA, J.; DYER, J. Simulation techniques for the sensitivity analysis of multi-criteria decision models. European Journal of Operational Research, v.103, p.531-546, 1997.

BYRON, H.J.; TREWEEK, J.; VEITCH, N.; SHEATE, W.R.; THOMPSON, S. Road developments in the UK: an analysis of ecological assessment in environmental impact statements produced between 1993 and 1997. Journal of Environmental Planning and Management, n.43, p.71-97, 2000.

CAFISO, S.; GRAZIANO A. DI; KERALI, H.; ODOKI, G. Multicriteria analysis method for pavement maintenance management. Transportation Research Record, n.1816, p.73-84, 2002.

CALIJURI, M.L.; MELO, A.L.O.; LORENTZ, J.F. Identificação de áreas para implantação de aterros sanitários com uso de análise estratégica de decisão. Informática Pública, v.4, n.2, p.231-250, 2000.

CAMPANELLA, R. Mapping measuring the cloud forest of Honduras for effective delimitation as nature reserves. Baton Rouge, 1993. 165p. Thesis (Ph.D.) Louisiana State University.

CARVER, S.J. Integrating multi-criteria evaluation with Geographical Information Systems. International Journal of Geographical Information Systems, v.5, n.3, p.321-329, 1991.

CHEN, K.P.; BLONG, R.; JACOBSON, C. MCE-RISK: integrating multicriteria evaluation and GIS for risk decision-making in natural hazards. Environmental Modelling \& Software, v.16, n.4, p.387-397, 2001.

COLLINS, M.G.; STEINER, F.R.; RUSHMAN, M.J. Land-use suitability analysis in the United States: historical development and promising technological achievements. Environmental Management, v.28, n.5, p.611-621, 2001. 
CONGALTON, R.G.; ODERWALD, R.G.; MEAD, R.A. Assessing Landsat classification accuracy using discrete multivariate analysis statistical techniques. Photogrammetric Engineering and Remote Sensing, v.49, n.12, p.1671 - 1678, 1983.

CRÓSTA, A.P. Processamento digital de imagens de sensoriamento remoto. Campinas: IG; UNICAMP, 1993. 170p.

COUTINHO, L.M.A. Aspectos do Cerrado: domínio e bioma. http://eco.ib.usp.br/cerrado/. (17 nov. 2003).

DUNSTER, J.; DUNSTER, K. Dictionary of natural resource management. Vancouver: University of British Columbia, 1996.379p.

DURIGAN, G.; da SILVEIRA, E.R. Recomposição da mata ciliar em domínio de cerrado, Assis, SP, Brasil. Scientia Forestalis, n.56, p.135-144, dez. 1999.

EASTMAN, J.R. Idrisi for Windows user's guide. Worcester: Clark University, 1995. 109 p.

EASTMAN, J.R. Idrisi for Windows, Version 2.0. Tutorial exercises. Worcester: Clark University, 1997. p.93.

EASTMAN, J.R. Decision support: decision strategy analysis. Idrisi 32 release 2: guide to GIS and image processing, Worcester: Clark Labs, Clark University, 2001. v.2, 22p.

EASTMAN, J.R.; JIANG, H.,. Fuzzy measures in multi-criteria evaluation. In: INTERNATIONAL SYMPOSIUM ON SPATIAL ACCURACY ASSESSMENT IN NATURAL RESOURCES AND ENVIRONMENTAL STUDIES, 2., Colorado, 1996. Proceedings. Colorado: USDA, 1996. p.527-534.

EASTMAN, J.R.; KYEM, P.A.K.; TOLEDANO, J. GIS and decision making. Genebra: UNITAR,1993. 112p. (Explorations in Geographic Information Systems Technology).

ENGESAT. www.engesat.com.br. (24 ago. 2004).

FARINA, A. Principles and methods in landscape ecology. Londres: Chapman \& Hall, 1998. 235p. 
FERREIRA, L.G.: YOSHIOKA, H.; HUETE, A.; SANO, E.E. Optical characterization of the brazilian savanna physiognomies for improved land cover monitoring of the Cerrado bioma: preliminary assessments from an airborne campaign over LBA core site. Journal of Arid Environments, n.56, p425 - 447, 2004.

FORMAN, R.T.T. Land mosaics: the ecology of landscapes and regions. New York: Cambridge University, 1997. 632p.

FORMAN, R.T.T.; GODRON, M. Landscape ecology. New York: John Wiley, 1986. $619 \mathrm{p}$.

FORMAN, R.T.T.; COLLINGE, S.K. Nature conserved in changing landscapes with and without spatial planning. Landscape and Urban Planning, v.37, p.129-135, 1997.

FOSTER, G.R.; McCOOL, D.K.; RENARD, K.G.; MOLDENHAUER, W.C. Conversion of universal soil loss equation to SI metric units. Journal of Soil and Water Conservation, p.355-359, nov-dez, 1981.

FUNK, V.A.; ZEMOGLIO, M.F.; NASIR, N. Testing the use of specimen collection data and GIS in biodiversity exploration and conservation decision making in Guyana. Biodiversity and Conservation, v.8, p.25, 1999.

GARCIA, L.B.R. Ocupação e desenvolvimento econômico da Bacia do Corumbataí séculos XVIII a XX. DEPLAN/IGCE/UNESP, Rio Claro, 2000; Atlas Ambiental da Bacia do Rio Corumbataí.www.rc.unesp.br/igce/ceapla. (02 set. 2001).

GENELETTI, D. Biodiversity impact assessment of roads: an approach based on ecosystem rarity. Environmental Impact Assessment Review, v.23, p.343-365, 2003.

GENELETTI, D. Using spatial indicators and value functions to assess ecosystem fragmentation caused by linear infrastructures. International Journal of Applied Earth Observation and Geoinformation, v.5, p.1-15, 2004a.

GENELETTI, D. A GIS-based decision support system to identify nature conservation priorities in an alpine valley. Land Use Policy, v.21, p.149-160, 2004 b. 
GRARAVELI, A.; GOOD, J.E.G.; WILLIAMS, J.H. Determining priority areas for native woodland expansion and restoration in Snowdonia National Park, Wales. Biological Conservation, v.115, p.395-402, 2004.

GUTZWILLER, K.J.; BARROW JÚNIOR, W. C. Influences of roads and development on bird communities in protected Chihuahuan Desert landscapes. Biological Conservation, v.113, p.225-237, 2003.

HARPER, K.T.; SANDERSON, S.C.; McARTHUR, E.D. Riparian ecology in Zion National Park, Utah. USDA. Forest Service. International General Technical Report, n.298, p.32-42, 1992.

HAVELINK, G.B.M.; BURROUGH, P.A.; STEIN, A. Propagation of errors in spatial modelling with GIS. International Journal of Geographical Information Systems, v.3, n.4, p.303-322, 1989.

INSTITUTO DE PESQUISAS E ESTUDOS FLORESTAIS. Conservação dos recursos hídricos e da cobertura florestal na bacia do Rio Corumbataí. Piracicaba: IPEF, 2001. 118p. (Relatório do projeto).

IVERSON, L.R.; SZAFONI, D.L.; BAUM, S.E.; COOK, E.A. A riparian wildlife habitat evaluation scheme developed using GIS. Environmental Management, v.5, n.28, p.639-654, 2001.

JANKOWSKI, P. Integrating geographical information systems and multiple criteria decision making methods. International Journal of Geographical Information Systems, v.9, p.251-273, 1995.

JENSEN, J.R. Biophysical remote sensing. Annals of the Association of American Geographers, n.32, p.73-111, 1983.

JENSEN, J.R. Introductory digital image processing: a remote sensing perspective. 2.ed. New Jersey: Prentice Hall, 1996. 316p.

JIANG, H.; EASTMAN, J.R. Application of fuzzy measures in multi-criteria evaluation in GIS. International Journal of Geographical Information Science, v.14, n.2, p.173-184, 2000.

JONES, J.R.; LANEY, R.; FULK, M.; AUBLE, J. TOSCA: reference guide: version 2.0. Worcester: Clark University, 1993. 86p. 
KAGEYAMA, P.Y.; GANDARA, F.B.; SOUZA, L.M.I. Conseqüências genéticas da fragmentação sobre populações de espécies arbóreas. Série Técnica IPEF, v.12, n.32, p.65-70, dez. 1998.

KANGAS, J; ALHO, J.; KOLEHMAINEN, O.; MONONEN, A. Analyzing consistency of experts' judgments - case of forest biodiversity. Forest Science, v.44, p.603-609, 1998.

KANGAS, J.; STORE, R.; LESKINEN, P.; MEHTÄTALO, L. Improving the quality of landscape ecological forest planning by utilising advanced decision-support tools. Forest Ecology and Management, v.132, p.157-171, 2000.

KHAN, M.A.; GUPTA, V.P.; MOHARANA, P.C. Watershed prioritization using remote sensing and geographical information system: a case study from Guhiya, India. Journal of Arid Environments, v.49, p.465-475, 2001.

KINDVALL, O.; PETERSSON, A. Consequences of modelling interpatch migration as a function of patch geometry when predicting metapopulation extinction risk. Ecological Modelling, v.129, p.101-109, 2000.

KOFFLER, N.F. Uso das terras da bacia do Rio Corumbataí em 1990. Geografia, v.18, n.1, p.135-150, 1993.

KOFFLER, N.F. Carta de declividade da bacia do Rio Corumbataí para análise digital (SIG). Geografia, v.19, n.2, p.167-182, 1994.

KRONKA, F.J.N.; NALON, M.C.; MATSUKUMA, C. Áreas de domínio do cerrado no Estado de São Paulo. São Paulo: Secretaria do Meio Ambiente, 1998. 84 p.

LANDIS, J.R.; KOCH, G.G. The measurement of observer agreement for categorial data. Biometrics, v.33, p.159-174, 1977.

LATHROP, R.G.; BOGNAR, J.A. Applying GIS and landscape ecological principles to evaluate land conservation alternatives. Landscape and Urban Planning, v.41, p.27-41, 1998.

LEVY, M.C.T.C. Avaliação de cenários da produção agrícola visando à sustentabilidade do uso das terras de Piracicaba (SP). Piracicaba, 1995. 104p. Dissertação (Mestrado) Escola Superior de Agricultura “Luiz de Queiroz”, Universidade de São Paulo. 
LIMA, G.S. Estudo da paisagem do município de Ilha Solteira-SP: subsídios para o planejamento físico-ambiental. São Carlos, 1993. 149p. Tese (Doutorado) Universidade Federal de São Carlos.

LIMA, W. de P. Importância das florestas para produção de água. In.: SIMPÓSIO SOBRE RECUPERAÇÃO DA COBERTURA FLORESTAL DA BACIA DO RIO CORUMBATAÍ, 3, Piracicaba, 2000. Anais. Piracicaba: IPEF, 2000. p.3-5.

LIOTTE, S.V. Utilização de técnicas de geoprocessamento para apoio ao planejamento fisico-territorial do Município de Pariquera-Açu/SP. São Paulo, 170p. Dissertação (Mestrado), Instituto de Geociências, Universidade de São Paulo.

LODWICK, W.A.; MONSON, W.; SVOBODA, L. Attribute error and sensitivity analysis in geographical information systems: suitability analysis of map operations in geographical information systems. International Journal of Geographical Information Systems, v.4, n.4, p.413-428, 1990.

LORD, J.M.; NORTON, D.A. Scale and the spatial concept of fragmentation. Conservation Biology, v.2, n.4, p.197-262, 1990.

LOVEJOY, T.E.; BIERREGARD JUNIOR, R.O.; RYLANDS, A.B.; MALCOM, J.R.; QUINTELA, C.E.; HAPER, L.H.; BROWN JUNIOR, K.S.; POWELL, A.H.; POWELL, G.V.N.; SCHUBART, H.O.R.; HAYS, M.B. Edge and other effects of isolation on Amazon forest fragments. Conservation Biology, v.2, p.257-285, 1986.

MALCZEWSKI, J. A GIS-based approach to multiple criteria group decision-making. International Journal of Geographical Information Science, v.10, n.8, p.955971, 1996.

MALCZEWSKI, J. GIS and multicriteria decision analysis. New York: John Wiley, 1999. 362p.

MALCZEWSKI, J. On the use of weighted linear combination method in GIS: common and best practice approaches. Transactions in GIS, v.4, n.1, p.5-22, 2000.

MALCZEWSKI, J. GIS-based land-use suitability analysis: a critical overview. Progress in Planning, v.62, p.3-65, 2004. 
MALCZEWSKI, J.; CHAPMAN, T.; FLEGEL, C.; WALTERS, D.; SHRUBSOLE, D.; HEALY, M. A. GIS-multicriteria evaluation with ordered weighted averaging (OWA): Developing management strategies for rehabilitation and enhancement projects in the Cedar Creek watershed. Environment and Planning, v.35, n.10, p.1769-1784, 2003.

MARQUES, J. C. Cerrado: tipos de solos. http://www.dcs.ufla.br/cerrado/. (17 nov. 2003).

MCGARIGAL, K; MARKS, B. J. FRAGSTATS: spatial pattern analysis program for quantifying landscape structure. Portland: Department of Agriculture, Forest Service, Pacific Northwest Research Station, 1995. 122p.

MCNEELY, J.A.; MILLER, K.R.; REID, W.W.; MITTERMEIER, R.A.; WERNER, T.B. Conservating the world's biological diversity. New York: The World Bank, 1990. 93p.

MENDOZA, G.A.; PRABHU, R. Multiple criteria decision making approaches to assessing forest sustainability using criteria and indicators: a case study. Forest Ecology and Management, v.131, p.107-126, 2000.

METZGER, J.P. Relationships between landscape structure and tree species diversity in tropical forests of south-east Brazil. Landscape and Urban Planning, v.37, p.2935,1997

METZGER, J.P. Como restaurar a conectividade de paisagens fragmentadas. In: SIMPÓSIO DE RESTAURAÇÃO DE ECOSSISTEMAS DEGRADADOS COM ESPÉCIES NATIVAS. São Paulo, 2000. Anais. São Paulo: Edusp, 2000. p.7-11.

METZGER, J.P. Como restaurar a conectividade de paisagens fragmentadas? In.: KAGEYAMA, P.Y.; OLIVEIRA, R.E.; MORAES, L.F.D.; ENGEL, V.L.; GANDARA, F.B. Restauração ecológica de ecossistemas naturais. Botucatu: FEPAF, 2003. cap.3, p.51-76.

METZGER, J.P.; GOLDENGERB, R.; BERNACCI, L.C. Caminhos da biodiversidade.

Ciência Hoje, v.25, n.146, p.62-64,1999. 
MITTERMEIER, R.A.; MYERS, N.; THOMSEN. M.B. Biodiversity hotspots and major tropical wilderness areas: approaches to setting conservation priorities. Conservation Biology, v.12, p.516-520,1998.

MYERS, N.; MITTERMEIER, R.A.; MITTERMEIER, C.G.; FONSECA, G.A.B.; KENT, J. Biodiversity hotspots for conservation priorities. Nature, v.403, p.853$857,2000$.

NOSS, R.F. Indicators for monitoring biodiversity: a hierarchical approach. Conservation Biology, v.4, p.355-364, 1990.

NOSS, R.F.; O'CONNELL, M.A.; MURPHY, D.D. The science of conservation planning: habitat-based conservation under the endangered species. Washington DC: Act. Island, Press, 1997. 154p.

OLIVEIRA, J.B.; PRADO, H. Levantamento pedológico semidetalhado do Estado de São Paulo: Quadrícula de São Carlos. II. Memorial Descritivo. Campinas: Instituto Agronômico, 1984. 118p.

O’NEILL, M.P.; SCHMIDT, J.C.; DOBROWOLSKI, J.P.; HAWKINS, C.P.; NEALE, C.M.U. Identifying sites for riparian wetland restoration: application of a model to the Upper Arkansas River Basin. Restoration Ecology, v.5, p.85-102, 1997.

PIVELLO, V.R.; COUTINHO, L.M. A qualitative successional model to assist in the management of Brazilian cerrados. Forest Ecology and Management, v.87, p.127138, 1996.

PONZONI, J.F.; ALMEIDA, E.S. A estimativa do parâmetro Kappa (K) da análise multivariada discreta no contexto de um SIG. In: SIMPÓSIO BRASILEIRO DE SENSORIAMENTO REMOTO, 8., Salvador. 1996. Anais. São José dos Campos: INPE, SELPER, 1996. p.52-58.

PRADO, H. do. Solos do Brasil: gênese, morfologia, classificação, levantamento, manejo. Piracicaba, SP: ESALQ, 2003. 275p.

PROJETO PIRACENA. Banco de dados "Geoprocessamento". http://www.cena.usp.br/piracena. (15 ago. 2000). 
PUTZ, F.E.; BLATE, G.M.; REDFORD, K.H.; FIMBEL, R.; ROBINSON, J. Tropical forest management and conservation of biodiversity: an overview. Conservation Biology v.1, n.15, p.7-20, 2001.

QUINTANILHA, J.A. Erros em bases digitais de dados espaciais para uso em sistemas de informação geográfica. São Paulo, 1990. 236p. Tese (Doutorado) - Escola Politécnica, Universidade de São Paulo.

RAMOS, R.A.R.; MENDES, J.F.G. Avaliação da aptidão do solo para localização industrial: o caso de Valença. Revista Engenharia Civil, n.10, p.7-29, 2001.

RANDHIR, T. O.; CONNOR, R.O.; PENNER, P.R.; GOODWIN, D.W. A watershedbased land prioritization model for water supply protection. Forest Ecology and Management, v.143, p.47-56, 2001.

RAO, M.S.V.C.; SASTRY, P.D.; YADAR, K.; KHAROD, S.K.; PATHAN, P.S.; DHINWA, K.L.; MAJUMDAR, D.; PHATA, K. A weighted index model for urban suitability assessment - a GIS approach. Bombay: Metropolitan Regional Development Authority, 1991. 134p.

RODRIGUES, R.R. A vegetação de Piracicaba e municípios do entorno. Circular Técnica IPEF, n.189, agos. 1999. 17p.

ROSA, D.; MORENO, J.A.; MAYOL, F.; BONSÓN, T. Assessment of soil erosion vulnerability in western Europe and potential impact on crop productivity due to loss of soil depth using the ImpelERO model. Agriculture, Ecosystems and Environment, v.81, p.179-190, 2000.

ROY, P.S.; TOMAR, S. Biodiversity characterization at landscape level using geospatial modelling technique. Biological Conservation, v.95, p.95-109, 2000.

RUSSEL, G.D.; HAWKINS, C.P.; O’NEILL, M.P. The role of GIS in selecting sites for riparian restoration on hydrology and land use. Restoration Ecology, v.5, p.56-68, 1997.

SAATY, T. A scaling method for priorities in hierarchical structures. Psychology, v.15, p.234-281, 1977.

SAATY, T. The analytic hierarchy process. New York: McGraw-Hill, 1980. 287p. 
SALATI, E. Análise ambiental sintética e qualidade da água do rio Corumbataí (SP) como subsídio para o planejamento regional integrado da bacia de drenagem do rio Corumbataí. São Carlos, 1996. 198p. Tese (Doutorado) - Ciências da Engenharia Ambiental, Universidade Federal de São Carlos.

SAUNDERS, D.A.; HOBBS, R.J.; MARGULES, C.R. Biological consequences of ecosystem fragmentation: a review. Conservation Biology, v.5, p.18-32, 1991.

SERRANO, M.; SANZ, L.; PUIG, J.; PONS, J. Landscape fragmentation caused by the transport network in Navarra (Spain) two-scale analysis and landscape integration assessment. Landscape and Urban Planning, v.58, p.113-123, 2002.

SHIMABUKURO,Y.E; YI, J.L.R.; DUARTE, V. Classificação e monitoramento da cobertura vegetal do Estado do Mato Grosso através de imagens NOAAAVHRR. São José dos Campos: INPE, 1999. 25p.

STORE, R.; KANGAS, J. Integrating spatial multi-criteria evaluation and expert knowledge for GIS-based habitat suitability modelling. Landscape and Urban Planning, v.55, p.79-93, 2001.

SWANSON, F.J.; FRANKLIN, J.F.; SEDELL, J.R. Landscape patterns, disturbance, and management in the Pacific Northwest, USA. in: ZONNEVELD, I.S.; FORMAN, R.T.T. Changing landscapes: an ecological perspective. New York: Springer-Verlag, 1990. p.191-213.

TABARELLI, M.; MANTOVANI, W. Colonização de clareiras naturais na floresta Atlântica no Sudeste do Brasil. Revista Brasileira de Botânica, n.20, p.57-66, 1997.

TABARELLI, M.; MANTOVANI, W.; PERES, C.A. Effects of habitat fragmentation on plant guild structure in the montane Atlantic forest of southeastern Brazil. Biological Conservation, v.91, p.119-127, 1999.

TEMPLE, S.A. Predicting impacts of habitat fragmentation on forest birds: a comparison of two models. In: VERNE, J.; MORRISON, M.L.; RALPH, C.J. Modelling habitat relationships of terrestrial vertebrates. Madison: University of Wisconsin Press, 1986. p.301-304. 154p. 
THILL, J.C. Multicriteria decision-making and analysis: A Geographic Information Sciences approach. New York: Ashgate, 1999. 354p.

TRANI, M.K.; GILES, R.H. An analysis of deforestation: Metrics used to describe pattern change. Forest Ecology and Management, v.114, p.459-470, 1999.

TROPPMAIR, H.; MACHADO, M.L.A. Variação da estrutura da mata de galeria na Bacia do rio Corumbataí (SP) em relação à água do solo, tipo de margem e do traçado do rio. Biogeografia, n.8, p.1-28, 1974.

TUCKER, C. J.; TOWNSHEND, J.R.G.; GOFF, T.E. African land-cover classification using satellite data. Science, v.75, p.227-369, 1985.

TURNER, M.G.; GARDNER, R. H. Quantitative methods in landscape ecology: the analysis and interpretation of landscape heterogeneity. New York: Springer Verlag, 1990. 536p.

VALENTE, R. de O. A. Análise da estrutura da paisagem na bacia do Rio Corumbataí, SP. Piracicaba. 2001. 144p. Dissertação (Mestrado) - Escola Superior de Agricultura “Luiz de Queiroz”, Universidade de São Paulo.

VALENTE, R.O.A.; VETTORAZZI, C.A. Análise da estrutura da paisagem na bacia do Rio Corumbataí, SP. Scientia Forestalis, n.62, p.114-129, dez. 2002.

VALENTE, R. O. A.; VETTORAZZI, C.A. Mapeamento do uso e cobertura do solo na bacia do Rio Corumbataí, SP. Circular Técnica IPEF, n.196, 10p. maio 2003.

VARMA, V.K.; FERGUSON, I.; WILD, I. Decision support system for the sustainable forest management. Forest Ecology and Management, v. 128, p. 49-55, 2000.

VETTORAZZI, C.A.; VALENTE, R.O.A.; BALLESTER, M.V.R. Forest fire hazard mapping in a GIS environment for a river basin in the State of São Paulo, Brazil. In: INTERNATIONAL CONFERENCE ON GEOSPATIAL INFORMATION IN AGRICULTURE AND FORESTRY, 2., Lake Buena Vista, 2000. Proceedings. Ann Arbor: ERIM International, 2000. v.1, p.10-12.

VIADANNA, A.G. Análise de qualidade hídrica do alto e médio Corumbataí (SP) pela aplicação de bioindicadores. Rio Claro, 1985. 112p. Dissertação (Mestrado) Instituto de Geociências, Universidade Estadual Paulista “Júlio de Mesquita Filho". 
VLAHOS, N.; HERBST, J. Prioritizing watershed land for conservation: a case study in the Hammonasset watershed, Connecticut. Journal of New England Water Works Association, v.144, p.10-25, 2000.

VOOGD, H. Multicriteria evaluation for urban and regional planning. London: Pion., 1983. 125p.

WISCHMEIER, W.H.; MANNERING, J.V. Relation of soil properties to its erodibility. Soil Science Society of America Proceedings, n.33, p.65-69, 1969.

WISCHEMEIER, W.H.; JOHNSON, C.B.; CROSS, B.V. A erodibility nomograph for farmland and construction sites. Journal of Soil and Water Conservation, v.26, n.6, p.189, 1971.

YAGER, R.R. On ordered weighted averaging aggregation operators in multi-criteria decision making. IEEE Transactions on Systems, Man an Cybernetics, v.18, n.1, p.183-190, 1988.

YAHNER, R.H. Changes in wildlife communities near edges. Conservation Biology, v.2, p. 333-339, 1998.

YONG, A.G.; MERRIAM, H.G. Effects of forest fragmentation on the spatial genetic structure of Acer sacvharum Marsh. (sugar maple) populations. Heredity, v.1, p.277-289, 1994.

ZADEH, L.H. Fuzzy sets. Information and Control, v.8, p.348-353, 1965.

ZHOU, J.; CIVCO, D.L. Using genetic learning neural networks for spatial decision making in GIS. Photogrammetric Engineering and Remote Sensing, v.11, p.1287-1295, 1996.

ZHU, X.; DALE, A.P. JavaAHP: a Web-based decision analysis tool for natural resource and environmental management. Environmental Modelling and Software, v.16, n.3, p.251-262, 2001.

ZORZETTO, R.; FIORAVANTI, C.; FERRONI, M. A floresta renasce. Pesquisa FAPESP, p.48-53, set. 2003. 